\title{
The lived experience of midwives caring for women facing termination of pregnancy in the late second and third trimester
}

Susanne Armour

A thesis submitted to Auckland University of Technology in fulfilment of the requirements for the degree of Master of Health Science

2018

School of Midwifery

Faculty of Health and Environmental Sciences Auckland University of Technology 


\begin{abstract}
Termination of pregnancy (TOP), in the late second and third trimester, is planned fetal loss that is medically and socially complex, and has lasting consequences for women. In New Zealand TOP after 20 weeks gestation may be performed to save a woman's life or to preserve her physical or mental health, which might be at risk of permanent damage due to fetal abnormality or severe intrauterine growth restriction. Core midwives in New Zealand are the main caregivers for women who face this procedure after 20 weeks gestation.
\end{abstract}

A small number of international studies have demonstrated the ethical, moral and professional challenges midwives face when providing TOP care; however, the New Zealand maternity system, as well as its legal framework, cannot be compared to countries overseas. This hermeneutic phenomenological study aims to uncover the lifeworld of New Zealand midwives in the context of TOP and seeks to establish what enables midwives in their role, the effects of TOP care, if any, and the shortcomings in support networks that midwives would benefit from.

Eight midwives from two District Health Boards in the North Island of New Zealand were interviewed about their experiences of caring for women who underwent TOP in the late second and third trimester. Data from the interviews were analysed using Max van Manen's methodological framework. The midwives' experience is described in three themes that emerged through reflection and writing: 'a different kind of midwife'; 'staying true to oneself'; and 'melting an iceberg'.

The findings of this thesis suggest that TOP care is a different, specialised role within midwifery. Midwives facilitate death within the space of birth, not daily, yet on a regular basis. Addressing the mother-baby dyad the midwives support women in their decision, provide a positive childbirth experience, and address women's complex needs by meeting them in their emotional space. Midwives enable memory making, honour the life and death of the baby and provide the baby with dignity. Yet, the findings suggest that midwives are unprepared for 
this role and its effects. Feeling unsupported and unacknowledged they are left trying to sustain themselves as support structures are missing. A growing iceberg of unprocessed emotions ensues that midwives are not equipped to negotiate.

This research study recognises the value of midwifery care in the context of TOP; yet, also the complexity of this specific role. The beneficiaries of this study will be the general midwifery community, managers, midwives who provide TOP care, students and education providers. 


\section{Table of Contents}

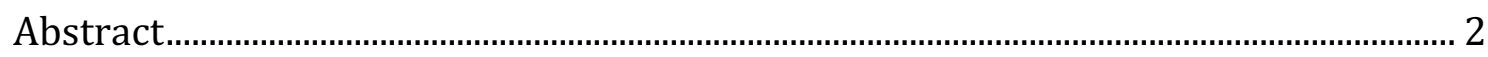

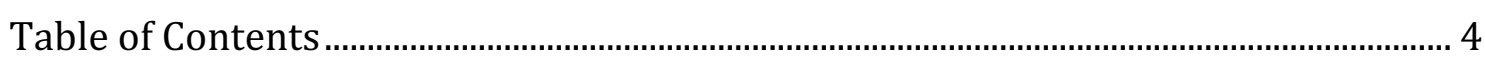

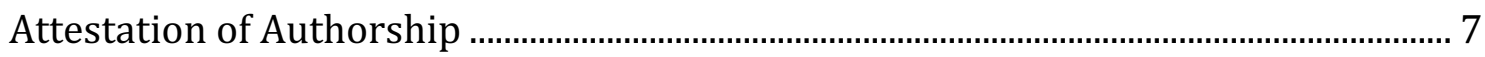

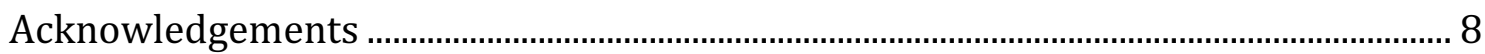

Chapter One: Orientation to the Study

Research Question and Aims of the Study ……….......................................................10

Background and Justification for the Study ....................................................................10

The New Zealand Core Midwife ......................................................................................11

A Brief Overview of New Zealand Midwifery …….......................................................12

Termination of Pregnancy after 20 weeks Gestation....................................................12

Women's Experiences of Termination of Pregnancy ...................................................13

Tūranga Kaupapa and Māori Cultural Practices in the Context of TOP ...................14

The Legal Framework for Abortion in New Zealand and its Interpretation..........16

Conscientious Objection ................................................................................................

The Role of Maternal-Fetal-Medicine ………..............................................................19

Induced Fetal Death or Feticide ...............................................................................

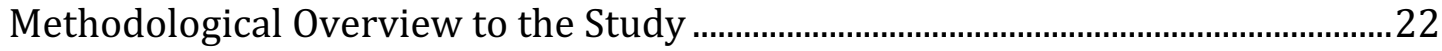

Declaring my Interest in Midwifery Care for Women who face TOP ........................22

Structure of My Thesis...................................................................................................24

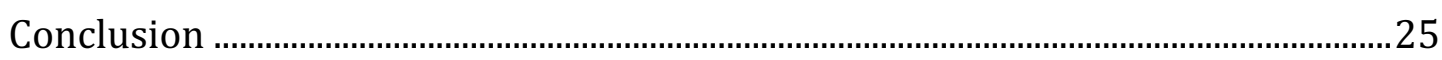

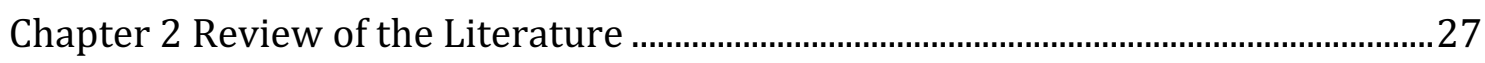

Theme One - Midwives' Experience of Late TOP Care ..................................................29

Expressing Conscientious Objection .......................................................................... 30

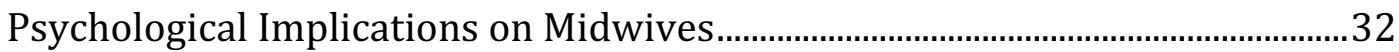

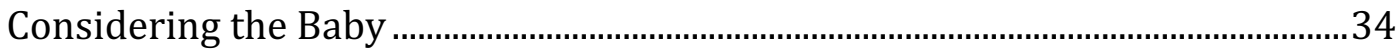

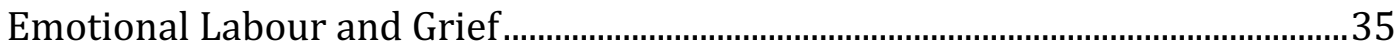

Theme Two - Supportive Structures for Midwives in Late TOP Care .......................38

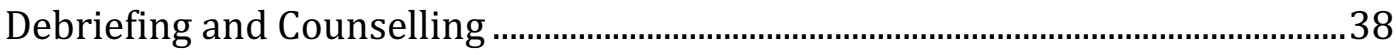

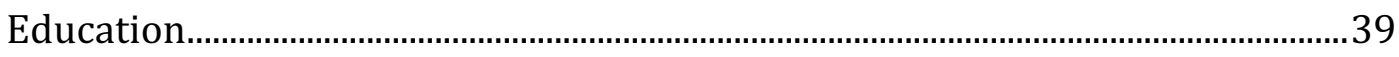

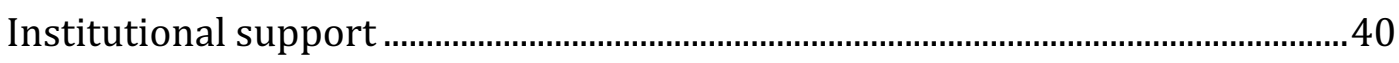

Team Work

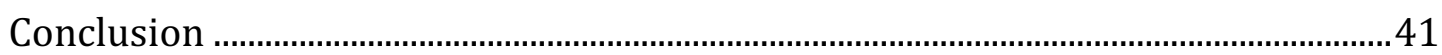

Chapter Three - Research Methodology and Methods ...................................................... 42

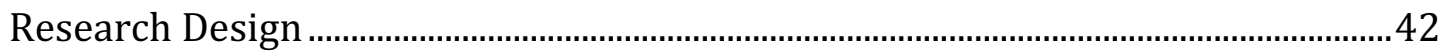

Max van Manen - Hermeneutic-Phenomenological Research ................................42 
Philosophical Traditions Shaping van Manen's Thinking ......................................43

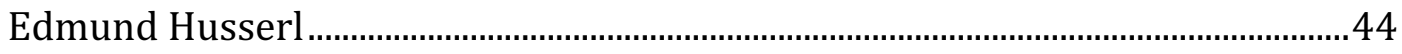

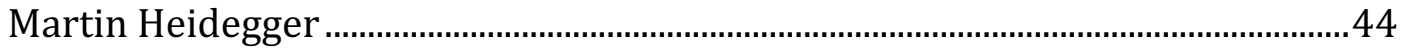

The Hermeneutic Circle ........................................................................................ 45

The Hermeneutic Lens - Interpreting Meaning .....................................................46

The Six Methods - a Framework for Hermeneutic-Phenomenological Research

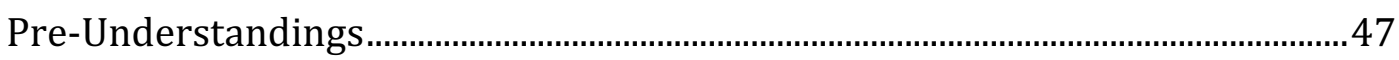

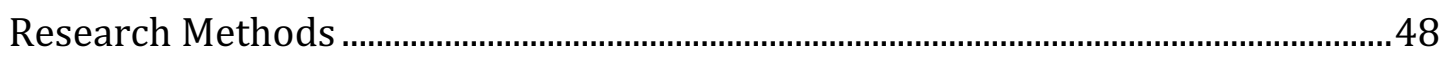

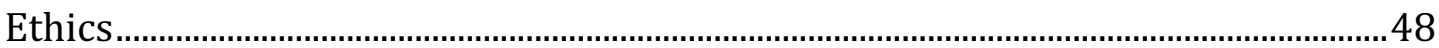

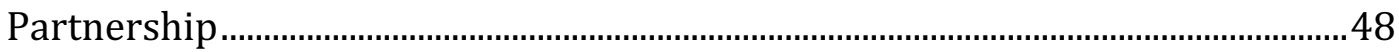

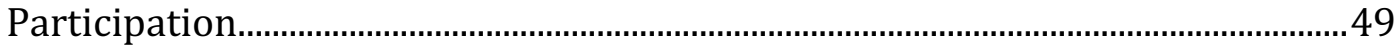

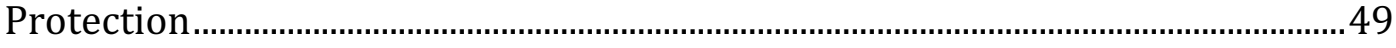

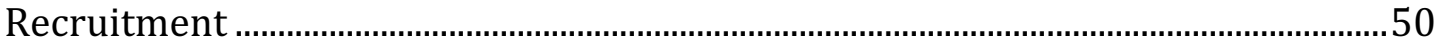

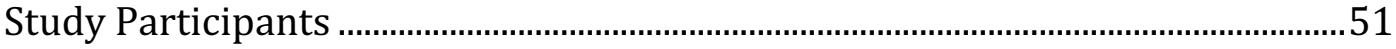

Reflection and Data Analysis .................................................................................. 51

van Manen's Lifeworld Existentials - Guidance for Reflective Analysis.............53

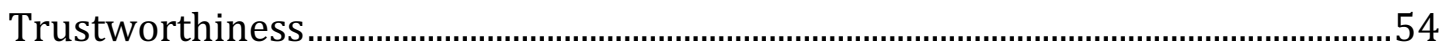

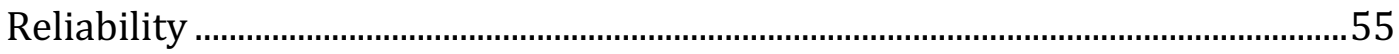

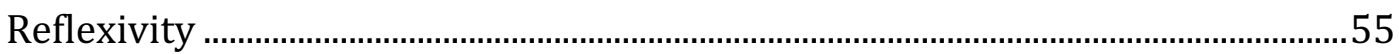

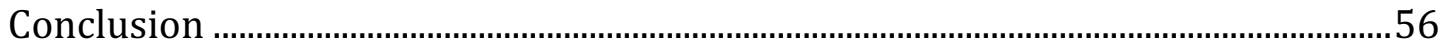

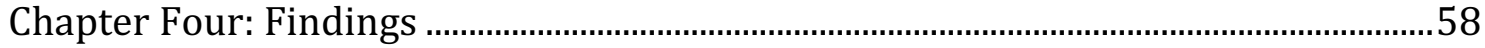

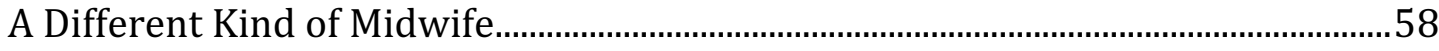

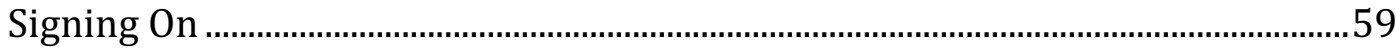

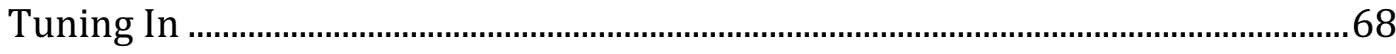

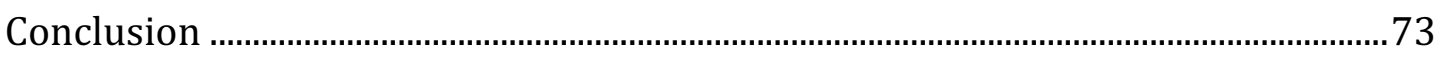

Chapter Five: Staying True to Oneself ........................................................................ 74

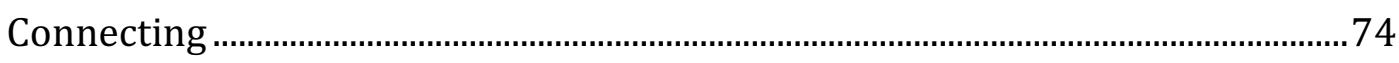

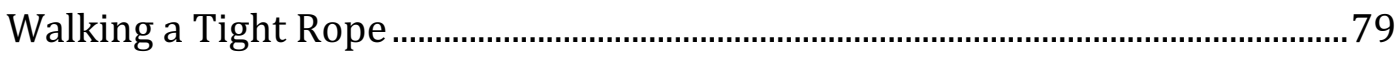

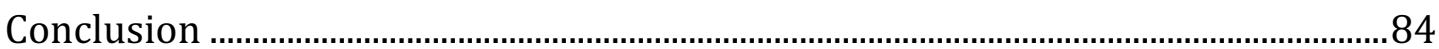

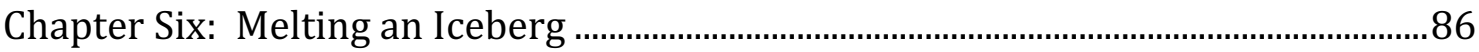

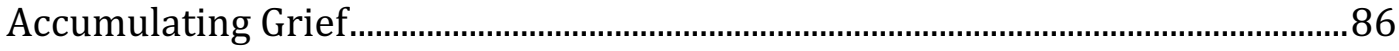

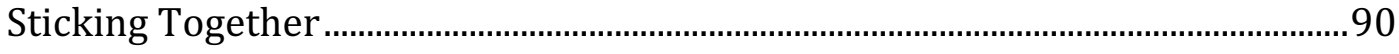

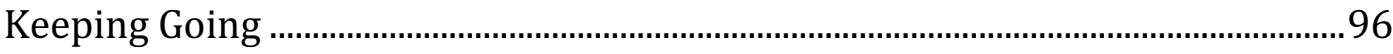

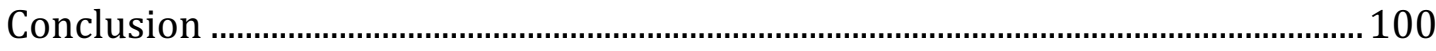

Chapter Seven: Facilitating the Space of Birth and Death............................................ 102

Midwives Facilitate the Space of Birth and Death ...................................................... 102 
Supporting Women in Their Decision ......................................................................... 103

Midwives Preserve the Dignity of the Baby ................................................................... 104

Connecting with Women in Their Emotional Space ...................................................... 105

Managing a Growing Iceberg ………………….......................................................... 106

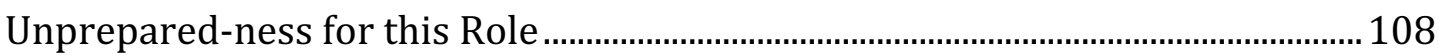

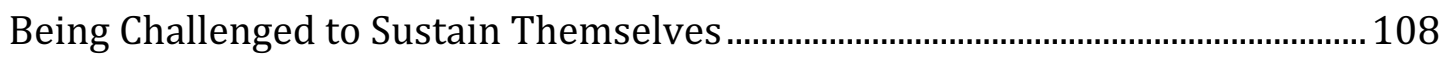

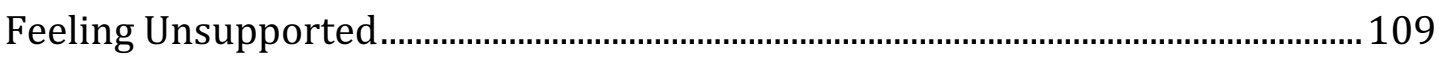

Finding Community ........................................................................................................ 111

Valuing the Care of Midwives in Second and Third Trimester Terminations.... 111

Strengths and Limitations.......................................................................................... 112

Recommendations for Education ............................................................................... 113

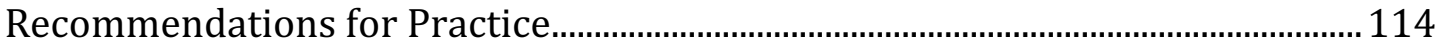

Recommendations for Further Research ................................................................. 114

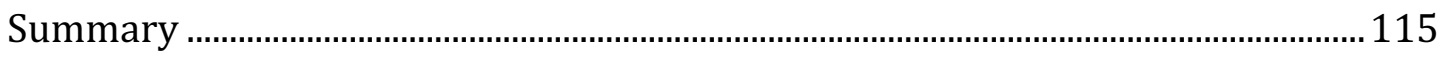

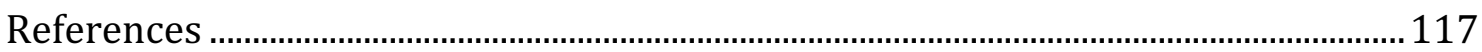

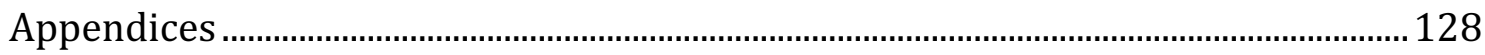

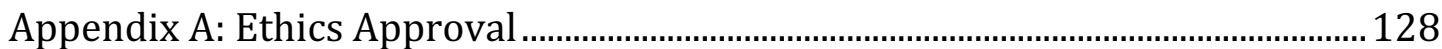

Appendix B: Participant Information Sheet ................................................................. 129

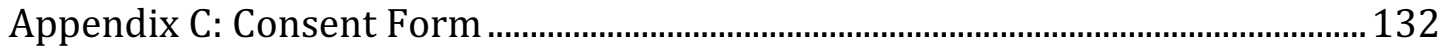

Appendix D: Confidentiality Agreement................................................................... 133

Appendix E: Researcher Safety Protocol ..................................................................... 134

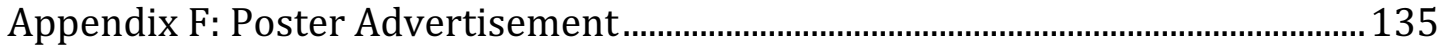




\section{Attestation of Authorship}

"I hereby declare that this submission is my own work and that, to the best of my knowledge and belief, it contains no material previously published or written by another person (except where explicitly defined in the acknowledgements), nor material which to a substantial extent has been submitted for the award of any other degree or diploma of a university or other institution of higher learning."

Wollongong, $10^{\text {th }}$ of November 2018 


\section{Acknowledgements}

A heartfelt thanks goes to my participants for the generous sharing of their time and the spirited, candid contribution of very personal and professional stories. You revealed the love, dedication, and passion you have for caring for women through your stories. Reading them still gives me goose bumps. Thank you!

A very special thank you to my supervisors - Dr. Andrea Gilkison and Dr. Marion Hunter. Your wisdom, expert guidance, insights, practical tips, reassurance, kind words, and 'leg-work' supported me throughout this study. Even if I had lost some faith in myself I trusted you, and you made me 'trust the process'. Thank you!

Thank you to my husband Mike. Your dry sense of humour, down-to-earth encouragement, computer skills, and unwavering belief in me gave me the strength I needed to push myself.

Thank you to my parents and my mother-in-law for all your loving support along the way. It has, and always will be, much appreciated.

To my friends and colleagues - thank you for your patience, kind words, and encouragement.

And last, but not least, thank you to the New Zealand College of Midwives and Workforce New Zealand for the postgraduate study grant; and Shoba Nayar for her expert and timely transcription, editing, and feedback. 


\section{Chapter One: Orientation to the Study}

In this hermeneutic phenomenological research study, I aim to uncover the experience of midwives who provide care to women during termination of pregnancy in the late second and third trimester. Termination of pregnancy (TOP) after 20 weeks gestation is planned fetal loss that is medically and socially complex for women ${ }^{1}$ and can have lasting psychological effects (Deas, 2017; Jones, Baird, \& Fenwick, 2017; Lotto, Armstrong, \& Smith, 2016). In regions of New Zealand, where my study is situated, core midwives ${ }^{2}$ are the main providers of care for women who undergo TOP after 20 weeks gestation.

Research has revealed the experience of health care providers with TOP in the first and early second trimester up to 20 weeks gestation (Gallagher, Porock, \& Edgley, 2010; Hanna, 2005; Huntington, 2002; Nicholson, Slade, \& Fletcher, 2010; Yang, Che, Hsieh, \& Wu, 2016). However, there is a dearth of studies that have specifically explored the experience of midwives with late second and third trimester TOP. Midwives, who predominantly care for women with the outlook of a live baby, are also tasked to manage terminations. Thus, they face the death of a baby in the context of labour and birth. This is a contrasting role for midwives. Instead of guiding women through the pains and joys of labour and birth, the midwives are required to support women through labour in a space of utter devastation, sadness, grief and sometimes guilt.

The focus of my study is to uncover the lived experience of midwives when caring for women through TOP. The findings of this study will be applicable to midwifery practice as they will provide a deeper understanding of the role. It is anticipated that the findings will reveal effects of providing TOP care and what supports midwives in this role. To date, no studies have been located that reveal the experience of New Zealand midwives when caring for women through TOP in the late second and third trimester.

\footnotetext{
1 The term 'women' in the context of this study refers to the population of pregnant and birthing parents of all gender, trans-gender and non-binary identity. This term is inclusive of partners and families.

${ }^{2}$ Core midwives $=$ midwives employed by District Health Boards across New Zealand.
} 


\section{Research Question and Aims of the Study}

My study developed through an encounter that was situated in an everyday midwifery life situation. The recognition of the depth and complexity of TOP care led to the formulation of the research question: What is the lived experience of midwives caring for women facing termination of pregnancy in the late second and third trimester?

The main aims of my study are to:

- Gain a deeper understanding of the role of midwives in TOP care

- Reveal what might support midwives in their role

- Uncover the effects for midwives of providing TOP care

\section{Background and Justification for the Study}

Termination of pregnancy is the deliberate ending of a pregnancy with the intended outcome of fetal death (Ellis, Fisher, Leigh, Schott, \& Mahmood, 2010; RCOG, 2011). The New Zealand Perinatal and Maternal Mortality Review Committee (PMMRC), in its $11^{\text {th }}$ annual report, reported a rate of $1.8 / 1000$ births for late terminations of pregnancy in 2015. Within one year, 107 terminations of pregnancy were performed after 20 weeks gestation with the majority (66) between 20 to 22 weeks gestation, 27 between 23 to 24 weeks gestation and 14 beyond 24 weeks gestation. The reasons for the 14 terminations of pregnancy after 24 weeks gestation were fetal congenital abnormality, maternal condition and severe intrauterine growth restriction (PMMRC, 2017). The PMMRC did not further define maternal condition; however these would include, but not be limited to, mental health, fulminating preeclampsia, HELLP syndrome, and sepsis. TOP is only allowed to be performed in licensed institutions and hospitals as per the current legislation (Ministry of Justice, 1977). TOP after 20 weeks gestation occurs within women's assessment units and birthing suites in hospitals which hold a licence. Unlicensed hospitals with obstetric and gynaecological departments can still manage labour and birth if fetal death has occurred through feticide. 


\section{The New Zealand Core Midwife}

Core midwives, New Zealand midwives employed by the District Health Boards (DHBs) across the country, practise in clinical and non-clinical roles. Core midwives work across various departments, hospitals and in the community. Described as the pillar of the New Zealand maternity services these midwives are ready to provide care and services where- and whenever needed, able to develop a trusting relationship with women in a short amount of time, and work effectively in multidisciplinary teams for the benefit of women, babies, and families (Gilkison, McAra-Couper, Fielder, Hunter, \& Austin, 2017). Core midwives work in antenatal and postnatal wards, birthing units, women's assessment units, community based midwifery clinics, high risk maternity care (maternal and fetal medicine), diabetes services, Māori health, drug and alcohol, and other services. Working in hospitals means midwives are part of a multidisciplinary team, working in collaboration with obstetricians and under the values and core principles of their profession, as well as the DHB by whom they are employed. Hence, the scope of core midwives' practice can extend from primary care to high risk maternity care. Midwives work to the same principles in any setting: working in partnership with women, providing woman-centred care, empowering women to make informed decisions and delivering high quality maternity care to achieve best possible outcomes for babies.

While the scope of midwifery practice extends over the three pregnancy trimesters, labour and birth, and postnatal period, midwives based in hospitals care for women from 20 weeks gestation. This date line seems arbitrary. However, in New Zealand the legal status of the fetus changes at 20 weeks gestation and any birth over 20 weeks gestation must be registered (New Zealand Government, 2018). Furthermore the increased size of the uterus, placenta and fetus call for the specialist care provided by midwives. These aspects have contributed to a separation of women's care into nurse or midwife-led care within most New Zealand hospitals. In general midwives support women who present to hospital after 20 weeks gestation, and nurses care for women under 20 weeks gestation. 


\section{A Brief Overview of New Zealand Midwifery}

New Zealand's unique maternity care model was introduced in early 1990 (Midwifery Council, 2015). An initiative driven by consumers and supported by midwives, to offer women the choice of having midwifery care, led to the change in legislation. The implemented model restored midwives' right to provide care to women as autonomous practitioners. Midwives attend to individual women's maternity care predominantly in the community, either at home or in communitybased locations. Registered with the Midwifery Council of New Zealand, midwives are equipped with the skillset to provide an all-round service for women from the beginning of pregnancy, through labour, birth, and the postnatal period up to six weeks postpartum. Midwives can work in any setting, treat various conditions within their scope of practice, provide an initial response to problems, refer to other services, as well as provide care in emergencies (New Zealand College of Midwives, 2018). Midwives who provide continuity of care as the main health professional throughout pregnancy, birth and the postnatal period are known as Lead Maternity Carer (LMC) midwives. LMC midwives are contracted to the Ministry of Health and currently work under Section 88 of the New Zealand Public Health and Disability Act 2000 (Pairman, Pincombe, Tracy, \& Thorogood, 2015). In New Zealand $37 \%$ of midwives work community based, with the majority being self-employed LMC midwives; $50.5 \%$ of midwives are employed by DHBs ${ }^{3}$ as core midwives (Midwifery Council of New Zealand, 2015).

\section{Termination of Pregnancy after 20 weeks Gestation}

Late second and third trimester TOP is medically managed, mostly with a combination of an antiprogesterone (Mifegynae/Mifepristone) and uterotonics (Misoprostol). Third trimester TOP management can vary, dependent on local policies or consultant obstetricians' preference. Prostaglandin induction, epidural and syntocinon infusion have been used in these instances. Specialist obstetricians sign the necessary documents and consents with the women, and prescribe all relevant medications. However, unless complications arise, it is midwives, and in

\footnotetext{
3 DHBs (District Health Boards) provide and fund health services in their local health district. There are 20 DHBs in New Zealand.
} 
particular core midwives, who administer the antiprogesterone and who manage labour and birth during TOP after 20 weeks gestation. Maternal risk factors increase with gestational age and can include postpartum haemorrhage, retained placenta, infection, fever, and even sepsis (Ellis et al., 2010; Gemzell-Danielsson \& Lalitkumar, 2008; Mauelshagen, Sadler, Roberts, Harilall, \& Farquhar, 2009). In cases of previous caesarean section uterine rupture is a risk factor. Midwives are educated to recognise pathological processes as well as seeking obstetric assistance to deal with these emergencies. Third trimester TOP are routinely managed in birthing suites in case of complications.

In most instances midwives meet the women who are scheduled for TOP for the first time on the day of the procedure. The midwife who takes on TOP care often cares for other women during her shift; however, depending on staffing levels and skill mix, aims to provide as much one-on-one care to her TOP women. The midwife's role includes establishing rapport with the woman, administering uterotonics (the medication that starts labour), taking observations, providing support and pain relief through labour and conducting the birth. The midwife then measures, weighs and takes care of the baby, coordinates post-mortem examinations, assists with memory making like taking photos, hand and foot prints and castings, provides emotional support and completes the necessary paperwork.

\section{Women's Experiences of Termination of Pregnancy}

While it is beyond the scope of my current study to explore the experience of women, to understand what TOP care means to midwives it is important to acknowledge women's experience of TOP. The literature has shown that TOP after 20 weeks gestation is a major life event for many women with long-term mental and emotional consequences (Lyus, Creed, Fisher, \& McKeon, 2014). Self-blame, guilt, and social isolation are part of women's grief through termination, and continue long past the actual event with a substantial amount of women experiencing signs of post-traumatic stress disorder (Deas, 2017; Korenromp et al., 2005; Maguire et al., 2015). Women with TOP at advanced gestational age have increased feelings of guilt, especially when the fetal anomaly would have been compatible with life (Korenromp et al., 2005). Lafarge, Mitchell and Fox (2013) 
studied women's coping strategies during the process of labour in the context of termination. Findings showed that women seek comfort in their partner's and family members' presence, and through the support from the health professional caring for them during labour. Acknowledging the baby, memory making, giving meaning to their birth experience, and postnatal support helps women cope with the experience (Lafarge et al., 2013). Lotto, Armstrong and Smith (2016) found that the emotional complexity regarding TOP requires individualised care for parents which differs from care provided for other bereavements like stillbirths. Parents identified the need for education and preparation as important for the labour and birth process. Further, staffing levels and access to their allocated midwife are integral to their experience (Lotto et al., 2016). A recent metasynthesis by Jones, Baird and Fenwick (2017) highlighted how deeply traumatic labour and birth is experienced by women when terminating their pregnancy. Women's emotional suffering amalgamates with the agonising pain of induced labour; with women describing this as 'torture'. Clearly TOP is a highly complex, individual, and intimate mental, emotional, and physical experience (Jones et al., 2017). Midwife care during TOP has been acknowledged by all authors as essential to the women's experience.

\section{Tūranga Kaupapa and Māori Cultural Practices in the Context of TOP}

The principles of Te Tiriti 0 Waitangi, the Treaty of Waitangi, are embedded in midwifery practice. Partnership, participation, and protection are integrated into healthcare in general and demonstrated by midwives in their daily practice. Tūranga Kaupapa is the cultural framework developed by Nga Maia, the Māori arm of the New Zealand College of Midwives. This framework comprises a set of health principles and values and was implemented as a tool to assist midwives who work with Māori wahine (women) and whānau (family).

These beliefs and values incorporate:

- Whakapapa - the acknowledgement of wahine and whānau and their ancestral connection

- Karakia - Māori whānau may use prayer 
- Whānaungatanga - the ability of Māori whānau to incorporate extended family in the birthing process

- Te Reo Māori - Māori whānau may speak Te Reo

- Mana - maintaining dignity, honour, and respect of wahine and whānau

- Tikanga Whenua - the recognition of customs regarding the placenta

- Mokopuna - acknowledgment of the individuality of the child who inherits the future

- Te Whare Tangata - acknowledgement, protection and nurturing of the wahine as 'the house of the people'

- Manaakitanga - the acknowledgement of the role of the midwife and the sharing of a common goal, the safe delivery of a healthy baby and a healthy mother.

- Hau Ora - holistic health (Conectus, 2016)

The views regarding TOP amongst Māori are complex; however, this practice is thought to be frowned upon by many Māori (Le Grice \& Braun, 2017). It is difficult to estimate how many wahine proceed with TOP after 20 weeks gestation. Māori values and beliefs in the context of fetal congenital abnormality or late TOP have not yet been researched. Despite some historical accounts that abortion was sometimes practiced, the pre-European colonisation, traditional belief is that TOP disturbs the wairua (spirit) of the new life, and that whānau have an obligation to the community to care for the child (Le Grice \& Braun, 2017). Stories and knowledge are often passed on verbally by Māori; thus I am recounting my own experience from having had the honour of working alongside Māori wahine and whānau and my consultation with Nga Maia midwives to describe Māori cultural practices in the context of late TOP.

The baby is a recognised part of the wider whānau and therefore whānau is often part of the counselling and decision making process. I remember sitting in a very crammed counselling room with doctors, many relatives, and the young couple to discuss and make a very difficult decision. All options were considered and a decision made that all agreed on. In cases of congenital abnormality many wahine continue with the pregnancy in accordance with their values. If wahine and her 
partner feel they might be unable to care for the pēpi (baby) whānau may offer to whāngai (foster or adopt) the child. Where the decision is made to proceed with TOP supporting wahine and whānau in their cultural practices is important for holistic health and healing.

Hospitals offer flax woven baskets in order to keep the baby with its mother as it is cultural practice to stay with the body of the dead at all times. Māori tikanga (custom) is to touch their deceased and to keep them warm; however a baby's condition after birth deteriorates quickly and midwives offer ice bags in the basket or cooling cots (if purchased by the hospital) to keep baby with the mother. The whenua (placenta) is taken home to be buried with the pēpi. The practice of taking the placenta home to be buried has been adopted by some Pākehā (non-Māori) and I have regularly encouraged wahine and women to bring a container or basket that might be decorated with feathers, shells etc. or painted. Māori have a duty of care to their tūpāpaku (deceased); the cultural practices of Māori surrounding death are unique and sacred. Māori wahine and whānau tend to discharge from hospital within the shortest possible time frame after birth to start mourning. The pēpi is usually taken care of and taken home by whānau where it is never left alone. Whānau and extended whānau then come together at their marae (meeting grounds) in mourning and to bury the pēpi in the urupa (family cemetery). Postmortem examinations are often declined by Māori wahine and whānau as this breaches Māori values and customs. However, if postmortem examination has been requested by Māori whānau a family member might accompany the baby to the exam and back.

Once a trusting relationship has developed I have found it to be a special experience to work alongside Māori wahine and whānau, particularly to be asked to participate in karakia and other practices. Māori values and customs are part of midwives' experience when caring for women through TOP.

\section{The Legal Framework for Abortion in New Zealand and its Interpretation}

The controversy and ensuing debate surrounding TOP is too complex and diverse to be discussed in my study. My intention is to uncover the experience of midwives 
when providing TOP care. However, it is important to keep in mind that these midwives work within the laws that regulate abortion in New Zealand. The midwives are aware of the legal framework and its implications, and quite likely the discourses within society and the stigma that is still attached to TOP which might be part of their experience.

TOP in New Zealand is currently regulated by two different laws, the Crimes Act 1961 (The Ministry of Justice, 1961) and the Contraception, Sterilisation, and Abortion Act 1977 (The Ministry of Justice, 1977). Under the Crimes Act, TOP is unlawful in New Zealand and carries a prison sentence of 14 years. It is illegal to supply medications or use instruments to induce an abortion and doing so carries a sentence of up to 7 years imprisonment. TOP up to 20 weeks gestation may be legal in certain circumstances. Section 187A of the Crimes Act states these as: a) if the continuation of pregnancy could result in permanent harm to the mental or physical health of the woman, aa) if there is a considerable risk that the child, if the pregnancy continues, would be born "so physically or mentally abnormal as to be seriously handicapped", b) if the pregnancy is the result of incest, c) if the pregnancy is the result of rape, or d) if the pregnant woman or girl has significant mental impairment (The Ministry of Justice, 1961). If a pregnancy is over 20 weeks gestation TOP is lawful if the woman's life is at risk or if there is risk of permanent damage to her physical or mental health.

The Abortion Supervisory Committee (ASC) is a regulatory body appointed by Parliament under the Abortion, Sterilisation, and Contraception Act 1977. The functions of the ASC are to review if the abortion law is effective, as well as licensing of facilities and certification of consultants. Medical practitioners apply to the ASC to become certifying consultants under the law. The ASC issues New Zealand abortion statistics in their annual reports (The Ministry of Justice, 2018).

The ASC has repeatedly called for changes to be made to the Contraception, Sterilisation, and Abortion Act 1977 to bring it in line with contemporary healthcare services, improved technologies, and to change the outdated language (Holloway, Habib, \& Allan, 2017). The Convention on the Elimination of all forms of Discrimination Against Women (CEDAW) recommended the New Zealand 
government review the law and simplify it with an emphasis on women's choice, and remove the provision of punishment (United Nations, 2012).

The current law regulating abortion in New Zealand was based on a report issued by the Royal Commission of Inquiry into Contraception, Sterilisation and Abortion in 1977. The Royal Commission was established following public outrage and heated debate between pro-life and pro-choice voices regarding the opening of New Zealand's first abortion clinic in 1974 (McCulloch \& Weatherall, 2017). The commission's report was conservative in nature and led to the criminalisation of abortion yet allowed for exceptional circumstances (McCulloch \& Weatherall, 2017). The provision for these exceptional circumstances has been a source of discussion as the legal framework influences social and political opinion (Leask, 2015). While over 12,000 women have access to abortion in New Zealand per year (Holloway et al., 2017), most of these are performed under the mental health clause, giving women the label of being mentally unwell rather than making an informed choice regarding their reproductive health. Leask (2015) interviewed young New Zealand women on their views of abortion. Findings showed that the self-prescribed labels of pro-choice and pro-life ultimately did not echo the participants' views which were predominantly based around the exceptional circumstances for termination and followed a 'based on merit' approach. Women's right to self-determination was not considered by the participants (Leask, 2015). Leask concluded that the current legal framework shapes the discourses around abortion and contributes significantly to its stigmatisation. McCulloch (2017) supported the argument that the criminalisation of abortion in New Zealand strengthens the stigma of TOP within society, violates human rights, and leaves individual health professionals at risk of prosecution if the law is too liberally interpreted. This renders abortion an 'exceptional choice' rather than a choice based on health (McCulloch \& Weatherall, 2017).

\section{Conscientious Objection}

Under the Health Practitioners Competency Assurance Act 2003 section 174 health practitioners can express conscientious objection for personal reasons and are thus exempt from providing care to women who request TOP. Midwives also have 
the right to express conscientious objection if faced with the prospect of providing TOP care. Subsequently, not all midwives who practise in New Zealand will care for women facing TOP. This has implications for the number of midwives available and who agree to provide TOP care for women.

Service provision is reliant on the willingness of midwives to care for women who face TOP. Therefore, depending on rostering and staff availability, this service might not be available on a daily basis. The possibility of having to wait several days for a TOP presents added trauma to women once they have made the decision to proceed. For midwives it means they can be called on to provide TOP care more regularly, rather than occasionally, if many midwives in their department conscientiously object. Safe staffing, support, even relief during breaks can be limited if they are the only midwife on shift who has not expressed objection. This can present significant challenges to the midwives.

\section{The Role of Maternal-Fetal-Medicine}

Fetal anomaly screening has become a core component of antenatal care regardless of risk factors (McLennan \& Walker, 2015). Antenatal screening for trisomy 21 (Down's syndrome) and other conditions is performed in the first trimester by ultrasound and serum testing (The Ministry of Health, 2012a). Some fetal structural abnormalities can be detected by ultrasound scan in the first trimester; however the anatomy or morphology ultrasound between 18 to 22 weeks gestation is more likely to detect structural abnormalities as the fetus is more developed and technological advances have made detailed imaging much easier (Edwards \& Hui, 2018). These screening tests are routinely performed in the community.

Where the fetus has been found to have congenital abnormalities or severe intrauterine growth restriction, or a serious pregnancy complication has arisen, women will have further detailed scanning and other investigations in a maternalfetal-medicine (MFM) unit (The Ministry of Health, 2012b). These MFM units have been established in Auckland, Wellington, and Christchurch as part of the large tertiary maternity centers. MFM subspecialists are qualified MFM obstetricians. 
They manage high-risk pregnancies with advanced surgical and medical skills which include genetics, fetal physiology, ultrasound scanning, invasive prenatal diagnosis, fetal surgery or treatment in utero, complex multiple gestations, complex maternal conditions, and counselling of women and their families (RANZCOG, 2018; Sciscione et al., 2014). MFM specialists work in a multidisciplinary team with other specialties including midwives. Not many obstetricians practise in this subspecialty; therefore only four units exist in New Zealand. As a consequence, women from rural communities have to travel, often substantially, to attend visits while leaving their families behind. Travel time, arranging child care, overnight stays, and having to take time off work can delay consultation and, subsequently, diagnosis and possible treatment. While the MFM centres are aware of this stressful time for women and attempt to see patients within short time frames, delays can add to the women's anxiety and trauma.

The completion of all necessary investigations and counselling is a process that requires time. Decision-making to terminate a pregnancy is often delayed until well into the second trimester (RANZCOG, 2016). In a statement addressing late TOP, the Royal Australian and New Zealand College of Obstetricians and Gynaecologists (RANZCOG) (2016) declared "the college recognises special circumstances where late termination of pregnancy may be regarded by the managing clinicians and the patient as the most suitable option in the particular circumstance" (p.2) especially where the prognosis or diagnosis is not known until later in the pregnancy.

If, after consideration of options, risks, benefits, prognosis, and the woman's wishes, TOP is recommended to save a woman's life or to prevent her from permanent mental or physical harm, the obstetricians act as certifying consultants under the Contraception, Sterilisation and Abortion Act (The Ministry of Justice, 1977). Under current legislation, two obstetricians are required to agree that TOP is indicated (RCOG, 2011). 


\section{Induced Fetal Death or Feticide}

Since TOP is the deliberate ending of a pregnancy, with the intended outcome of fetal death, careful consideration has to be given if there is a possibility the fetus might be born alive (Ellis, Fisher, Leigh, Schott, \& Mahmood, 2010). An unintended live birth of a fetus during TOP can add to the distress women and their families are already experiencing (Megaw \& Dickinson, 2018). Midwives have found this challenging, especially when they had to comfort the baby while it passed away (Christensen, Christiansen, \& Petersson, 2013; Mauri, Ceriotti, Soldi, \& Guerrini Contini, 2015). Determining the viability of a baby is difficult and dependent on various factors. In the context of TOP it is presumed that a baby might survive the effects of the antiprogesterone, labour and birth from 22 weeks gestation. However, some babies can survive the TOP process under 22 weeks gestation and midwives and parents might be faced with a baby that shows signs of life, even if this occurs only briefly. Midwives have to prepare women and themselves for this possibility. In some instances women welcome signs of life as they are able to hold and comfort their baby. Precious memories can be made and this can support women's mental and emotional healing process.

Fetal death can happen during labour or shortly after, depending on the condition of the fetus. However, if there is a chance of signs of life after birth the Royal College of Obstetricians and Gynaecologists (RCOC) recommends feticide for TOP from 22+0 weeks gestation onwards (RCOG, 2011). Feticide is an intervention performed by fetal medicine consultants. After informed consent is obtained the specialist injects $2-3 \mathrm{ml}$ potassium chloride $15 \%(\mathrm{KCl})$ into the fetal heart under ultrasound guidance to achieve fetal cardiac asystole (RCOG, 2011). In New Zealand feticide is performed in one of the MFM units. Women who face TOP after 22 weeks gestation might have to travel long distances either by car, shuttle bus or plane, to attend this procedure. For some women this travel can present significant financial and logistical challenges. It is core midwives specialising in fetal medicine who coordinate the appointment, travel and procedure, and who support women emotionally through this traumatic event. Where the fetal abnormality is so severe and incompatible with life, feticide may be omitted at the discretion of the fetal medicine specialist in agreeance with the parents (RCOG, 2011). 
Graham, Mason, Ranking and Robson (2009) described feticide as a "small but significant, recurring event for health professionals" (p. 878), while parents viewed it as part of the overall experience of TOP. Midwives and consultants delivering women during TOP regarded feticide as a necessary procedure to safeguard against the distressing event of fetal signs of life at birth (Graham et al., 2009).

\section{Methodological Overview to the Study}

The methodology that underpins this qualitative research study is hermeneutic phenomenology informed by Max van Manen (1942). van Manen (1997) wrote that "phenomenological texts offer us a sensitive description and interpretation of a life experience" (p. 10). Phenomenology aims to uncover lived human experience that has not been reflected on; therefore the findings will not result in undoubtable truth (van Manen, 2017). Rather, through phenomenological research one can reach an understanding, an insight, into the phenomenon in question. van Manen's interpretive-descriptive methodology provides the novice researcher with a more structured approach to research that is generally non-methodical, while uncovering meaningful insights into the lived experience of midwives caring for women facing TOP in the late second and third trimester.

\section{Declaring my Interest in Midwifery Care for Women who face TOP}

In keeping with hermeneutic phenomenology it is important to declare and acknowledge who I am, what I bring, and how my pre-understandings might influence me throughout this study. A researcher must declare his or her interest to let the research question become reality. van Manen (1997) wrote "the question of knowledge always refers us back to our world, to our lives, to who we are, and to what makes us read and write... it stands iconically behind the words, the speaking and the language" (p. 46).

I finished my midwifery education in Germany 20 years ago. During work experience I realised that medical school would not be able to offer me what I really wanted to do - work with women; be hands on, be with, be present. For me, 
midwifery ticked all the right boxes. My new graduate year was spent in a large tertiary hospital in southern Germany before I joined a midwifery team at a small Christian hospital in the same city. I moved to New Zealand in 2002 and worked in the far north where I immersed myself into midwifery. It was not until I started working in one of the large Auckland DHBs in 2004 that I was introduced to the concept of caring for women through TOP. Orientation to the women's assessment unit was 'trial-by-fire' as staff was short and it was always busy. Nobody had mentioned to me that midwives (including self) would provide care during TOP. It was a foreign concept to me. However, as a young and energetic midwife who loved the complex cases, the 'never knowing what was round the corner', the adrenaline rush, I was happy to try my hand at anything. It never occurred to me that I could object, and I believe I never would have. I recall the violent labour pain, amplified by bouts of diarrhoea, that no pain relief was able to curb. I recall the urgency I felt when I had to pop out the room to check on another woman, knowing that I was needed much more next door. And I recall the grief, the tears, the loss I witnessed. In 2007 I changed employment. I was burnt out and in hindsight I understand that I gave too much to too many women and did not allow myself to re-set the balance. In 2013 I completed the complex care course with Auckland University of Technology and Auckland DHB and was subsequently recruited by the fetal medicine team as a fetal medicine midwife.

I recall this about my role in fetal medicine:

It was challenging but not because of my values, I just felt that these women have come to this point and now they find out there is something wrong with their baby, how do they feel? What must they feel like? Helping somebody go through that traumatic time, explaining over and over again what's going to happen, supporting women through such a difficult decision to let their baby go at 28 or 30 or 32 weeks, seeing them make that decision, understanding that this is the most life changing event for them and being part of that is kind of humbling. It gives you a very different understanding of women's lives. And it is challenging to find the right way to approach it, as every woman needs a different kind of guiding. They want to know so many things, but foremost they want to know is my baby safe? Am I going to be safe? Is my baby going to be in pain, is my baby suffering at the moment? Then there are all the intrinsics of the procedure, working up to the feticide which usually happens after 22 weeks. Then there is the what happens next? I have to explain that they have to go home and wait until they can come back into the hospital to 
then be induced to go through the most tremendous labour to give birth to a baby that is not going to be alive, that has already been dead for a few days. Then I see them process all of that but they can't retain a lot because they are just devastated. At the end of the day you are exhausted, drained, because there is the emotional part, the information part, the medical part, then you can't forget about the partner and the family, they go through their own stuff in their kind of way, so it's pretty complex. But then I was lucky, I could hand the women over when I booked them into the women's assessment unit. Generally I did not provide care during TOP, that is another step in the pathway. If you are the midwife who looks after the women for maybe 2 or 3 days, you are there to care for them through the birth and then do all the things that need to be done afterwards as well, that has its own unique challenges again.

In times of need I was that midwife who managed labour and birth. I bring a mingled understanding to my research study that is composed of my role as a core midwife who cared for women through TOP and my role as a fetal medicine midwife who guided women through the decision making process.

My research question and the development of my research study, however, arose out of an experience that was situated in my everyday midwifery life, when I was a fetal medicine midwife. I had to book a time slot for a woman for TOP in the assessment unit's busy schedule. Holding the paperwork I walked into the unit. My colleague, who frequently cared for women through TOP, noticed me and as she recognised the documents her friendly and open demeanour instantly changed. Her expression and her words "not another one" triggered a renewed awareness of the challenge in this process - both for the women and for the midwives providing care. I started to comprehend that within our experience was something that needed to be grasped. My research question arose out of this encounter.

\section{Structure of My Thesis}

Chapter one: Orientation to the study. In this chapter I provide the background and justification for the research question and the research aims, as well as the context to the study itself, and the declaration of my pre-understandings. 
Chapter two: Review of the literature. This chapter is dedicated to the review of the existing body of evidence in the context of midwives' experience when caring for women facing TOP.

Chapter three: Methodology and methods. In this chapter I will detail the philosophical notions underpinning this hermeneutic-phenomenological research study informed by van Manen. I will further explain the design of the study, ethical considerations, recruitment, data collection, data analysis, and rigour.

Chapter four: 'A different kind of midwife'. This first data chapter is dedicated to revealing how the midwives who provide TOP care see themselves as different to their peers and how they prepare themselves to meet the women for whom they are about to care.

Chapter five: 'Staying true to oneself'. In this second data chapter I will show how midwives work with women through TOP.

Chapter six: 'Melting an iceberg'. The final data chapter will reveal the effects of TOP care on midwives and shows what supports midwives in their role and which, if any, support structures are missing.

Chapter seven: Discussion of findings. This final chapter is dedicated to the discussion of the research findings and to answering my research question. I provide recommendations for education, practice, and future research. I conclude with a summary of my thesis and a comprehensive reference list.

\section{Conclusion}

Caring for women who face TOP after 20 weeks gestation is complex. Core midwives are the main caregivers for women through this traumatic event. TOP care is situated within the day-to-day running of birthing suites or women's assessment units, and despite the often busy workloads midwives aim to give as much care as possible to the women who are going through this event. TOP still carries a stigma and can be the source of heated debate. Midwives are aware of this 
when they support women; their care sits quietly and protectively within the centre of the various discourses. While the midwife's role seems straight forward, research has shown that women's experience of TOP after 10 weeks gestation is life changing, deeply traumatic and can have lasting mental-emotional effects. The care provided by midwives is viewed as essential for a positive experience for women. However, the experience of New Zealand midwives when providing TOP care has yet to be explored and acknowledged. 


\section{Chapter 2: Review of the Literature}

This chapter is dedicated to the narrative review of the current literature pertaining to midwives' experience with late gestation TOP. The review of the literature assists with understanding the experience of midwives who care for women through TOP in the late second and third trimester, as well as identifying gaps in the literature. van Manen (1997) stated: "A human science researcher might benefit from studying how other human science scholars have addressed and brought to text their understanding of selected topics" (p. 79). An overview of the existing body of evidence was obtained prior to developing my study to suspend understanding of the literature. In keeping with van Manen's methodology (1997), the literature was then thoroughly examined following the completion of data analysis to compare the findings of my research with others who have conducted research within this field.

This literature review has considered New Zealand and international research evidence. EBSCO, Medline, CINAHL and Google scholar have been searched. Search terms included 'midwives and experience termination of pregnancy', 'midwives and abortion', 'registered midwives and termination of pregnancy', 'midwives and late abortion', 'midwives and grief' and 'midwives and trauma'.

The literature was searched from the years 2000 to current day to ensure relative currency in the literature cited.

The review of the literature has revealed a limited number of studies that have explored midwives' experience when caring for women through TOP in the late second trimester. No studies were found that explored the experience of midwives with TOP in the third trimester. Studies were chosen based on a similar economic, political, legal, social, and health context to New Zealand. Research which examined the experience of midwives with TOP from sub-Saharan and other developing countries was excluded. This review of the literature does not focus upon women's experiences with TOP as it is beyond the scope of my project.

While my study focuses on the experience of midwives with TOP care in the late second and third trimester, it was not possible to separate out the experiences of midwives from nurses. In this literature review, as within the local and 
international literature, nurses and midwives cross over in the provision of care. Nurses care for women in general who have TOP up to 20 weeks gestation. On the other hand, midwives also care for women through first trimester and mid-second trimester TOP up to 21 weeks gestation. The review of the literature shows that midwives outside the New Zealand context frequently support women through first and second trimester medical terminations (Andersson, Gemzell-Danielsson, \& Christensson, 2014; Christensen et al., 2013; Cignacco, 2002; Garel, Etienne, Blondel, \& Dommergues, 2007; Lindström, Jacobsson, Wulff, \& Lalos, 2007; Lindström, Wulff, Dahlgren, \& Lalos, 2011; Mauri et al., 2015; Mauri \& Squillace, 2017; Mayers, Parkes, Green, \& Turner, 2005; Mizuno, 2011), with upper gestational age for legal TOP depending on the legislation of each country. My review of the existing body of evidence has shown that midwives work within the contexts of their country, and that generalisation of the findings is, therefore, limited.

The studies included in my review used a varying number of participants - from 3 (Mayers et al., 2005) to 216 (Lindström et al., 2007). Two questionnaire surveys (Garel et al., 2007; Lindström et al., 2007) were found where open ended questions were analysed using qualitative content analysis. In the studies using a qualitative approach the researchers conducted semi-structured or structured participant interviews (Andersson et al., 2014; Christensen et al., 2013; Lindström et al., 2007; Mauri et al., 2015; Mayers et al., 2005; Mizuno, 2011). All studies used different methods to analyse their data. However, the common use of thematic analysis is important to note as no study explored the experience of midwives to the depth that hermeneutic phenomenology offers. The different aims and purposes of each study mean that minimal comparison can be made regarding the experience of midwives with late second and third trimester TOP.

Two themes arose from the literature reviewed: 1) midwives' experience of late TOP care, and 2) supportive structures for midwives in late TOP care. In the first theme I will describe the midwives' experience throughout the process of caring for women through TOP. In the second theme I explore the structures that might support midwives to work in this role. A conclusion will follow the discussion of the themes. 


\section{Theme One - Midwives' Experience of Late TOP Care}

Several aspects have been identified comprising the experience of midwives with late gestation TOP. Five different subheadings identify and discuss these aspects in theme one: respecting women's rights to self-determination, the expression of conscientious objection, psychological implications of late TOP care, considerations regarding the baby, and emotional labour and grief.

\section{Respecting Women's Right to Self-determination}

The experience of midwives with late TOP can be influenced by their stance on women's right to self-determination (Andersson et al., 2014; Christensen et al., 2013; Garel et al., 2007; Mauri et al., 2015; Mayers et al., 2005; Mizuno, 2011). The studies found that midwives essentially support women in their choice and perceive TOP care as part of their general midwifery duties. Midwives have a clear understanding of the factors that influence women to choose TOP and place importance on caring for women without judgement, wanting to provide the 'right care' on an individual basis (Andersson et al., 2014; Cignacco, 2002; Garel et al., 2007; Lindström et al., 2011; Mauri et al., 2015). Garel et al. (2007) reported that the participating French midwives described a low level of moral distress with the process as they saw TOP for fetal abnormality justified to prevent suffering for both the child and the parents. A questionnaire survey, conducted by Garel et al., revealed that midwives felt compassion and empathy with women as they had to endure labour and birth without the reward of a live baby. Midwives who participated in a Swedish study viewed their role as important for women and their commitment to improved TOP care, as well as the importance of women's rights for society (Andersson et al., 2014). On the contrary, Mizuno (2011) found that Japanese midwives, faced with the choice of preserving the life of the fetus or supporting women's right to self-determination, felt they had to choose the latter as they viewed TOP care as part of their general duties. This stance, Mizuno reported, led to serious identity issues and emotional suffering (Mizuno, 2011).

New Zealand midwives, as discussed in chapter one, work in partnership with women, wherever they might practise. Grigg and Tracy (2013) stated that this concept of maternity care is based on trust, 'sharing' of control and responsibility, 
informed decision making, mutual understanding, and a shared meaning of the experience. Working in partnership is achieved when the relationship midwives and women enter into becomes the 'medium' through which midwifery is practiced (Guililand \& Pairman, 2010). Within this woman-centred notion the expectation rests on midwives to meet the needs of women in a holistic sense. The respect for women's right to self-determination and support of their decision making by midwives is an integral part of partnership and, in the context of my study, forms a part of the midwives' experience.

\section{Expressing Conscientious Objection}

The right to express conscientious objection, as discussed in chapter one, has been provided within the law nationally and internationally to enable health care professionals to protect their religious, moral or ethical values, and object to caring for women through TOP. In New Zealand, the midwives' responsibilities are to the woman, the wider community, and the profession (New Zealand College of Midwives, 2018). While the code encourages midwives to stay true to their values it also states that personal belief must not deprive women of care. This places the burden of duty onto the midwives while leaving out clarification regarding ethical issues affecting midwives.

Garel et al. (2007) and Mayers et al. (2005) found that despite having expressed conscientious objection on moral, religious, or personal grounds, midwives still provide care to women through TOP as they see TOP care as part of their role.

Several studies found that contradictory feelings and increasing misgivings emerged amongst midwives when TOP was performed at higher gestational age or if the fetal abnormality would have been compatible with life (Andersson et al., 2014; Garel et al., 2007; Lindström et al., 2011; Mauri et al., 2015). However, Hammarsted, Jacobson, Wulff and Lalos (2005) and Lindström et al. (2011) found that midwives who had experienced TOP themselves or who had several years experience working in this field were more understanding towards women.

Huntington (2002) discussed the integration of nursing and feminist viewpoints in the gynaecological setting in the context of first and second trimester TOP. The 
author pointed out that nurses who express conscientious objection might not have considered the impact TOP care has on their colleagues who do support women through this process. Midwives or nurses who provide TOP care have to deal with an added role that comes with certain challenges and emotions, yet without extra support or recognition. If all healthcare professionals chose to conscientiously object, as it is their right provided by law, there would be no service caring for women through TOP. Fiala and Arthur (2017) have suggested that conscientious objection should not be allowed in reproductive healthcare as it is a personal expression rather than based on professional ethical code. However, personal and professional beliefs and values are intertwined and cannot necessarily be separated. Perhaps it should be recognised that the nurses and midwives who do not object to providing TOP care require additional support to undertake this role (Huntington, 2002).

Fleming, Frith, Luyben and Ramsayer (2018) conducted a systematic review of ethical arguments within the existing literature regarding conscientious objection expressed by midwives and nurses. The review aimed to identify any reasons stated in the literature why nurses and midwives might be for or against conscientious objection in the context of TOP care. Findings showed that there is no clear argument for or against conscientious objection; however, there is a distinct lack of presence of nurses and midwives within this debate, hinting at a disparity between literature and practice. Fleming et al. (2018) concluded that the debate must be held with the health professionals providing TOP care, especially in view of major organisations like the WHO emphasising the value of nurses and midwives as TOP care providers.

A recent opinion paper (Gardenier, McMullen, \& Philipsen, 2018) reviewed the question 'Do conscience clauses violate patients' rights?' from opposing viewpoints. The authors concluded that nurses' and midwives' right to protect their personal values stand against the violation of patients' rights, the ethical code of the profession, and the smooth provision of services in a busy hospital environment (Gardenier et al., 2018). A solution to the issues this question raises was not proposed in the paper - the debate is ongoing. 


\section{Psychological Implications on Midwives}

Cignacco (2002) explored the experiences of midwives when caring for women through TOP in Switzerland. For this study Cignacco interviewed 20 midwives and analysed the interview data using qualitative content analysis. Cignacco placed the experience of the midwife participants within the socio-ethical and theological context of Switzerland. The author declared her pre-understandings as a midwife and raised the issue of bias as she herself felt emotionally impacted by TOP care. Cignacco revealed that midwives saw TOP care as part of their role; yet, it was the most difficult, emotionally burdensome, and conflicting work of a midwife. The midwives experienced anger, helplessness, and significant unease as their personal moral code, which would have supported the right of the fetus, clashed with their professional duty of supporting women's right to choice. Cignacco concluded that midwives are the most directly and intimately involved health professionals in the process of late TOP. It is interesting to note that in 2002, the year Cignacco's study was published, Switzerland went through a legislative change in their criminal code, legalising TOP before 12 weeks, as well as legalising TOP after 12 weeks without an upper gestational limit if either maternal mental distress or physical injury have been diagnosed (Reinholz, Casati, Beretta, \& Merlani, 2018). Such change to legislation signals a shift in social perceptions.

Society's opinion of TOP was also a cause of concern for Japanese midwives. Mizuno (2011) thematically analysed semi-structured interviews with 11 midwives who worked in the delivery unit of a large hospital in Tokyo. Mizuno revealed that the midwives found their role in TOP most challenging, confusing, and conflicting due to the social stigma regarding TOP in Japan. Unable to talk to friends or family about their thoughts and feelings, the midwives held conversations in their mind, criticising themselves for their involvement in TOP, and thus adding to confusion between their professional and personal identity. It was noted that this qualitative study used the term 'midwives' and 'nurses' interchangeably, likely due to midwifery being a postgraduate module for further education.

Mizuno (2011) and Cignacco (2002) both found that midwives tend to suppress their moral concerns during care delivery in favour of the woman, leading to 
internal conflicts and distress. These findings were confirmed by Christensen et al. (2013) who explored the experience and attitudes of Danish midwives with late TOP. Ten midwives participated in structured interviews which focused on midwives' perception of their role and how their professional identity might be influenced by technological advances in regards to prenatal screening. Christensen et al. found that midwives suppressed their feelings towards the fetus in favour of the woman's right to choose. However, the Danish midwives appeared not to emotionally struggle as much as the Japanese midwives, pointing to a more liberal stance towards TOP in Denmark compared to the more conservative Japanese society.

Mizuno (2011) and Mauri et al. (2015) reported that the midwife participants struggled to contain their emotions while supporting women throughout the TOP process. Garel (2007) discussed that midwives found it difficult to provide psychological support to parents as well as giving midwifery care. Moreover, the Italian midwives in Mauri et al.'s study felt that supporting women emotionally was the most difficult part of the role; so much so, that they regularly requested moral support from a colleague, otherwise they would feel emotionally overwhelmed and lonely in the birthing room.

Garel et al. (2007) and Mauri et al. (2015) found that TOP care occupies midwives' minds outside of work and that midwives have a distinct awareness of the number of women for whom they have cared. The lonesome discussions Japanese midwives hold with themselves (Mizuno, 2011) strengthen the findings of international research studies that TOP care is emotionally burdensome, not just during the care encounter but beyond.

The psychological impact of TOP care is felt along a continuum amongst the midwives from different countries and not every midwife will experience emotional distress when providing TOP care. Andersson, Gemzell, and Christensson (2014) conducted a thematic analysis on data obtained through interviews held with 21 Swedish nurse-midwives. The authors commented that this study had significantly more nurse than midwife participants which is likely reflected in the findings. This study found that midwives gained valuable 
experience through repeatedly caring for women through TOP which grew inner safety, confidence and maturity, and lessened the emotional impact of TOP care (Andersson et al., 2014).

\section{Considering the Baby}

Several authors found that considerable anxiety was experienced by midwives throughout labour care regarding the possibility the baby might be born alive; if a baby was actually born alive this anxiety amplified, posing significant ethical and legal predicaments and uncertainty as to how to handle the situation (Andersson et al., 2014; Christensen et al., 2013; Garel et al., 2007; Mauri et al., 2015; Mayers et al., 2005). A cross-sectional survey exploring the experiences of obstetricians with late TOP over 23 weeks revealed Swedish and Italian obstetricians are obligated to call neonatal services if the fetus is born alive after TOP (Habiba et al., 2009). Habiba et al. (2009) also found that obstetricians in France and the Netherlands have performed active euthanasia in such cases. Garel et al. (2007) discussed that the French midwife participants opposed postpartum euthanasia; however, the author did not clarify this practice in the paper. Christensen (2013) described that midwives placed the fetus with the parents if the pregnancy was wanted; however, if parents declined involvement the responsibility fell to the midwives to care for the child until it died. Feelings of anger were a common emotional response in Christensen's study. Midwives also expressed feeling angry and upset if the fetal anomaly that led to TOP would have been compatible with life, in particular with increasing gestational age (Christensen et al., 2013).

Fetocide, as a procedure to induce fetal death before induction of labour, can to some degree eliminate the chances of the fetus surviving and lessen the anxiety of health professional; however, the process presents challenges, in particular, for parents and the health professionals involved (Graham et al., 2009). A number of studies found that handling the dead fetus posed a significant challenge for many midwives (Andersson et al., 2014; Garel et al., 2007; Mizuno, 2011; Mizuno, Kinefuchi, Kimura, \& Tsuda, 2013). Mizuno (2011) found that the midwives felt deeply affected by the handling of the fetus and experienced guilt, sadness, and confusion over the loss of life. However, Andersson et al. (2014) and Christensen et 
al. (2013) reported that there has been a change in awareness of the traumatic nature of TOP for women. The studies found that midwives increasingly appreciate and acknowledge the loss and grief women and their partners feel, which has led them to respect the fetus as a child, the woman as a mother, and to engage in memory making.

\section{Emotional Labour and Grief}

Grief is as individual as humans are. Grief is not lineal, it is dynamic in nature, it transcends culture and it is experienced in different ways (Kuebler-Ross \& Kessler, 2005a). Customs and traditions surrounding death arise from different cultural backgrounds. The beliefs and customs of Māori surrounding birth, TOP, and death are important to acknowledge in a study conducted in Aotearoa-New Zealand. For indigenous Māori women the concept of life and death is fluid. Le Grice and Braun (2017) helped clarify this fluidity in their findings. Māori view the unborn as an individual wairua (spirit) and as such the fetus deserves protection (Le Grice \& Braun, 2017). Kenney (2009) described a dearth of literature in regards to Māori and miscarriage and midwifery. However, Cogins (2012), Clair (2008), and Stodart (2018) have described how Māori customs have influenced the processes around death, dying, and the mourning of loss. The care for those who are dying is viewed as facilitating processes of cultural significance that are deeply embedded in Māori society (Clair, 2008; Coggins, 2012; Stodart, 2018). This is an experience and belief that many midwives might share.

Following on with cultural influences surrounding death and dying, Mizuno (2013) conducted a cross- sectional survey to assess the professional quality of life of midwives and nurses involved in TOP and childbirth. This study found that midwives performed a high level of emotional labour when caring for women through TOP, leading to significant distress (Mizuno et al., 2013). Emotional labour is a skill that is largely invisible and still under recognised in nursing and midwifery (Elliott, 2017; Funk, Peters, \& Roger, 2017). Elliot (2017) argued that the under recognition of the value of emotional labour contributes significantly to stress and burn-out in nursing and midwifery staff. 
Drach-Zahavy, Buchnic, and Granot (2016) suggested that midwives are also expected to manage their emotions and detach themselves on a professional level while being compassionate, caring, empowering, and facilitating a good childbirth experience for women. Yet, the authors of this prospective-correlational field study also discussed that unique encounters like TOP or traumatic events can be characterised by intense emotions and present challenges for the midwives to protect their normal boundaries (Drach-Zahavy, Buchnic, \& Granot, 2016). A number of authors have shown that midwives experience compassion fatigue from their work and suffer secondary traumatic stress, loss, and grief after unexpected stillbirth and traumatic obstetric events (Austin, Smythe, \& Jull, 2013; Cohen, Leykin, Golan-Hadari, \& Lahad, 2017; Foureur, Besley, Burton, Yu, \& Crisp, 2013; Jones, 2012; Leinweber \& Rowe, 2010; Wahlberg et al., 2017). These findings suggest that midwives suffer with the women and are significantly affected as the main care providers in the context of TOP.

Kirkham (2007) suggested that midwives are expected to cope with their emotions professionally and quietly, crying is perceived as 'not coping' and as such can be judged negatively by colleagues and management. Their study revealed that midwives viewed it as pertinent not to show emotions in front of the women. The midwives related their clinical experience to professional maturity and inner safety throughout the TOP process, which they felt was helpful in keeping their emotions contained (Andersson et al., 2014).

For broader insight I will provide a brief overview of how other health professionals experience death and grief in their role. An interpretive inquiry influenced by symbolic interactionism explored the understanding and interpretation of grief and the emotional labour of paid carers working with dying patients and grieving families (Funk et al., 2017). The participant nurses engaged in palliative care described their conflict with grief and grieving. The authors identified that nurses experienced death and dying as sources of emotional distress and found dealing with their subsequent grief responses challenging. Funk (2017) reported that nurses required time and space to process their grief; however, this was often impossible due to time constraints in their work place. Expressions of grief were found to be unwelcome as the expectations from 
management and senior nurses were that nurses remained in control, professional, and composed at all times. Funk described that crying was perceived as a sign of weakness.

The notion of crying as a sign of weakness was echoed by Kain (2013) who interviewed neonatal nurses who cared for dying babies and their families. Neonatal nurses also experience bereavement in their role and are subsequently forced to deal with death and grief, which is intense emotional labour (Kain, 2013). During focus groups the nurses revealed that they struggled with the empathy they felt with parents while simultaneously needing to keep their professional boundaries. The study showed that the nurses felt lonely, unsupported, and unacknowledged by colleagues and management when a death had occurred. Kain (2013) proposed that neonatal nurses are expected to deal with their workplace distress professionally, yet they are wholly untrained and unprepared for dealing with grief.

Kisorio and Langley (2016) explored the experiences of ICU nurses with end-of-life care and revealed that nurses felt unprepared for dealing with death. This study found that nurses felt emotionally challenged by having to support dying patients, especially if they had formed a bond (Kisorio \& Langley, 2016). Emotional respite could be achieved by swapping shifts following end-of-life care. Kisorio and Langley proposed that insufficient recovery time in between patients or verbalisation of emotions to process the experience could lead to an accumulation of grief and result in secondary traumatic stress and burnout.

The review of the literature has uncovered several aspects which form the experience of midwives with TOP. Theme one arose out of the consideration of these aspects. The current body of evidence has revealed that the experience of midwives is influenced by personal and professional beliefs, social, and cultural backgrounds. However, while the studies included in this review had differing methodologies, aims and purposes, and were placed within different contexts, the comparison revealed that TOP care is challenging and an emotional burden for midwives. 


\section{Theme Two - Supportive Structures for Midwives in Late TOP Care}

Considering the review of the literature has demonstrated TOP care as ethically and emotionally challenging for midwives, the existing body of evidence has identified several shortcomings in support structures which would improve midwives' experience. In this theme I will discuss debriefing and counselling as well as education in the context of TOP care, institutional support, and team work.

\section{Debriefing and Counselling}

Repeatedly midwives have asked for psychological support to help them deal with the effects of their role. Yet, several authors have identified a distinct lack of debriefing and counselling for midwives who care for women through late gestation TOP (Garel et al., 2007; Huntington, 2002; Mauri et al., 2015; Mayers et al., 2005).

Andersson et al. (2014) revealed that debriefing with colleagues between patients helped midwives to cope, although the time between cases was perceived to be too short to process their experiences fully. From the literature reviewed, the midwife participants of the Swedish study (Andersson et al., 2014) were the only midwives who were offered counselling. The authors reported the positive effects and personal growth midwives experienced through debriefing and ethical discussions with counsellors. Initially developed to reduce psychological trauma in military populations regularly exposed to traumatic events, critical incident stress debriefing (CISD) has become a formal intervention amongst frontline emergency personnel like police and firefighters, nurses, doctors, and midwives (Austin et al., 2013; Gardner, 2013; MacDonald, 2003; Sattler, Boyd, \& Kirsch, 2014). Dufrene and Young (2014) and Gardner (2013) suggested that debriefing as a reflective process requires active engagement, encourages reflection, and fosters learning to improve outcomes.

Ling, Hunter, and Maple (2014) reported that personal growth has the potential to mitigate the sense of distress in trauma counsellors when exposed to secondary or indirect trauma, and was helpful in keeping trauma counsellors engaged in their 
work. The counsellors were able to rely on a range of resources to support them in their work, which included counselling, professional supervision, professional development, flexible working arrangements, self-care strategies, and work-place activities (Ling, Hunter, \& Maple, 2014).

Professional supervision, counselling, or debriefing seem to be offered sporadically to nurses who work in abortion clinics or other settings with first and very early second trimester terminations. Parker, Swanson, and Frunchak (2014) described that nurses found debriefing in small groups helpful after complex situations. Yet, the authors noted that not everyone was comfortable enough to share their feelings within these group settings (Parker, Swanson, \& Frunchak, 2014). The more common thread throughout the literature is that death and dying in caring professions is seen as part of the job and any professional support to alleviate short- and long term psychological consequences is sorely lacking (Funk et al., 2017; Gallagher et al., 2010; Huntington, 2002; Jones, 2012; Kain, 2013).

Winter (2018) discussed how to promote wellbeing and foster resilience amongst midwives and nurses when working with bereavement. However, individual resilience might not be sustainable in the face of an unsupportive environment. Building resilience is a team approach and practices to foster such must be embedded in the organisational culture and carefully cultivated (Crowther et al., 2016; Foureur et al., 2013; Hunter \& Warren, 2014). The offer of debriefing and counselling for midwives who care for women through TOP is a support structure that might promote resilience in midwives. From the review of the literature it appears that counselling is not commonly facilitated for midwives, with the exception of Sweden. However, counselling may be beneficial for those involved in the provision of TOP care.

\section{Education}

Targeted training to prepare midwives for the role, as well as ongoing education, has been identified as a shortcoming by several authors (Andersson et al., 2014; Christensen et al., 2013; Cignacco, 2002; Garel et al., 2007; Mauri et al., 2015; Mayers et al., 2005). The review of these studies has revealed that the participant 
midwives were unprepared for the role psychologically, ethically, legally, communication- and skill-wise. The authors concluded that further training would be highly beneficial to sustain midwives in the role.

The French and Italian midwives expressed a need for communication skills training in particular to support women emotionally through their bereavement (Garel et al., 2007; Mauri et al., 2015). Andersson (2014) and Mauri (2015) have highlighted mentorship to be valuable for midwives to gain confidence and knowledge, which might also improve patient care. This suggestion evolved in light of their findings that midwives learn their TOP care skills on the job from more experienced midwives.

\section{Institutional support}

The lack of support and acknowledgement from institutions, in particular management, is another shortcoming that has been identified by several studies (Cignacco, 2002; Garel et al., 2007; Mauri et al., 2015; Mayers et al., 2005; Mizuno, 2011). Midwives have been asking for safe staffing levels with extra midwives on duty when TOP is scheduled. Garel et al. (2007) and Mauri et al. (2015) found that midwives placed importance on the ability to provide one-on-one care without time pressures and to request peer support without placing the unit under pressure. Andersson et al. (2014) revealed that midwives needed more time for reflection between cases. The lack of clear policies, in particular when the fetus is born alive, has been also been identified repeatedly across the literature (Christensen et al., 2013; Garel et al., 2007; Mauri et al., 2015; Mizuno, 2011). Additionally ethical discussions for clarification and acknowledgement of the role of midwives in regards to TOP care from their professional institutions is another factor that would reduce the professional confusion experienced by midwives (Christensen et al., 2013; Cignacco, 2002; Garel et al., 2007; Mizuno, 2011).

\section{Team Work}

Team work and communication have been identified by the Swedish, Danish, French, and Italian midwives as the most important factors which help them cope in their role of caring for women having late TOP (Andersson et al., 2014; Christensen et al., 2013; Garel et al., 2007; Mauri et al., 2015). These midwives call on their colleagues to be with them when they feel distressed or lonely, to help 
them take care of the baby, to offer support and debrief following the completion of the care, and reflect on their practice. Andersson et al. (2014), Garel et al. (2007) and Mauri et al. (2015) found that midwives who care for women through TOP also care for each other by coming together for informal debriefing to deal with the emotional burden. Reed (2011) found that during informal sessions, in tea rooms or hallways, midwives share stories with each other. It has been acknowledged that the midwifery narratives shared in these moments build a repertoire for practice and increase knowledge (Reed, 2011). Despite the challenges and psychological effects, the authors of the Swedish, Danish, and Italian studies, have found that midwives perceive TOP care to be a source of job satisfaction and joy when the care they have given has been well received by women and when the process has gone smoothly (Andersson et al., 2014; Christensen et al., 2013; Mauri et al., 2015).

\section{Conclusion}

Despite the different legal, political, social, and health care contexts in which midwives in New Zealand and across the world practise, the literature has shown that caring for women through TOP in the late second and third trimester is a complex, multi-dimensional experience that can have profound personal and professional effects for midwives. Many midwives see TOP care as part of their role and support women in this choice. Yet, the literature has revealed that midwives are not prepared for the ethical dilemma that ensues if their own values are in dissonance with their professional duties. This creates substantial personal and professional conflicts for midwives as they stand unsupported by the institutions for which they work and their professional bodies. Handling the fetus, especially if born alive, appears to be a significant challenge for midwives. There have been repeated calls by midwives and researchers for ethical discussions to define and acknowledge the role of midwives in TOP care, for counselling and debriefing, for clear guidelines, ongoing education and safer staffing levels so midwives can feel valued for their work, call on colleagues when issues arise, and dedicate themselves to caring for the women.

The following chapter will discuss the research methodology, design, and methods. 


\section{Chapter Three: Research Methodology and Methods}

In this chapter I describe how descriptive-interpretive phenomenology, informed by Max van Manen, is the most appropriate methodology to explore the research question: What is the lived experience of midwives caring for women facing termination of pregnancy in the late second and third trimester? I will describe the methodical approach of van Manen's phenomenology, including an overview of the history and philosophical tradition of the phenomenological movement and the most influential philosophers that shaped van Manen's thinking. The four life world existentials that guided data analysis will be explained. Further, I discuss the methods employed in this research study, which include recruitment of participants, data collection, ethical considerations, data analysis and trustworthiness of research.

\section{Research Design}

It was my lived experience of meeting my colleague and a moment of shared understanding that led me onto this research path. Wanting to explore the phenomenon of midwives caring for women through late gestation TOP, which was part of the humanistic aspect of midwifery care, called for a methodology that would allowed the study of lived human experience and acknowledge the uniqueness of individual human beings-my participants (Miles, Chapman, Francis, \& Taylor, 2013). Hermeneutic-phenomenology revealed itself in the reflection on this experience and the formulation of the research question; demonstrating to me that this research begins and ends with lived experience.

My research aims are:

- Gain a deeper understanding of the role of midwives in TOP care

- Reveal what might support midwives in their role

- Uncover the effects for midwives of providing TOP care

\section{Max van Manen - Hermeneutic-Phenomenological Research}

van Manen's (1997) approach to hermeneutic-phenomenological research supported my research aim; yet, encouraged my imagination and allowed for 
flexibility and the artistic expression of insight in a narrative. His approach is unique, as it is fundamentally a "writing activity" (p. 124), doing research and the writing of text as two aspects of one process.

To explore the nature of the lived experience as intimately as possible, van Manen's phenomenological human science research is situated in the lifeworld, the immediate, every-day life as we experience it in situations and interactions (van Manen, 1997). The nature of lived experience is understood as an automatic awareness of being present without any form or structure. Once we are consciously aware of an experience it becomes objectified and we try to conceptualise and make sense of it. van Manen emphasised that phenomenological research is a retrospective, reflective practice as phenomena present themselves to our conscious mind but through awareness and reflection they become what they are. He encouraged the phenomenological researcher to produce a narrative with the use of words that set free memories that have not been recognised previously, eliciting the 'phenomenological nod' (Smythe, 2011). He argued that describing an object or experience is equal to interpretation as the choice of words will never capture the essence as it is but be an interpretation of what is seen or understood. The philosophers that van Manen drew on in relation to developing his approach will be discussed later in this chapter.

\section{Philosophical Traditions Shaping van Manen's Thinking}

van Manen's contribution to phenomenology is a contemporary approach which combines traditional philosophical elements based on Dilthey, Husserl, and Heidegger, the teachings of the Utrecht school and some newly developed notions of the North American method-driven approach to phenomenology (de Chesnay, 2014; Dowling, 2007; van Manen, 1997). van Manen professed his interest in reading philosophical and phenomenological literature by famous and other literary authors which were fashionable when he was an adolescent (van Manen, Higgins, \& van der Riet, 2016).

First roots of phenomenological thinking were born in Germany and can be found in the writings of Immanuel Kant (1724-1804), Georg Hegel (1770-1831), and 
Franz Brentano (1838-1917) (Miles et al., 2013). An unsatisfactory political, social and cultural landscape in early 1900 Germany, led academic philosophers to form the phenomenological movement. One of the driving factors for this movement was the advance of science and the belief that knowledge obtained through science was the only, verified truth (de Chesnay, 2014). The movement quickly spread throughout Europe with various perspectives and schools of phenomenology arising out of the traditional philosophical notion. The two main figures of the phenomenological movement are Edmund Husserl and Martin Heidegger.

\section{Edmund Husserl}

Edmund Husserl (1859-1938), regarded as the "father" of the phenomenological movement, had a major influence on van Manen. Discontented with the methods of naturalistic inquiry ("Naturwissenschaften") Husserl conceptualised the method of classical phenomenology, a purely descriptive philosophical school of thought striving to also be a rigorous science with concrete findings. Concerned with the nature of knowledge Husserl called his phenomenology "the science of the essence of consciousness" (Grbich, 2013, p. 93). Husserl's abstract concept considered experience as fact and, therefore, the essential source of knowledge (Racher \& Robinson, 2003). The central part of Husserl's phenomenology was for the researcher (subject) to examine phenomena (object) as they appear in his consciousness with directed intent (de Chesnay, 2014). In order for the essence of something (phenomena) to emerge and to remain objective, the researcher must put private preconceptions, values or theories aside, also referred to as bracketing, phenomenological reduction or, in Husserlian words, 'epoche' (Dahlstrom, 2012; de Chesnay, 2014). This concept differentiates Husserl's philosophy from followers. Husserl's term "to the things themselves" (van Manen, 2014, p. 92) became the essence of phenomenological research - the description of lived human experience.

\section{Martin Heidegger}

Martin Heidegger, another major influence on van Manen's work, was born in Germany and is one of the most important Western European philosophers of the $20^{\text {th }}$ century. Heidegger moved away from Husserlian abstract philosophical 
thinking and conceptualised a different pathway of phenomenology. He sought to reach an understanding of the meaning of being as opposed to Husserl's descriptive phenomenology (Racher \& Robinson, 2003). Heidegger called for a renewed contemplation of being or, in Heidegger's word, 'Dasein'. Difficult to translate into English 'Dasein' is an expression of 'being-there', being present in a moment in time, within a context that shapes the experience of being. Human beings are always present in the world, immersed in a situation right now, interacting and communicating within our social norms (Miles et al., 2013; Smythe, 2011). Therefore, humans and the world are connected and human knowledge arises from being in this world, the connection with it and experiencing life in it everyday (Smythe, Ironside, Sims, Swenson, \& Spence, 2008). Heidegger was concerned with revealing the taken-for-granted and hidden away aspects of everyday human life (Miles et al., 2013). He rejected Husserl's notion of bracketing and, quite the opposite, urged to embrace prior knowledge and experience. Heidegger viewed pre-understandings as part of the researcher's life and, therefore, as inseparable from the thinking and research process (Dowling \& Cooney, 2012). Heidegger (2006) promoted the use of hermeneutics based on his view that lived experience is an interpretive process.

\section{The Hermeneutic Circle}

Much like a 'perpetual motion' the notion of the hermeneutic circle alludes to the infinite, fluid movement between parts and the whole. In Heidegger's phenomenology this is an analytical, interpretive process of making sense of our being-in-the-world (Heidegger, 2006). The circle essentially describes the complex process of writing, reflection, and re-writing. Moving between the consideration of parts of the data and the whole in an inward and outward movement contributes to the circularity of this process (Crotty, 1998). Just as the words we read draw us in to the writing space (van Manen, 2014), essentially, in a similar notion, Heidegger encouraged us to take a "leap into the circle" (Crotty, 1998, p. 98) to bring about understanding. 


\section{The Hermeneutic Lens - Interpreting Meaning}

Etymologically the word 'hermeneutic' is derived from Hermes, the Greek god who served as the messenger of the other gods (Palmer, 2001). Hermes brought the decisions of the Gods to the people. He applied reflection, translation, interpretation and explanation to godly words to help the people understand something wholly unfamiliar (Crotty, 1998).

The interpretation of biblical texts can be traced throughout history since the time of the Greeks. Hermeneutics is, therefore, the act of passing on meaning from words, texts, even art, to whole communities to reach a deeper understanding. A modernised form of hermeneutics is being applied to help us understand human experience, behaviour, or situations. The fundamental tool to enable interpretation is human language. As Crotty (1998) stated "hermeneutics assumes a link between the two that make this exercise feasible" (p. 91). During the process of interpretation the act of description itself can lead the interpreter to reach an understanding that might not have been evident previously or too complex to express (Kafle, 2013).

In summary, van Manen's philosophy was influenced by Husserl and Heidegger as he translated their philosophical ponderings to his field of expertise, education and research. He developed a framework which applied the notions of phenomenology to a research method which attributes meaning to the understanding of human existence and lived experience. van Manen's phenomenology has been applied to various research projects, in particular to health research. In the following section I will discuss van Manen's framework for hermeneutic-phenomenological research.

\section{The Six Methods - a Framework for Hermeneutic-Phenomenological Research}

In Researching lived experience (1997) van Manen set out his framework comprised of six elemental activities to make hermeneutic phenomenological research more 'user-friendly'. He addressed how to formulate the research question ("turning to the nature of lived experience"), the concept of data and design of research studies situated in the life world ("investigating experience as 
we live it"), the analysis of data and reflection process ("reflecting on essential themes"), the writing process and use of language ("the art of writing and rewriting"), keeping a focus on the research question to stay connected to the phenomenon throughout the reflection and writing process ("maintaining a strong and oriented relation") and general considerations of the effects of the research study ("balancing the research context by considering parts and whole") (van Manen, 1997, pp. 31-33). While the framework might look inviting as a set of steps to follow, van Manen's intention is for these activities to be part of a dynamic process that allows creativity and stimulates insight.

\section{Pre-Understandings}

In starting the research process, as urged by van Manen (1997), I turned towards the phenomenon of interest of what it is like for midwives to care for women during TOP. My first supervisor interviewed me at the beginning of my research. I 'knew about' my experience with supporting women through late gestation TOP. Most of my experience was years in the past, even though I had provided care throughout the TOP process for a couple of women during my time in fetal medicine. The understandings from my pre-assumptions led me to carefully prepare for my interviews. I had bought large amounts of tissues to give out, expecting many tears, almost steeling myself as I was sure the interviews would be emotionally challenging. I did not anticipate what I experienced during the interviews. I understood, as I reflected by myself and with my supervisor, that I had my own assumptions but each midwife shared their very own experience that contributed to further understandings. Thinking back to the conception of my research question made the suspension of my own understanding clear. My research is not about me. It is about the experience of midwives who provide care to women through late gestation TOP as part of their midwifery lifeworld. While at times it was challenging to keep the question of 'what is their experience?' foremost in my mind, I constantly reflected on my writing. This reflecting guided me through keeping my own understandings at bay. 


\section{Research Methods}

In this following section I discuss the ethical considerations given to this research study, the recruitment and interview process, reflection and data analysis.

\section{Ethics}

Ethical approval for my study was granted by the AUTEC (Auckland University of Technology Ethics Committee) on January $20^{\text {th }}$ 2017, numbered 16/350 (Appendix A). The application process gave me a chance to consider my research study in a wider context and the implications my research might have. Te Tiriti o Wāitangi (The Treaty of Waitangi) as the founding document of New Zealand, and its principles of partnership, participation and protection were acknowledged and are a central part of my research study. Consultation was sought with Nga Maia, the Māori arm of the New Zealand College of Midwives. I sought separate approval from each of the DHB's research committees and wrote to the Directors of Midwifery from where I intended to recruit participants. Finally, I spoke to the charge midwives of the departments I intended to recruit from once approval had been obtained.

\section{Partnership}

In keeping with the methodology and the principles of Te Tiriti o Waitangi, the participants were encouraged to be an equal partner in my research process. Information was provided to the participants through the Participant Information Sheet (Appendix B) in regard to how I would conduct the research, ensure anonymity, analyse data and disseminate the findings. Opportunities to discuss questions or concerns were offered during recruitment as well as at the start of each interview. Prior to commencement of the interviews we discussed the research aims, the recording and transcription of the interviews, as well as informed consent. The participants were offered the choice of venue either at home or another suitable place outside of work that would be quiet, as the interviews were going to be taped, and private due to the sensitive nature of the content. I visited five participants in their own home; two met me in an external private and quiet venue and one interview was conducted over the phone. Seven of 
the eight interviews were conducted within seven days. This was because I reside overseas and was not able to travel multiple times to New Zealand. The midwives who participated in my research were all available and, in the spirit of partnership, offered times over the space of seven days which made for focussed gathering of rich data. The transcribed interviews were returned by email for comments, clarification or withdrawal of comments, however no adjustments were requested by any of the participants.

\section{Participation}

As the main aim of my research was to explore and understand the experience of caring for women through late second and third trimester TOP from the midwife participant's view, I encouraged participation on their terms. Once the midwives had agreed to participate in my study they engaged whole heartedly. The interviews I held were in a spirit of coming together for a special time; the participants made it their time. We had tea/coffee and I took freshly baked goods to the interviews which we shared. For the interview I held over the phone, the participant had chosen a time where she was alone at home, comfortably resting on the sofa, with a cup of tea in hand. Each participant received a fuel or shopping voucher as koha/gift. I had prepared for the interviews using van Manen's (1997) guide for open-ended questions. At times information shared led to insight on both sides and to another question and more information. I valued the stories the midwives shared. However, until I received message from the participants I did not realise how much they had valued my time for listening and providing an opportunity to talk about their experiences and emotions. This truly reflected the principle of participation.

\section{Protection}

The midwife participants approached me via email to signal their interest in participating in my research study. I followed this up by sending each prospective participant a Participant Information Sheet (Appendix B). The midwife participants then signed a Consent Form (Appendix C) prior to the interviews being conducted. Each participant chose a pseudonym with no actual name used at any stage of the research process. I also explained that the professional 
transcriptionist had completed a separate Confidentiality Agreement (Appendix D). All participants were happy to sign the consent form and proceed with the interviews.

The participants were also made aware that, should emotional issues surface, during or after the interview, telephone or face-to-face counselling was available to them. I also provided the phone number for lifeline. The head of the AUT Health Counselling \& Wellbeing Department was approached by me for support for participants. In turn I was provided with the agreed wording for the Participant Information Sheet (Appendix B) in regard to the provision of counselling support should participants identify the need for such.

To ensure my own health and wellbeing, I completed a researcher safety protocol (Appendix E). Prior to, and following each interview, I messaged or called my first supervisor to check in and out.

These actions demonstrate the principle of protection in a sense of partnership the midwives were protected by me and vice versa I was protected by the participants. To ensure my own emotional wellbeing I debriefed with my supervisor and saw my counsellor prior to and following the interviews.

\section{Recruitment}

To fully explore the phenomenon of the experience of midwives caring for women through late second and third trimester TOP, it was important to obtain rich, meaningful data. Midwives who were currently or had been working with women through TOP within the last 12 months were recruited to my study.

The number of midwives providing TOP care in hospitals licensed to perform this procedure is currently unknown. From my experience I was aware that this number might be relatively small. AUTEC approved my choice of poster advertisement (Appendix F). These posters were placed within the tearooms of maternity units of tertiary hospitals in two DHBs in the North Island of New Zealand. 
Initially recruitment was slow as the work load in both hospitals was enormous. However, eventually snowball sampling occurred as midwives read the poster and heard from their colleagues that they were going to participate in my study. They discussed amongst themselves that this was an important chance to tell their story.

\section{Study Participants}

Participants were all midwives working in maternity units of hospitals who, at the time of recruitment and interviewing, had been working with women through TOP for a minimum of one year. All midwives had at least three years clinical experience with the longest serving midwife working with women for over 40 years. The age range of the midwifery participants was between 25 to 60 years. Several midwives had been case-loading midwives previously or at some stage during their career.

\section{Reflection and Data Analysis}

The analysis of the data in hermeneutic phenomenological research is the process of finding meaning structures within the text that holds the experience of the participants (van Manen, 1997). Themes are elements within the text that occur repeatedly. Themes give order to reading and writing, sense to the meaning, yet are not a summarising description of the experience. van Manen (1997) has provided three approaches to discover thematic aspects within the rich data provided by the transcription of the taped interviews:

1. the "wholistic reading approach" - considering the text in its entirety

2. the "selective or highlighting approach" - reading the text several times and highlighting the most relevant or essential parts that describe the experience

3. the "detailed or line-by-line approach" - considering single sentences or sentence bundles which might reveal something that contributes to the experience

(van Manen, 1997, p. 94) 
Reading the transcripts I was initially overwhelmed by the amount of rich data I had been provided by the participants. Finding a start seemed impossible until I remembered to 'trust the process' and started highlighting the parts that seemed the most relevant, going over single sentences, before considering the whole. Together with my supervisors we discussed the single sentences and highlighted parts. I then isolated the parts that revealed themselves repeatedly throughout the transcripts while maintaining a strong orientation to the research question.

van Manen (1997) called hermeneutic phenomenological research in essence a 'method' or a "writing activity" (p. 124) and his description of the "spatiality" (van Manen, 2014, p. 358) of phenomenological writing resonates with me. Writing is being in a certain space, in a certain mood. This is not just the room or locality where writing is being done, not just the sitting and typing away. It is the experience of stepping from the lifeworld into the world of "textual reality" (van Manen, 2014, p. 359), of diving in, being engrossed in the activity where we forget ourselves, where writing and reflection happens and insights come. van Manen (1997, 2014) also described the difficulties encountered within this space, where 'writers block' becomes part of this reality, where we can be lost for words or the language we have available might not be enough to express what we really want to say. I reflect back to how these hours of writing were spent staring into space, sometimes impatient and even frustrated. Then, insight would come and writing would happen with myself becoming the observer in this different reality. Reading the text back to myself I realised it had struck a chord when I removed myself from the space content, maybe even feeling tears in my eyes; or the reading left me unsatisfied, taking me back to the original data to reflect if I had missed or misunderstood something. As the first reader of my text it evoked feelings in me which led to more insights, drawing me back into the space of reflection and writing.

Considering the hermeneutic circle, as well as van Manen's spatial and temporal concept of writing, the process of "theme analysis" (van Manen, 2014, p. 319) was indeed circular, an analytic process of writing, reflecting and re-writing. Leaping into the data with faith I considered sentences, parts and the whole, regularly discussing and checking with my supervisors until we reached consensus. I gained 
further insight through presenting data extracts at conferences, assessing the reaction of my audience and then going back to undertake further data analysis. The themes emerged over this time. Miles, Chapman and Francis (2015) echoed the challenges and have termed this process "peeling the onion" (p. 286). Eventually, the lived experience of midwives caring for women facing TOP in the late second and third trimester was revealed and the research question could be satisfactorily answered.

\section{van Manen's Lifeworld Existentials - Guidance for Reflective Analysis}

"Ultimately the project of phenomenological reflection and explication is to effect a more direct contact with the experience as lived" (van Manen, 1997, p. 78). The description and interpretation of lived experience is as complex as the lifeworld itself. To uncover the structures or meanings of lived experiences van Manen has identified four fundamental existential life themes which pass through the life worlds of all people, regardless of race, culture, gender, ethnicity, social situation, or age. These fundamental themes provide a lens through which life stories can be analysed and reflected on (Rich, Graham, Taket, \& Shelley, 2013). The four lifeworld existentials are: lived space (spatiality), lived time (temporality), lived body (corporeality) and lived human relation (relationality or communality) (van Manen 1997, p. 101).

Lived space is the subjective, felt experience of the space in which we are physically situated. Spatiality includes how certain spaces make us feel a certain way and, conversely, how we experience space when we feel a certain way.

Lived body relates to the physical body and our presence in the world. With our body we express ourselves, interact, communicate, feel, share, conceal, or reveal parts of ourselves, consciously or unconsciously, when meeting other people and experiencing the world.

Lived time is the experience of subjective time, the temporal experience of the world we live in as opposed to objective, measurable time on clocks and calendars. 
Lived human relation refers to relations we create and uphold with others in our world. It expresses how we experience relationships and communications with others in spaces we create or meet in together.

While these four existentials differ from each other it is impossible to keep them separate as they interact with each other and intertwine in the experience of the lifeworld (Rich et al., 2013; van Manen, 1997). In the following data chapters I will demonstrate this interlinking of the lifeworld existentials within the midwives' experience. van Manen's philosophical notion and conceptualising of hermeneutic phenomenology research have been a significant part of my research study from the beginning to the end. Human science research starts and ends with lived experience (van Manen, 1997).

\section{Trustworthiness}

While the phenomenological writing in my thesis is my own interpretation, drawn from the transcripts of my midwife participants' stories, I acknowledge that my interpretation might not be the only or the 'right' interpretation. The possibility of a different, even richer, interpretation exists (van Manen, 1997).

Establishing rigour, research validity, or trustworthiness in qualitative research has been a contentious subject over the years. Establishing procedures or frameworks to assess the trustworthiness of hermeneutic phenomenological study might not do it justice. Although van Manen spoke of validity of phenomenological research, others use the terms trustworthiness (Smythe et al., 2008) or rigour (Koch, 1994). Authors such as Lincoln and Guba have proposed frameworks and models to assess the trustworthiness of qualitative research (Thomas \& Magilvy, 2011). However, van Manen (2014) wrote:

"the validity of a phenomenological study has to be sought in the appraisal of the originality of insights and the soundness of interpretive processes demonstrated in the study. No predetermined procedure such as 'member checking' or 'triangulation of multiple methods' can fulfil such demand for validating a phenomenological study". (p. 348) 
Furthermore, Sandelowski (1993) suggested these methods of checking often do not recognise the techniques, creativity and artistic writing of phenomenology.

Smythe, Ironside, Sims, Swenson and Spence (2008) have discussed the trustworthiness of hermeneutic phenomenological research in the sense of resonance. If the research resonates with others it can be deemed 'trustworthy' (Smythe et al., 2008b). Testing out the findings from analysis of the data the researcher engages in discussion with those who have an interest or are even living the phenomenon. Firstly I 'tested' my findings with my supervisors. Secondly, through presenting at three different national and international conferences I tried my findings out on a larger audience. The 'graced moments' Smythe et al. (2008b) described are what I also encountered with each presentation - silence filling the room, quiet tears, and delegates coming up to me to say "thank you, this is exactly how I feel but I never been able to say this". This was confirmation of the trustworthiness of my findings.

\section{Reliability}

Addressing reliability van Manen (2014) explained that a phenomenological study can ask the same question; however, it is unlikely that findings can be repeated to evaluate an outcome. Yet, each time the same question is asked new insights into a phenomenon can be gained.

\section{Reflexivity}

van Manen (1997) stated that writing is a "reflexive activity" (p. 132). I have demonstrated reflexivity through the declaration and examination of my preunderstandings. The impetus for the study, the design and methodology of my research study, along with the data analysis, findings and the discussion have been detailed within this thesis. Reflection often happened for me through visual stimulation with large sheets of paper on the wall containing key sentences or words in the center. Other times it was the staring into space, as previously described, that brought insight and stimulated writing. As reflection progressed I wrote thoughts and insights around the key sentences. Notes were taken into 
discussions with my supervisors and there was a trail of progressing data analysis and the writing and re-writing process.

Reflecting on the process and progression of my thesis I have dedicated this poem to Sam:

we cannot talk yet we communicate

in solitude and quiet companionship we walk

every day

I watch you

explore the world around you afresh

tirelessly

reflecting on the old

finding insight I know nothing of

yet I understand

look again and you find something new

previously hidden

every day

\section{Conclusion}

Methodology, design and methods are the essential components of the research process. In this chapter I have described the design of the study, which methodology was used, reasoned the use of this methodology and explained the practical aspects of the research process which included a description of the data analysis process. van Manen's approach to hermeneutic phenomenology, which is the underpinning philosophy of my study, has been discussed, along with his framework for research and the four lifeworld existentials - van Manen's tool for data analysis (van Manen, 1997). My pre-understandings were made explicit and considered. The research methods were detailed. This included recruitment, study participants, data collection, ethical considerations and a demonstration of how the principles of the Treaty of Waitangi were respected. 
The following three chapters will detail the findings and explain the themes that emerged from the rich data obtained in the candid interviews with my midwife participants. 


\section{Chapter Four: Findings}

The following chapter is dedicated to the interpretation of the data obtained during the interviews I conducted with the midwives. Phenomenological reflection using van Manen's lifeworld existentials: lived space, lived time, lived body, lived relationality was applied for this purpose. The midwife participants shared their stories with a depth that provided an abundance of rich and meaningful data. The participants' experience ranged from four to over 40 years working as midwives. Initially all midwives shared some of their life stories, what inspired them to become midwives as well as their motivations to care for women through TOP. Throughout each of the eight interviews there was an immense sense of respect and dedication to women and a passion for their work that left a real impression on me.

Four themes emerged from the data: 1) a different kind of midwife, with the subthemes signing on and tuning in; 2) staying true to oneself, with subthemes creating connections, protecting the baby, protecting the mother; 3) secret sisterhood, and 4) keeping going.

I will guide the reader through the chapter by following the midwives' chronological experience of caring for women through TOP. The themes reveal the start of their journey, their approach to the day that lies ahead and how it subsequently evolves, and how they attempt to make sense of their experience at the end of the day. The reader will be able to attain an understanding of the challenges the midwives face, the elements of support that help them through their day and how they manage to keep going.

\section{A Different Kind of Midwife}

The eight midwives who participated in this study talked about being different to their colleagues; providing care that not every midwife was happy to give, doing something that was not part of the normal, everyday role of being a midwife. This led to the theme "a different kind of midwife" emerging from the data. The 
following subthemes will explain the midwives' experience of what it is that leads them to feeling 'different'.

\section{Signing On}

The notion "signing on" emerged from the data as the midwives who participated in this study described how they were asked to sign a form at their interview or their very first day at work in their new role. The midwives' place of work are tertiary hospitals that, as part of their services, offer termination of pregnancy. Midwives applying for work are asked, either at the interview or at the beginning of their new role, if they have conscientious objection to providing care for women terminating their pregnancies. As discussed in chapter one the 'Conscientious Objection' clause (p. 25) is part of the Contraception, Sterilisation and Abortion Act 1977, one of the laws that regulate termination of pregnancy in New Zealand (The Ministry of Justice, 1977). It is aimed at settling moral conflicts for religious or non-religious health-care providers who object to providing termination of pregnancy.

Vivian recalls the beginning of her role:

When I started in my current role I was asked to sign a form to say that I was happy caring for women through TOPs. It narrows it down to a small pool of midwives that provide this kind of care in our hospital. Then the midwife in charge of our service approached me a few times to ask if I would look after a couple of women who were booked for TOP and once I had done it once or twice they saw that I was good at it and that I was doing ok. (Vivian)

Vivian's description of the start of her new role sets the scene for all of the midwives who participated in this study. A formality for the hospital, signing the form marked the start of a journey beyond the everydayness of the role of the midwife. Vivian was 'happy' to provide TOP care, she had no objection to caring for women through this procedure. As Vivian had 'signed on' she had become part of a small group of midwives who had expressed no objection to termination of pregnancy. She was now a midwife providing 'this kind of care'. Vivian's words describe midwifery care that is different, specialized, not part of the routine, not the everyday work of midwives. Yet, starting out in her new role she did not know 
what the experience would be like, what the care would entail. Reflecting on the first two terminations she cared for, Vivian realised she had a special skill, an ability to give care and cope emotionally.

The 'conscience clause' has been in place for many years, as described by Rose, a senior nurse and midwife:

It was my first year of nursing and there was a conscience clause asking if you wanted to be involved in terminations. A lot of the Catholic nurses wouldn't do it. I didn't want to make a decision until I knew what was involved but when they did the suction, vacuum, aspirations all you could see was froth so that didn't bother me. But I was working on the gynae ward and the stigma that was attached to those ladies bothered me. Having a termination, it was really frowned upon then. I looked after a woman, and she actually wrote me a letter two weeks later to say thank you. She said I was never judgmental and I just looked after her and supported her. It meant the world to me that she had sent this letter because I was only a junior nurse in my first year out. (Rose)

Rose's experience with termination started early on in her career as a young nurse in her first year of practice. Being presented with a conscience clause she was careful to consider her response. She wanted to find out first what termination of pregnancy entailed. Rose did not find the surgical side of the procedure difficult to deal with. However, what did not sit right with her as a young nurse in her first year, was the treatment women received from other staff. Rose did not agree with the stigma attributed to the women undergoing termination, to women being "frowned upon". That judgement was unacceptable for Rose. It initiated a response of wanting to shield women, who had to endure a termination, from further emotional trauma. Her experience led her on a journey of dedication to non-judgemental work with women who terminated their pregnancies. She was supported and strengthened in that work by the feedback she received from the first woman for whom she cared. This letter "meant the world" to Rose; it served as an encouragement for her to continue on this particular path. Rose's memory of feeling acknowledged and valued, and the difference she made for this woman, carried her through her years of service. 
Maria had been in her current role for about three years. Prior to this role, she practised as a self-employed LMC midwife for several years. She wanted a change hence applied for a position at the hospital. The last family she cared for as an LMC had lost their baby due to an illness that was incompatible with life.

Maria recalls the start of her new role:

When I applied to the District Health Board and I got the job I was given a form that says - Are you ok with providing care for women having terminations? At that time I had recently had a stillbirth with an LMC client, so I was coming fresh off that. When I thought about all the aspects of termination care I decided actually, my role as a midwife is to support women and families, they have already made one of the hardest decisions in their lives and that's their choice. My role is to support their choice and give them midwifery care. So that is where my decision came from to sign the form and say that I was ok with it but I might change my mind at a later stage because I haven't had much experience with this. (Maria)

At the job interview Maria was asked to sign a form to formally acknowledge that she had no conscientious objection to care for women through termination of pregnancy. Just prior, Maria had supported one of her community clients through the stillbirth of their baby. The experience had given Maria confidence that she could work with women through loss, not just through stillbirth but also through termination of pregnancy. However, Maria took time to think about what care through TOP meant to her. She did not quite know 'how to be' in this context. It was new, unfamiliar territory for her and she had to redefine her midwifery role and values. van Manen's 'lived relationality’ (van Manen, 1997) explains how we experience the meeting and engaging with people within the world, within the space we share with them. We form impressions of the other when we meet, or if we have done so beforehand, through meeting those impressions can either be confirmed or become invalid. Through developing a rapport, a relationship with the other person, we then can move past ourselves and engage on an interpersonal level. Maria was planning and preparing for this relationship she was going to have with the women and families she would be meeting in this new role. She thought through the care she had given to her last client; she tried to foresee how she might feel, how she might be when she would finally meet women and their families. Reasoning out her role in this anticipated relationship, she settled on supportive midwifery care, putting any other feelings she might have had aside. 
Being supportive was a familiar concept, something that was attainable in a situation in which Maria felt uncertain. She formulated the uncertainty into the proviso of 'I might change my mind later' to keep a feeling of control. Maria left the door open to withdraw if providing this care would not work for her.

Maria continues her dialogue:

She [my mother] was weirdly supportive. She went down this whole God pathway that wasn't really a consideration for me. I was raised quite religious but I'm not actively practising at the moment. So when I rung her and asked her how she would feel if I offered this service and explained it all to her she went down this weird pathway and said I don't think God would mind. It wasn't what I was ringing her about, I just wanted to make sure she wasn't going to disown me because I was doing this. Or that it was something that I could broach with her if need be. That's strangely how it went, and I thought alright, I'll sign the piece of paper. (Maria)

Maria put a lot of thought into her response, calling a friend and her mum. She sought reassurance, something to ground her, by calling her mum during her considerations regarding whether or not she should sign the document. Maria had grown up in a Christian household; however, as an adult she was not actively involved in the church, hence religious values were not a deciding factor for her. Yet, Maria knew that offering to care for women through TOP might be frowned upon by members of her family (and possibly the community) as traditionally TOP is a controversial subject in society and religion. Maria wanted to know she would not be "disowned" by her mum. She sought reassurance that her mum would not be upset or offended. What Maria did not expect was her mother arriving at the conclusion that "I don't think God would mind". Maria's mum expressed her support through a thought process that involved her faith. One might view this response as quite unusual for someone devoutly religious. However, it was important to Maria to have her mother's blessing along with reassurance that she could broach the topic further with her mother should the need arise. Maria had carefully thought through her response and she proceeded to sign the form.

Vivian, Rose, and Maria described an experience that clearly defines the beginning of a journey that travels beyond the normality of midwifery care. This signature, acting as a formality for the hospitals, is a demarcation line drawn into the 
midwives' professional pathway. It throws the midwives into a new role that identifies them to themselves, their colleagues and their superiors as different. They move forward and become a certain midwife, a different kind of midwife. It forces the evaluation of comfort zone, motivations, boundaries, professional and ethical values. Therefore it creates a headspace where midwives know that their job description has been extended, their willingness to provide TOP care can be called on at any given time, and that their day at work might entail significant challenges.

Catherine describes a time that was challenging:

I had this quite difficult case quite recently. She was a 13 year old girl, from out of town. who had been raped by her step-father while she was on holiday at her mum's place. It all came out when she was back at her grandmother's where she lived. There was quite a lot of preparation involved in bringing her in. The big thing around it was that it was a forensic case with a lot of unusual elements. The police had come up to the hospital but I didn't speak to them because I was on night duty that night... So I got all this information passed on and it felt like a biggie. I knew I was on night duty that night and I knew she was being induced so I knew that day that it was going to be me looking after her. I can't remember who I was working with but I knew I was going to be the one. (Catherine)

Catherine had been aware of this young woman coming in for a termination. This was an unusual case with a lot of planning involved and the process stretching over several days before the actual procedure could take place. The unfamiliarity of the forensic steps that needed to be taken care of was an element that caused Catherine some uncertainty as she had not been personally briefed by police. Anticipating the encounter of caring for a teenager who had been raped and was facing TOP was not going to be easy. Catherine was now also required to collect forensic evidence for a successful prosecution. Catherine felt like she was standing in front of a big mountain, a "biggie", and she dreaded going to work. She knew that she would be the designated midwife to care for the woman terminating her pregnancy that night as she had been passed on all the necessary information regarding the collection of evidence. Catherine carried that thought with her in her head all day. A silent, uninvited mental companion, a burden. Throughout the day preceding that particular night shift, she felt present in that space. She could feel 
she was going to be the one standing out in a small group of midwives, identified as 'the one' to care for this young woman undergoing termination. In this space and place, Catherine did not feel the same as her colleagues, she did not feel like a 'usual' midwife. Her role was a lot more than that, with added responsibilities, additional challenges, unusual tasks that made her different in her role to that of her contemporaries.

Catherine experienced a nearness to the space she thinks of as work-space. Her place of work was a distance away; however, she had an awareness of what she was going to do that night, it was occupying her mind, therefore work-space was close. Catherine was mentally already in that work-space, being 'the one' to manage the care for this young woman who had been raped by her step-father. van Manen (1997) explained lived space as felt space, not usually reflected on or verbalised. Every space has a quality that we experience because of who we are. There are various aspects to lived space, one of them the experience of distance. Distance is not just experienced in a numerical, an objective way. For Catherine the hospital was a 20-minute drive away. But because it was in her mind she was 'nearby', already there, the distance insignificant, she was thinking about it, dreading, knowing how she would feel that night walking into work as "the one", the midwife assigned to care for this young woman.

As described by the midwives who participated in this study, the signing on to care for women undergoing termination has immense significance for the midwives. They agree to take on extra duties, added responsibilities, and some have to redefine their professional identity. However, the midwives described no formal training as a student or targeted preparation for the extra duties of this role. Kate had a positive experience with a bereaved mother during her midwifery training. She was allowed to care for the woman and her baby after an unexpected stillbirth at home, guided and supported by an experienced midwife. Kate had a safe learning experience in the company of this midwife that gave her the confidence that she had the skills to care for another bereaved woman when the opportunity arose. She met this midwife again in her third year when she came to class to talk with the students about practical aspects of bereavement care.

Kate remembers vividly: 
The same midwife came, she apparently has a passion for working with bereaved families, and spoke to us in my third year of study about caring for a deceased baby. She talked about practical things, which was awesome. I remember her saying to me that it was lovely working with me and that I was just serene with that family. Nobody has ever described me as that! I loved every minute of that day and it was such a privilege. And if such an experienced midwife who does this on a regular basis thinks that I was serene with this family then maybe this is something I need to be aware of. (Kate)

Confronted with death, some might feel anxiety and apprehension. Yet Kate, who has a bubbly and outgoing personality, found an immense peace and calmness in working with the grieving woman and her deceased baby; she "loved every minute of it". van Manen (1997) wrote that when we meet each other we are able to transcend ourselves and in that experience of the other we are able to find our meaning, our purpose in life. On that day Kate found her meaning. In the meeting with this woman Kate transcended herself. She exceeded herself, went beyond a limit she thought she had and discovered something about her own self she never thought possible. Kate recognised that the midwife she worked with granted her a very special gift: the liberty to really work with the woman, experience the special relationship she had the chance to form, and to carry the responsibility for this woman. Through calling Kate 'serene' the midwife reinforced Kate's experience of that day, leading to the realisation that she had a special skill to care for bereaved women that maybe not every midwife has. This formative experience led Kate to seek out a role where she would be caring for women through TOP.

Jody describes her experience of starting work in the maternity ward:

I never got any formal preparation or orientation for this role. I did come in for one of my ladies who had a stillborn baby with a CMV [Cytomegalovirus] infection. She lost the baby at 31 weeks and I delivered it. I think that was a little bit of preparation maybe. And, just life, but that's all. Your preparation is you watch a few babies being born and then you go experience it by putting your first foot forward and going for it. (Jody)

Like all midwives in this study, Jody had not received any formal training before joining the maternity unit. Similar to midwife Maria, Jody had cared for a woman through a stillbirth during her time as an LMC. That gave her an inkling, a faint idea, of how it might be to care for women through a TOP. Jody was oriented to 
TOP care during her regular work hours by her more experienced colleagues. She picked up the necessary knowledge through observation, and after watching a few times, it was her turn. Jody described how she had to 'put a foot forward', leaving the safe space of being a quiet observer, being guided and supported by experienced peers. Without much further support she had to step in, step up and head on in.

van Manen (1997) explained lived time as subjective time, the time we feel rather than watch tick by on a clock. Time can speed up or slow down, depending on our mood. Time stretches ahead of us or lies behind us. Time shapes us and leaves its marks, its traces on us. It is our past, our present, and our future. Somewhat offhand Jody adds the life experience she brings to her new role; it is part of her temporal landscape. It is part of who she has become and how she is stepping into this job. It is the prospect of the unfamiliar role, the time spent learning, getting to know, understanding and finding stability that lies ahead of Jody. It is a time of needing to draw courage, a time of uncertainty, insecurity, and self-doubt. But, for Jody, it is also a time of self-discovery and evaluation of her abilities.

The midwives step into their new role with an awareness of being different, of a challenge beyond the everyday hustle and bustle of midwifery work on the ward. Below Jody describes taking over the care of a woman/couple who terminate their pregnancy:

Before I meet a couple I always wonder what their situation is. Have they had a baby before? What is their point of reference? Because some people come from overseas. Some people are from our country, some people have a different understanding and if they can't speak our language I freeze up inside. I'm scared for them and of them because sometimes I can't get through to them, I can't culturally get through to them. Some of these relationships that people are having are so culturally different I don't know how they work together let alone how I'm supposed to work with them, especially if they're both coming from two different cultural places. And they don't speak great English. That's my worst nightmare, when they're not connected and when they're not connected I don't know how I can reach them. I get quite anxious. (Jody) 
Jody prepares herself when she comes on shift before her first meeting with the couple for whom she will be caring. She reads through the client files, forming an impression of the persons she is about to care for, anticipating her experience. Language and cultural background are important factors for Jody in predicting how her day might turn out. Jody identifies as Māori and honouring cultural traditions regarding death is an inherent part of who she is. Jody knows how important this day is for the couple, how the experience and processes around the day of termination of pregnancy will shape their memory and grief journey. Jody is "scared" for the couple if they come from different cultural backgrounds. She worries that they will not be able to communicate their needs and thoughts with each other. If they are not able to connect, become a team and work through the decision making and the loss and grief together, it has an effect on Jody. She needs to feel that she is on the same wave-length with the family, she needs to be able to connect and work in a way that allows her to stay true to herself. Her experience starts long before meeting the woman and her family, before opening the door to the room they are in. It starts with a name on the board, with a glimpse at a cultural background that might or might not honour life and death the same way Jody does. Already apprehensive and anxious, anticipating her worst nightmare turning into reality, only the meeting with the couple will confirm or negate her initial impression. It will make or break her experience.

van Manen (1997) explained how the four life world existentials can be seen as single entities but are always intertwined. One does not exist without the other. Jody's description of what goes through her mind before she meets a couple reveals the complexity of her experience. Jody anticipates her day by looking at the couple's medical file and cultural background. An impression forms in her mind of the woman and her partner. Connecting with the couple is an important part of Jody's experience, hence this preparation phase is the first part of Jody's day at work. Jody's day stretches out in front of her. The connection she forms with the couple, how well or bad things go, will determine Jody's subjective feeling of her time at work. The shift will either go fast or drag on. While Jody is doing her preparation at the nurses/midwives' station she is already anticipating being in the room with the couple, feeling the space into which she is about to step. 
This is Vivian's description of how she feels before meeting a new family:

If I have been asked to look after a family, I do get a little anxious before I meet them. I wonder who and what kind of people they are going to be. Because we have to be adaptable and be the right person for that family at that time. The challenge for me is knowing how to approach that, whether it's a family that appreciates a bit of humour or whether it is an extremely religious family. I have to adapt my care appropriately. I suppose I have kind of a build-up to my first meeting with a family. (Vivian)

Vivian describes a similar anxiety to Jody, like a build-up she experiences mentally and physically, until she finally meets the couple. Vivian wants to understand where the woman comes from, what her background is so she can accommodate the woman's needs. She worries about being able to adjust herself to the woman's space and the environment into which she is about to go. For a moment she doubts if she is 'the right fit' for this family because it is important to Vivian to get the caring right for the woman and her family. Care in this sense goes beyond the medical necessities, the routine duties and jobs that need doing. Vivian wants to also care on an emotional level. She anticipates, mentally already in the space, well before she actually steps into the room.

\section{Tuning In}

The rooms in which the midwives provide TOP care are routinely located away from the noise and business of the ward. It is meant to provide a safe space for women where there is maximum privacy and minimal disturbance. Little comforts are sometimes added for the families with larger beds for the husbands or family members to stay and tea/coffee making facilities. It is a little world on its own.

Sarah describes her first time caring for a woman through termination of pregnancy as a new graduate midwife in her first year of practice:

They were traumatized, absolutely devastated. They did not want to see the baby or think of it as a baby, they were really in a space of this is a procedure and this is an awful thing. Of course, as typically happens in those situations, she got up to the bathroom and birthed. So the ability to discreetly hide the baby just wasn't there and I wasn't prepared for it. I didn't have all of the stuff 
right at my hands to make it as discreet as possible and that meant that I wasn't able to fulfil her initial wish of not seeing anything.

I had this horrific guilt about the fact that I couldn't meet her wishes because of the circumstance that she got up and the baby came out on the toilet where there is nowhere to hide. I recall that I had grabbed a towel and covered the baby over. But then there was nowhere to go. And I had that medical responsibility because this baby didn't deliver in one piece as we kind of want them to. The waters had broken and the baby delivered and the placenta was still following so I couldn't just walk away. I didn't have clamps and things close to hand because we were in the bathroom, you don't have that stuff to hand in that context most of the time. So I looked at her and said I can keep baby covered but we have to move or we have to wait for the placenta, we have to decide how we want to do this'. And she went, 'I'll hold it'. I just wasn't able to put that baby on the floor. If she had told me to I would have but I just couldn't do it. (Sarah)

This was a very different space for Sarah to be in; she was confronted with a traumatized couple. There was not going to be the reward of a live, healthy baby that would immediately be scooped up by her mother. Instead, there was a grieving, devastated couple anticipating the birth of a dead baby they did not want to see. However, Sarah had committed herself to being in this space with the couple, and fulfilling their wish and creating a perfect birth moment for them was paramount for her. Yet in one swift moment of unpreparedness all that Sarah was striving for disappeared. The woman had gotten up to the toilet and gave birth. In the confines of the toilet Sarah had nothing to cover the baby over with, there was 'nowhere to hide'. The baby was out in the open. The crammed hospital toilet became the performance space for the intimate moment of birth. With the stage lying in darkness the suddenness of the event switched on a spotlight that had thrust Sarah, the mother, and the baby into bright light, the edges of the beam falling away. Acutely, Sarah felt the physical constraints of the small space as well as the emotional pressure that was now building up inside her as she realised she would not be able to fulfil the couple's wish. She wanted to create this perfect moment for the couple but failed. However, she had no choice, she had to keep going, she was the one responsible. And in the midst of this heightened awareness of the small physical space she was in, the keen feeling of failure, the guilt, and her professional obligations, was now a baby that had lived and died and that needed 
to be respected and taken care of. To not compromise herself further Sarah took the only way possible. She made eye contact and connected with the woman to find direction: "We need to decide how we do this." Sarah's emotional pressure she had placed on herself found release when the woman looked down and embraced her baby. In that moment Sarah was able to preserve a part of her identity by finding this baby the safe and protected space it was meant to be in, the mother's arms.

The experience of space is significant in Sarah's story. As van Manen (1997) explained: “... the space in which we find ourselves affects the way we feel... In general, we may say that we become the space we are in" (p. 102). Being in a room that is saturated with grief and devastation is a space in which most people would not feel particularly comfortable. The experience of being in a small hospital ensuite might make one feel anxious. Alternatively, it might present a place of privacy, a place of comfort to refresh oneself, a place of discomfort or even isolation if left on one's own in need of support. For Sarah that day the ensuite became her place of work and much more than that. A small but significant room filled with grief, trauma, pain, the suddenness of birth, the messiness that comes with birth, not having any of the usual equipment to hand, the devastation of not being able to comply with the parents' wishes, the intimacy of the moment, a midwife connecting with a woman by looking her in the eye, and finally the relief from pain, and the relief of a midwife's anguish over a mother simply embracing her baby.

Maria continues the theme of tuning in with the woman:

In a way I feel like I have to bring nothing to this job. Absolutely nothing. It is not my place to bring anything into that room. It is their space and if they are asking me for certain pieces of information or they need me to bring something, then I will. If they need me to bring in some strength to help her push, that's fine. I'll bring what they need me to bring. But when I first walk into the room there is nothing. No bias, no judgement, no anything, none of my views, it's all to do with them and their experience. I try to walk into those rooms just a blank slate. And I let them dictate what they need from me. And that gets easier the longer you work with a family. The woman is the centre of my care and focus. It is her space. Whatever she needs to get through this, I provide. (Maria) 
Maria says she brings 'nothing' into the room. The woman is the sole focus of her attention, her experience at the core of Maria's day at work. Yet, Maria has to step into this space to provide care. Walking across the threshold, at the door Maria leaves her present, her thoughts, biases, and distractions behind. She steps from her space into the woman's space. However, by bringing 'nothing' with her, Maria brings something visible and non-visible: she brings herself. She brings her physical presence as a midwife that projects confidence, approachability and reassurance. She brings an inner calmness and peace, her strength, her openness to listen and respond in whichever way asked for. Through her physical presence she builds the relationship with the woman that allows her to transcend herself and respond on a spiritual, mental, and emotional level to the woman's needs. By that she transfers "strength" to the woman; she is 'just' there or she draws on knowledge to answer questions sensitively. Maria does what it takes to 'get the woman through'.

Sarah reflects on being with women in their space:

It's about being respectful of that baby in death and that family in birth. Because they're happening at the same time, in the same space. That space of these moments that you only get once. As someone who had a really quite traumatic birth, I know the impact of that on my memory of the beginning of my child's life. If that was the end of my child's life as well, everything else around that has to be good. Because if it's not, then that's it, that's all you've got. So for me it's about trying to make it as much of a birth space as possible, and that's what allows me to move on from it. Everything that we do as midwives, we're always in the middle of someone's joy or someone's pain or someone's heartache or someone's terror or fear, like we're always in the middle of something - that's a big emotion. And so for me in that sense it's no different from any other time when you're in one of those situations where it's fear, it's pain or it's joy, and I've seen that there can be joy in birth even at termination, there can be love and there can be those things, in those moments, in that space. The space that has to be held is the space of a birth and the space of a death. (Sarah)

The traumatic birth of her first child has shaped Sarah's memory. She carries herself with the knowledge that one single moment can leave its footprints on a woman's life, especially when it is something as significant as termination of pregnancy where the time of birth and the time of death amalgamate into one. For 
Sarah, this moment has to be perfect, faultless, complete. Thus Sarah is set on creating an encounter that has the mood of a good birth, where there is joy and love. Yet, there is also respect and dignity for the death of a loved and longed for baby, where there is loss, sadness, raw grief and pain. Sarah 'holds' that space, she knows she is the one who can honour this experience of the woman. By holding and nurturing the space, seeing the woman and feeling her emotions with her, Sarah satisfies her inner self and becomes the space she is in (van Manen, 1997).

Kate describes her feelings during termination of pregnancy:

Looking after a woman who goes through termination of pregnancy - it is different. Like moving into another realm. It is surreal, almost like being in another world. It is a sacred time. Any birth is sacred, but when there is birth and death in the same space, it is so intense, it is almost other-worldly. (Kate)

For Kate, caring for a woman through TOP is beyond the everydayness of her midwifery work. What she describes as 'different' is an experience more extraordinary than any experience she has at a live birth. Being with the woman in the space of termination is a sacred experience for Kate. Similar to Sarah's experience, she recognises the amalgamation of birth and death as an outstanding event. Yet, unlike Sarah, Kate is feeling the space of termination as a transcendence into 'another realm', 'another world'. The sacredness Kate feels reverberates a feeling of blessedness, of privilege to be in the emotional space with the woman, a sense of purpose to serve and celebrate the creation of life. Kate's experience of the emotional, the interpersonal space she shares with the woman is deeply spiritual. Spirituality is often vaguely defined (Cicirelli, 2011); however, Crowther and Hall (2015) have shown that midwives view being with women during birth as a "key spiritual event' for them. The spirituality around birth and death is the feelings experienced in those moments. A baby passing through from the invisible world inside the mother's womb into the next world, briefly here, then gone forever. Kate is the facilitator of the baby's passing through. 


\section{Conclusion}

The data in this chapter shows that midwives who provide TOP care identify as a 'different kind' of midwife. By signing the conscience clause at the start of their role, a workplace formality, the midwives sign on to a job that comes with additional, beyond the norm duties for which they were not formally prepared. The midwives have described how they utilise previous work and even life experiences to help them find their feet as they receive essential on-the-job orientation before being 'thrown in' to the situation where they just have to step in and provide the care. This signature also embodies a demarcation line for the midwives where their ethical and professional values need to be redefined and their identity changes as they are now standing out from their colleagues, marked as 'the one', the midwife who will care for women through termination of pregnancy. This knowledge of being 'the one' can occupy the midwives sometimes well before they start their duties if they are aware that they will be providing TOP care to women in extraordinary circumstances or have to take care of unfamiliar elements in an already unusual situation. This is burdensome for some midwives.

Furthermore the data showed that the midwives feel apprehension and anxiety before they meet a woman and her family for the first time. They try to anticipate their relationship with the woman and her family as well as gauge their ability to communicate and provide care that is appropriate for the family's background and situation. This anxiety is driven by the midwives' knowledge that their care can impact on the woman's experience but also that the experience can have an impact on themselves. This mental engagement with the woman and her situation is part of the 'tuning in' with the women. The midwives share and hold the woman's space where they respond to the woman's needs on different levels while protecting their own ethical values and inner selves. 


\section{Chapter Five: Staying True to Oneself}

Following the chronological sequence of the midwives' journey, this chapter will show how the midwives work with the women, families, and babies through TOP. The theme 'staying true to oneself' emerged as the midwives who participated in this study explained how they took care of the complex needs of the women and their families while guarding their own needs concerning ethical and professional values. Two sub-themes emerged from the data, 'connecting' and 'walking a tight rope'. The subtheme 'connecting' came to light as the midwives spoke about the connection with the woman and her family, which holds special significance in TOP midwifery care. 'Walking a tight rope' describes the balancing act midwives experience as they are in the middle of caring for the women, babies, and their families.

\section{Connecting}

The notion 'connecting' emerged as a sub-theme from the data. The midwives stay true to themselves by creating meaningful connections with the women and their families. Midwives have a skill for connecting and nurturing the relationships they establish. Yet, the connection with women who go through termination of pregnancy becomes even more important in the face of the grief they feel.

Sarah describes how she approaches making the connection with the woman:

If you deal with a woman who is grieving, making that connection is just the same as with any other woman. We just do it, it is our job, it's what we have chosen as our pathway. It is who we are. You're always walking into a room, finding out what the connection can be in this room.

Providing TOP care to me is still just midwifery care. But it is also knowing what to do with your hands when you don't need to listen in every 15 minutes. The things that normally happen during a birth, they don't need to happen, the things we normally write that now don't matter. It feels weird but I replace that with caring, with connection, with those other things that are unique midwifery skills. The woman who loves to be massaged and touched and the other woman who will punch you in the face if you touch them - they exist within the TOP room. They're just women, who have the same senses of preference for quiet or chat, for laughter, silence, or music. All of those things 
are part of their birthing room as much as in any other situation. They're all as individual and different in this situation as they are in any other situation. And they are faced with the same challenges like how are they going to pay for their parking. And that's how you connect, the same as you do with anybody else. And then you meet them in their grief and guilt. (Sarah)

Sarah walks into the room trying to uncover common ground. She knows that the woman is grieving and experiencing guilt, however this is not something she will directly address as yet. She is looking for an 'in' that will break down barriers, melt the ice, and allow a connection to form that will lay a foundation of trust for the relationship with the woman and her family. Sarah feels that making connections with the women she cares for comes naturally, it is 'who she is'. Establishing successful connections requires knowing oneself, confidence, genuine interest, gentle persistence, and paying attention to seemingly small details. It is an active 'doing', a skill, that is honed as midwives grow in their professional practice. After years of midwifery, Sarah has developed this skill that has become an integral part of her professional identity. van Manen (1997) explained 'lived relationality' as the connection we establish and sustain with each other in a commonly shared space. We enter that interpersonal space firstly in a physical manner, presenting ourselves in certain ways, engaging, forming an idea of who the other person is before we can move past and connect on deeper levels. Sarah looks for everyday things to relate over, like parking fees or music preferences, likes and dislikes. Once she feels the connection is established she is able to address the woman's grief and guilt. Because certain routine midwifery tasks become obsolete in TOP care, like listening to the fetal heartbeat, Sarah has nothing with which to keep herself busy, there is no 'doing' to hide behind. Instead she meets the woman in the present moment, in the now, 'being with woman', the essence of midwifery, at the centre of her care.

Jody discusses how connecting with the woman is important for her experience:

It can be a good day at work but it can be very sad for the parents and their fear of how bad it will be makes it extra challenging for us as health professionals because you have to walk that journey with them. We have to get them to a place where they are ok. I have a good day when I can still have a laugh with people. When I can connect with them. I tell them while this is a 
really sad day for you, it can still be good, it can still be positive. If I can connect with them and they have an experience they think is okay, they don't think this is the worst day of their life, and they feel safe and trust me, that makes all the difference for me. When they can tell me what they need I know we have a connection. When we can communicate well, and get to a level of understanding where I'm not just doing what I think is the right thing to do but they communicate what is super important to them that I might not necessarily understand. Then I've had a good day. (Jody)

Connecting with women and their families is what satisfies Jody in her work. She fosters that connection to give women an experience 'they think is ok', an experience that does not affect women as the 'worst day of their life'. Yet, knowing that she has established a relationship and connected with the woman and her family has a positive effect on Jody's experience as well. When she can feel the connection with the woman she becomes part of the family's journey, and that means she has a good day at work. Jody finds that connection within everyday interactions with the people for whom she cares. Laughter and light banter are part of what makes Jody feel she has created a bond with the families. When the woman and her family communicate their needs and wishes to Jody, then she knows she has successfully built a trusting relationship. She can go beyond herself, beyond her values and beliefs, beyond the general care of TOP she routinely delivers and respond to what is important to the family.

Kate describes how connecting with families sustains her:

We had this Russian Orthodox family, they had been involved with MFM and the baby had died in utero ... When the baby was born they bathed him straight away in holy water, then wrapped him in a white blanket, put a cross over him and anointed him with myrrh. It was so divine. Any life and birth and death is so sacred but it is so wonderful to see how people grieve in different ways and how they honour a life. The relationship I formed with this family was so beautiful. They felt I was acknowledging how they were grieving and respecting their processes around grief. They tucked all the icons of their Saints into baby's bed and even sent me an icon, the patron saint of healthcare. (Kate)

Kate felt a sense of bonding between herself and the family she cared for on that day as she described their relationship as 'beautiful'. Kate found her purpose in the 
facilitation of a space where the family was able to care for and honour their baby with religious traditions and practices. She felt the spirituality of the moment as she witnessed traditions of celebration and grieving, giving a sense of reciprocity in this relational space. Kate speaks of a sacred experience that sustained, almost nourished her, through her witnessing of the tender care with which the baby was provided. When she received the icon from the family as a thank you it meant a lot to her, rounding off her experience.

Early on during the interview Vivian had recalled the story of how she had faced TOP herself and how the experience had changed her practice. Vivian speaks about her relationship with a grieving couple during TOP:

As midwives we are used to creating close relationships with women and their families in a very short amount of time. I can't remember why this particular family was having a TOP. They had already had two children, both girls, 5 and 7 , so they were quite aware that they were having a new baby join the family but then the couple got the news that there was a problem. The husband and wife were absolutely devastated. They were in tears, holding each other throughout the whole labour. The thing they were worried about wasn't the decision they had made. It was more than the loss of the baby. They were worried about their girls and how they would take it and how it might affect them. I just didn't know how to fix that for them. So I told them that the little boy I lost is something that I have always been really open about with my kids. He is part of the conversations I have with them, he is not a taboo subject. It made them realise that it is okay and that the best approach would be honesty. It really sat in my mind because it was probably the most intense emotion I have had from a family. I was actually quite upset. I didn't cry at the time, but I cried a little with them when the baby was born because she also experienced this immense relief like me, visibly breathing a sigh of relief once it was over. I just felt utterly sad and my heart was breaking that they had to tell their beautiful little girls. I think it is really important that the parents know that it is not just a job, that we are not just going in, ticking boxes, doing observations and writing notes. I am part of their experience. I go through it with them and after caring for a family I will carry a little bit of that forever with me. (Vivian)

Vivian, like Sarah and Jody, has developed this skill of establishing close relationships in a short amount of time. Vivian had connected with the couple and was now part of their experience and vice versa; the couple's experience had 
become her experience. This was not just another day at the office, not just another day being a midwife. Through this connection, Vivian not only witnessed the anguish they were feeling over having to tell their girls that the new baby was not going to come home; Vivian felt that anguish with them, especially as her midwifery knowledge and mental manual of trouble shooting did not offer a solution. Going through this alongside the couple, she did not know 'how to fix it' for them. She felt helpless. Vivian was touched on such a personal level that she revealed parts of her own story as a means to help the couple. The emotional intensity of the situation broke down her professional boundaries. Vivian will carry parts of the experience of that day with her forever.

van Manen (1997) wrote that the lifeworld is a finely woven net of all four of the lifeworld existentials lived body, lived, space, lived time and lived other/lived relationality; hence they can be individually discerned yet not separated into single units. Vivian's account of her relationship with the couple she cared for is an example of how the lifeworld existentials are intricately connected. Lived body is concerned with the phenomenological notion we are always bodily present in world. It is through our bodies that we meet and present ourselves to others, however we might not always show our full self, or we might reflect more of ourselves than we intend. Lived body explains Vivian's experience of the relief the mother felt when her baby was born. Vivian had experienced this relief herself during her termination. She saw herself in the woman's relief; she felt it with her there and then, breathing a sigh of relief, she cried with her over the loss of the baby. The connection Vivian had made with the couple has the sense of lived relationality or lived other. Within the connection Vivian found purpose, meaning. However, it led her to drop her professional boundaries, to remember her experience of TOP, to feel with the woman and reveal parts of herself. Yet Vivian's experience also has the sense of lived time. TOP is a life event that Vivian recalls during conversations with her other children as they talk and inquire about their sibling that did not join their family physically, yet is there nonetheless in spirit, in conversations, and storytelling. The day of her termination is close in her mind as she cares for the woman, talking, sharing moments. Vivian's experience with the woman on this day has given them history together: "I will carry a little bit of that forever with me". 


\section{Walking a Tight Rope}

Following on from connecting with the women the subtheme 'walking a tight rope' arose from the data as the midwives described how they balance the women's and families' wishes or requests with their own needs and beliefs. A walk along a tight rope ensues.

Ruby describes her viewpoint for working with the women who come through her service:

My motivation is to provide a service that is free of judgement. I often think that when our families come in to the service you can almost sense they come with an expectation that we're going to judge. And they come and I say to them, we offer you all the same memory making opportunities we offer any bereaved family. So they get castings, they get photography, they get huggable hearts, they get all of that and I say they are bereaved. It's a choice they've made out of love, it's not an unwanted pregnancy. It's a pregnancy that was conceived and wanted and this is the choice they've been forced to make and none of the choices presented to them would have been easy, and I genuinely tell them that. I've never had to face that choice, so I can only imagine. And unless I go home and live that woman's life and walk in her shoes I don't have the right to tell her which choices she should make. (Ruby)

van Manen (1998) described different ways in which lived body can be experienced in illness and health. In 'Modalities of body experience in illness and health' van Manen wrote "one person may detect in the body of the other person one's state of well-being from the manner in which he or she is in the world" (p. 8). Ruby's story shows her experience of the woman's body and her bodily reaction to what she sees and feels. In the manner of how the woman presents, Ruby senses her anxiety, she sees her apprehension, the fear of being judged, of having to justify as to why she has chosen to proceed with a termination of pregnancy. Ruby responds to the woman's state through her professional values. She presents herself as the midwife she is. Her motivation to provide non-judgmental care is demonstrated by her choosing her words to the woman carefully, using the term bereaved to value the woman's experience of loss, offering memory making as to any other woman experiencing stillbirth. While Ruby has no personal experience of this situation, she imagines the choice the woman has been forced to make; she imagines 'walking in her shoes' and this enables Ruby to support each woman. It is 
important to her that the woman can feel that she is safe, protected and cared for with empathy and compassion.

Catherine speaks of a particular challenging day at work:

I got a phone call from work asking if I would look after a lady who had been through a really traumatic event and was 23 weeks along already. I appreciated that it was her decision and I said yep, I would look after her. This lady was extremely reserved and didn't have any family members with her. It was all very functional. It was especially hard because she didn't want anything to do with the baby. My heart just broke. I delivered that little boy and I sat on the sofa in the room and I'm not particularly religious, but I actually christened him after my dad. I did it in my own mind. I just sat with him and he died in my arms after three quarters of an hour. It was awful. I felt really sick. I did the footprints and photos but they are in the file. I don't think she will ever really want them. She just walked out of the back door after the delivery. It left a real sadness. I walked in at home and stood in the shower and howled! This is going to stay with me forever. (Catherine)

Catherine had agreed to look after a woman who had had a traumatic experience. It sat right with her to provide midwifery care in this context as she respected the woman's decision. However, Catherine had found it challenging to connect with the woman. Unable to establish the relationship that is so important, Catherine had a difficult time at work. She felt a sense of functionality, of ticking off tasks rather than giving midwifery care. Catherine struggled even more when the baby was born alive and the mother declined to hold him. Notwithstanding the difficulties and strain Catherine had felt so far, she had become so involved that she was unable to leave the baby to die on his own. She held on to him, gave him warmth, comfort, and dignity until he died, sitting on the sofa in the room. She christened him, quietly. It broke her heart and she grieved. van Manen's (1997) lived time explains how past, present, and future are the temporal dimensions of our world. The act of grieving is comprised of different aspects of time. The past provides us with memories, thoughts and feelings that we are not always aware of, yet they show themselves to us in different situations. Catherine's grief transcended the immediate moment. A loss of the past, not forgotten but stowed away at the time, Catherine's grief flooded back into her mind and was brought to light while holding 
the baby as it died. Accumulated over time, this grief became her companion in her solitude, fresh, painful, adding to her memory.

Ruby describes respecting woman's wishes when they are different to what she knows:

Recently this couple came through. We did this whole spiel of presenting choices for memory making like huggable hearts, castings, photography and the lot and she didn't want any of that. I had the karyotype in our clinical notes folder which made it harder for me because I always encourage them to name the baby and then I use the baby's name. But she didn't want to name baby, didn't want to see baby, didn't want to know the sex, didn't want anything to do with it. She even said she didn't want me to call it a baby, it was the pregnancy. And I just couldn't because it is really hard when you have called something blue your whole life and then you see it and you have to call it red, it is very hard to swap just like that and call it something else. She very much wanted this baby to come out of her vagina, out of the room, out of the door, out of her sight. It was truly very difficult. But we went along with her wishes and when she had the baby we dutifully whisked it out of the room. And we dressed it separately and provided it with dignity. This is really hard and challenging for us because we so want to respect this baby and be tender and loving and call it by its name. (Ruby)

Ruby had offered this woman all she had, all she knew would help with memory making and grieving. She is proud of what she has to offer as she feels it is important for the woman's journey. However, the woman chose not to accept her offer. Acknowledging the baby, addressing it and giving it reality, using its name is part of the service Ruby provides. It is her routine that gives her the feeling of satisfaction, of a-job-well-done at the end of the day. While she knows it is a coping strategy for the woman not wanting to engage with her baby, the denial of care is in dissonance with Ruby's philosophy and therefore presented a real struggle for her. She wants to nurture the mother-baby dyad, even in TOP. Yet, caring for this woman she could not be herself, be comfortable and relaxed in her work. She had to stay focused, alert and professional at all times to respect the woman's wishes while concealing the struggle inside her. 
Jody tells how she protects the mother and her baby:

I find it really hard to deal with the husbands who want to shield their wives because they believe that you don't show her the baby, it's not a baby, it's not a life, she's got to get over this and get over it fast. I find that really hard to deal with, men telling women how to behave after they've given birth to a baby that won't be viable. Because culturally, that's not our way and sometimes I can see it in the mother's eyes that she wants to look at her baby and she wants to hold it and I'm being told to take it out of the room like it's something dirty and unclean and I don't like these men. So I'll fight, I'll fight for her in that regard. I'll just work on them! And I'll get that woman some time with that baby because he might be doing it from a place of protection but it's not helping her.

I'll do that by saying to her in the shower 'do you really not want to see baby? Would you like to just have a little cuddle or a little peek?' and then I'll beg them, I'll beg them to give her that chance. And he doesn't have to be in the room but just please give me 5 minutes just to let her have a look. Just let her have a hold. I do it for the baby and for the mother. (Jody)

Jody finds it "hard to deal with" when women are being protected by their partners in such ways that Jody knows are not beneficial for the woman's grief journey and recovery. Jody wants to see this mother embrace her baby. Seeing this through is who she is; it is her work, her job, her responsibility to ensure the woman's needs are being met. When she can see the longing and love in the mother's eyes to be able to hold her baby, despite a father's objection, Jody feels a sense of protectiveness towards mother and baby. Jody will do whatever she can to make this happen. She becomes an advocate and a warrior on the woman's behalf. She 'fights' for what she believes in.

van Manen's (1997) lifeworld existential 'lived body' allows an understanding of Jody's experience. She experiences the woman's body as well as her own. Through the woman's demeanour and the language of her eyes Jody sees the longing, the call for help to be able to hold the baby. Tending to the woman in the shower, Jody engages with her. She has cared for her, guided her through the pain of labour, of birthing a baby and even if it will not live, Jody sees the woman as a mother who needs to love her baby. She knows what it feels like to want to hold and love a child. Chancing moments of privacy, connected through the intimacy of the birth, 
Jody gently probes for even the subtlest physical hint of confirmation from the woman while caring for her in the shower. Jody places herself between the woman and her partner, experiencing herself as a shield and protector of the mother and baby.

Here Catherine talks about protecting the family unit:

I can't make their grief and sorrow any easier but I want to make that experience they are having with us the best they can. There was this one lady, she hadn't told her very smart 6-year-old daughter what was happening. I said to her 'don't you think that maybe you should include your daughter?' and initially they kept saying 'we can't do this'. Then suddenly she said 'my daughter thinks she has done something wrong because she came to me and said mummy I'm really sorry for what I've done'. And she said to her daughter 'but what have you done?' and the girl said 'I have made you sad'. I said to her 'she doesn't understand your grief'. So I gently encouraged them to bring their daughter in and we got the most beautiful photos of them holding the baby together. I think if I hadn't suggested that, that might have been with them forever. Because she might have always held her grief in in front of her daughter and holding in grief doesn't help. As a family we always held our grief in. It's only as an adult have I realised that that is not the way to do it. We need to talk and share. And they did, they talked and they shared and the little girl came in and was a part of that. While it [TOP] is so different from a live birth it is still a celebration. (Catherine)

Catherine has and still is feeling the effects of holding in grief as this is what had been modelled to her as a child. This experience is part of her temporal landscape as what happened in the past has influenced who she has become and continues to reach into her future (van Manen, 1997). Catherine does not want the women in her care to have a similar experience. While she is respectful of the woman's wishes she also wants to lay a positive foundation for the parents' grief journey. Her own experience has taught her that sharing and talking and celebrating together is a vital part in that foundation. Gently she encouraged the parents to talk openly with their first born daughter. And as they did, Catherine became a part of the family's sharing as she facilitated this birth and took photos to preserve their memories. Turning the birth space of TOP into a celebration became part of Catherine's past and present grieving and a step towards healing. 
Jody describes her feelings with regard to the baby:

They don't want to see it, they don't want any mementos of this journey, even little things for them. That offends me. It's all the little things. Once we had a Chinese couple and they didn't want to see their baby, they culturally don't want to see the baby. And the unit was crazy busy. And I had to hold that baby, I can't leave a baby in a room alone to die. As a practitioner that is offensive to me. We can't lose our humanity. We are human beings when we look after these people. (Jody)

Jody struggles to accept parents' wishes not to acknowledge their baby. As a professional she finds this refusal to show dignity and respect to a human being 'offensive'. Yet, this goes beyond her professional self. Jody feeling offended speaks of a personal insult on her core values, her humanity. To Jody it is an inhumane act not to comfort a baby while it is dying. With a busy unit needing her attention still Jody could not bring herself to walk away, the baby was her priority. Jody saw the baby's little body, and she felt she needed to provide comfort, warmth and protection, and the baby's experience became her experience (van Manen, 1998). She sat and comforted this baby to maintain her identity and humanity.

\section{Conclusion}

The process of reflective inquiry and descriptive interpretation to uncover the experience of the midwives caring for women through TOP was guided by van Manen's (1997) lifeworld existentials. The data analysis revealed that the midwives' experience of caring for women through TOP is complex and often comprised of more than one dimension; the notions of 'lived time' and 'lived body' are significant aspects of this phenomenon. Catherine experienced a recall of the grief from losing her father as she sat with the baby: "My heartjust broke. I sat on the sofa in the room and ... I actually christened him after my dad...This is going to stay with me forever". Catherine is surrounded by time - past, present, and future and the physical experience of sadness and grief as she sits on the sofa in the room, holding, christening the baby.

Vivian had a similar recall: "She also experienced this immense relief like me, visibly breathing a sigh of relief once it was over. ... I will carry a little bit of that forever with $m e^{\prime \prime}$. Vivian experienced the memory of herself breathing a sigh of relief as 
she birthed her baby, remembering, grieving again, knowing the impact of the present moment as she supported the woman through TOP.

Time beyond measure, incalculable, is Jody's experience of being part of the woman's journey “...you have to walk that journey with them”. Jody immerses herself into the woman's reality that is an unknown voyage, that holds the memories of the past, the being of the present moment, and the future of a shared experience.

The data in this chapter clearly shows that the midwives who participated in my study negotiate the complexity of the situation and their professional and ethical values to stay true to themselves. The subtheme 'connecting' shows how the relationships the midwives establish with the women are a significant part of their experience. The connections with the women take on meaning as the everydayness of midwifery care, the routine midwifery tasks that keep them busy and occupied are not part of TOP care. The midwives feel satisfaction and confirmation through the connection and feel a sense of reciprocity when women express their wishes and needs, include the midwives in their journey and provide positive, encouraging feedback. Yet, the connection with families can travel beyond the professional and touch the midwives personally, where the midwives can feel sadness and heartbreak with the family, and experiences become part of the midwives' life journey.

The subtheme 'walking a tight rope' shows that the midwives who care for women through late TOP experience internal struggles as they face amalgamating the women's wishes with their own professional and personal values and beliefs. The midwives adopt a non-judgemental attitude when supporting women's choice and decision making. Yet, they can face internal conflicts if the women's choices are not congruent with what they believe. For some participants, these struggles and juggling acts can bring up memories and feelings from the past that amplify the midwives' experience. To stay true to themselves the midwives do what they need to do, working around the women's or family's wishes while taking care of themselves, their values and beliefs. 


\section{Chapter Six: Melting an Iceberg}

'Melting an iceberg' emerged as a theme as the midwives spoke about the lingering effects of caring for women through TOP over time. This theme describes the emotional impact of TOP care on the midwives, how they deal with their experiences, and what makes them go back to work the next time when they know they will be caring for a family through TOP. This chapter is comprised of three subthemes: Accumulating grief, offloading and keeping going. 'Accumulating grief' describes how TOP care affects the midwives. 'Sticking together' describes the debriefing opportunities on hand to these midwives and how and when they undertake debriefing. The third sub-theme 'keeping going' shows what it is that motivates the midwives to continue in this particular role.

\section{Accumulating Grief}

Accumulating grief emerged as a subtheme as the midwife participants spoke about the lingering effects of their work experiences. They described their caring as a 'burden' or a 'load' that was not immediately felt; it generally accumulated over time.

Ruby described how she felt the building-up of her emotional load:

Somebody once said that if you keep putting ice cubes on the scale and you don't have any time for each ice cube to melt they will build into an iceberg. If you put one at a time it will melt and you are back to status quo. But if you don't have the time, it turns into an iceberg. I kind of feel like that at the moment. Work has been so busy recently and these cases, they do take an emotional toll. So I think it is really hard to say you just brush it off and treat it like just another day at the office. Each one of those cases do make a little mark on us. (Ruby)

Iceberg, a mountain of ice; Ruby is feeling the weight of the emotions that have been building up inside her. Each single ice cube symbolises the impact of each woman's story, each TOP impacting upon Ruby. Even though ice cubes are light and barely noticeable at first, Ruby has now realised that her ice cubes have been stacking up. There has just been no time for her to let them melt, to catch her breath, take time out and find respite. There have been so many women who needed her care. Acknowledging and addressing the grief and sadness each single 
time might have prevented Ruby's iceberg from forming but it is too late; the mountain has amassed. There is likelihood that how Ruby is feeling is just the tip of the iceberg. Ruby's experience has a sense of lived body (van Manen, 1997) as Ruby expresses a mental and physical reaction to the repeated caring for women through TOP. Yet, there is also a sense of lived space. While the hospital is a drive away, her place of work has become part of Ruby's home. Wherever she goes Ruby is still within her work space. The space surrounds her, it weighs her down, it occupies her thoughts, her feelings. Her work cannot 'just be brushed off'. Ruby has become confined in that emotional space.

Although Ruby's experience is her own, her analogy of the iceberg describes a similar experience of the other participants. Kate spoke of an unpreparedness for the emotional impact of TOP care:

I did not have any strategies for this. I was a complete nutter. It [TOP care] is such a heavy burden, it is full on. And it's so busy there isn't really any time for sitting and debriefing. I don't really talk to my colleagues about it. It is almost like complete isolation. There is no pastoral care in midwifery, it's just not a thing. Sometimes I just need to talk about it and it is really hard to find the right people. It would be a great idea if I could just verbalise what happened and that would make it feel less bad and inflammatory and hot. It would calm down the overwhelmed emotions. (Kate)

Kate was not prepared for what she might be feeling or dealing with when she signed on for caring for women through TOP. Subsequently she was struggling to cope with the mental-emotional burden of her experiences. The busyness of the ward prevented her from debriefing with colleagues, although Kate found it difficult to find 'the right people', a person she can trust and feel understood and supported by. Kate identified a lack of pastoral care in midwifery. If the offer of pastoral care existed Kate would be able to talk through her feelings and thoughts. She felt she had nobody to turn to, leading to the grief and emotional burden to grow inside her. Kate experienced this build-up in a corporeal sense as 'hot and inflammatory'. van Manen's (2014) lifeworld theme of lived body explains Kate's acute awareness of her body, the feeling of inflammation, of overwhelmedness, the urgent need to talk but not finding the right person, resulting in a feeling of isolation. Her knowledge regarding the women and babies, her participation in 
TOP and her experience are an intrusion on her normal self. Instead of feeling relaxed and happy Kate feels emotionally overwhelmed.

Kate continues:

I have noticed in the last month that I have flashbacks to the births and terminations and the women I have looked after. And although I have always maintained it is not my grief I have come up with this idea, this concept of accumulated residual grief. I am still carrying a little bit of it with me. I might think I am totally fine but then something happens, a stressful situation happens and it comes out that I'm still feeling, that I am feeling and carrying this sense of grief for these families all the time. It is always there. Because it is happening so often that I've got this part of me that is actually always aware of grief and there is this kind of residual accumulation of sadness around the death of the babies. (Kate)

Kate maintains that the family's grief is not hers. However, Kate has realised she partakes in the grief for the babies silently, on her own. Grief and sadness have become her constant companion. The flash-backs to the terminations she has cared for speaks of the bodily experience of the burden of grief that has accumulated and has now become overwhelming, intruding on her life. Kate has not been able to relieve herself of that burden as she cares for women through TOP on a regular basis. There has not been enough time for Kate to process and heal. Consequently, grief and sadness are now clinging to her, their weight increasing with every woman she cares for; ever present in her thoughts and challenging her resilience.

Jody speaks about the mental-emotional impact of caring for women through TOP:

It's a psychological burden because you don't stop thinking of them, you don't immediately forget them so you just hope you have a better day tomorrow and it's something about time that gives you that relief of not being torn apart by it. (Jody)

Jody described the caring for women through TOP as a burden, a mental-emotional heavy load that she carries with her in her thoughts. She anxiously anticipated the next day to be 'better'. Jody's experience has the dimension of time (van Manen, 1997). Her hope is a look towards the future, towards the respite from the burden she is feeling, towards healing and 'not being torn apart.' Each time she cares for women through TOP her capacities are stretched almost to breaking point. Jody 
longs for the moment when time has eased the burden, hoping that the good days at work will give her a reprieve from the emotional strain of caring for women having terminations, and that the memory will fade.

Rose describes:

I have looked after hundreds of terminations. I can still remember every one. And I can still feel everyone. (Rose)

Rose's words expressed an intensity of caring that does not diminish over time. The experience of TOP spans over Rose's past, the present moment and carries forward into her future. Her being with women through TOP is centred in time (van Manen, 2014).

Ruby, Kate, Jody, and Rose are hinting at a different emotional baseline that has established due to caring for women through TOP. Kate described a 'residual accumulation of grief', something of which she was not aware. Yet, as she is continuing to provide TOP care, it is becoming more and more obvious, especially in stressful situations that might not be connected with work. Jody speaks of time being a factor of 'not being torn apart'; however, Jody's words do not reflect her reaching normality, rather a reprieve before she cares for another woman through TOP.

Ruby described how she has reached the tip of an iceberg. This iceberg has been forming over a period of time. Ruby has not been able to address the mounting, increasing mass of emotions she has been experiencing. Too many women needed her care and there has been no time. Considering the bulk of an iceberg is submerged under the surface of water there is a hidden danger to icebergs which is largely invisible. Similarly, there is a possibility that expressions of emotional overload, tearfulness, and flashbacks, are the tip of the iceberg, the evident effects of the midwives' role. Yet the true nature and consequences of this work remain hidden as grief and sadness are not always obvious, as the midwives keep going they might not be aware of the bulk of their feelings. And just as icebergs can erode sea beds, repetitive TOP care on a regular basis might erode the midwives' capacity to recover. Thereby eroding their strength and resilience. The depth and 
complexity of caring for women through TOP might be vast and might have such a lasting impact on the midwives it cannot simply be 'melted'.

\section{Sticking Together}

'Sticking together' emerged as a subtheme as the midwives who participated in this study spoke about how and when they debrief. As the previous subtheme showed, the participants' impressions from their work do not end when they leave their unit or the hospital. These experiences carry on and grow into an overwhelming mental-emotional burden.

As discussed in Chapter 4 not all midwives 'sign on' to provide TOP care resulting in a limited number of midwives working in this role. This increases the likelihood of TOP care being a regular occurrence for the midwives, as well as the need for support. Midwives access support within their small circle of likewise 'signed-on' colleagues.

Maria speaks about her support network amongst friends and colleagues:

I do have friends at work, although we don't work much together. But they are awesome and are there for backup. If something does happen I can just send them a message like 'ugh' and we'll make a point to go out for coffee or we'll meet up for dinner somewhere or at each other's houses to debrief. I can vent some of the frustration out that way. But even then, I can't talk to all my friends. I have two really close friends that I would go to first, because they do it a lot, they know how to support me through it. So it is great that we can support each other within a circle and not throw it into everyone else's face that says we do this and you guys don't. For whatever reason that might be. I guess it is quite dividing in that sense but I think that is because of us being more aware of it and not wanting to offend other people's choices rather than feeling like we have to keep it a secret. (Maria)

Maria felt that she was unable to talk to her usual group of friends. She is sensitive to the fact that the work she does might be upsetting to others. Maria does not feel she has to keep her work 'a secret'; yet she cannot openly talk about the care she provides to women who terminate their pregnancy. However, Maria's two very close friends are midwives who work with her in the same unit. While work friendships are often formed to network and have a feel of 'business', Maria's 
friends are more than collegial friends. They are friends who have an understanding, who have the shared lived experience of what it is like to care for women through TOP. Their shared experience is the foundation for their debriefing with each other. There is mutual trust, compassion and the knowledge that whatever is being aired stays between them. Maria knows her friends are there when she needs them; they are just a text message or phone call away if the going gets really tough. A simple text message 'ugh' is all it needs for the group to make time to come together to allow Maria to express her frustration and debrief. They might meet at one of their homes, at a restaurant, or a café. Wherever they meet they create a space where Maria can be herself, feel listened to, supported, understood and cared for (van Manen, 1997). Maria appreciates the reciprocity of their friendship and ability to debrief. She does not want to offend her midwifery colleagues who do not provide TOP care by sharing her experiences, thoughts and feelings without their consenting to being a debriefing partner or their knowing what caring for women through TOP entails. There is a divide between midwives who agree to caring for women through TOP and midwives who do not. A divide felt by Maria when the need to talk becomes acute.

Similarly, Catherine recalls about sharing the load with her most trusted friends:

I do have a really good friend who works with me and I can talk to her for hours if I need to. We usually meet up once a week or we chat on the phone and if I need to offload I have another good friend whom I can call and say I need to chat and she would listen. They both understand. Other people might, too, but I don't have that relationship with them. Not every midwife might have that so I feel lucky that I can reciprocate as well if they have a tough time. I think it's part of the job, you need that, and if you don't have it I don't know how you process things. Thankfully I have my colleagues and friends to talk to. They won't give me advice, they are just going to listen. (Catherine)

Catherine has a regular meeting with a friend from work in place. It is their time to debrief, to "process things" and work through issues they have encountered at work. They have 'that' relationship with each other. It goes deeper than conversation, is deeply personal, and has significance to both. There is trust, understanding, listening, paying attention and putting whoever needs it first. Some of her other friends might understand, but Catherine simply does not have that 
connection, the shared experience with them. Catherine speaks of an occasional need to "offload", to relieve herself from a load created by her work. Catherine has the experience of TOP care sometimes getting too much, accumulating into a worry that she needs to share and reduce. She has another friend outside of midwifery, who is happy to receive that load and carry it with Catherine. Catherine does not require advice on how to handle herself or work through emotions, she just needs to be able to talk and have an active listener who is there, present, focused, understands and is able to hold the space Catherine needs.

'Offloading' is an experience of lived body (van Manen, 1997) for Catherine. She feels the build-up of an emotional load from her work in a sense of bodily awareness. She experiences her friend over the phone, a distance away, but physically close through their shared bond, trust and knowing of each other. She feels that safeness in their relationship where she does not need to hold back, where she can talk and at the end of it experience the lightness of having 'offloaded' the accumulated load.

Rose describes how friends rally around her at work in times of need:

As midwives who do terminations we stick together and support each other. Sometimes it gets to me and then they'll give me a cuddle and we'll sit down have a cup of tea. It's not that often that it gets to me. But they respect that you do break down, you just can't say when it's going to happen. So I find my colleagues are really good support. Because they have been doing it a long time and they are probably older as well, they have more life experience and they are able to cope with it. (Rose)

Rose and the other midwives at her work who care for women through TOP 'stick together' for support. Rose speaks of her work 'getting to her' at times yet she cannot predict when she might falter. The work is emotionally and mentally challenging for her although most of the time Rose is doing alright. There is a sense of build-up in Rose's experience. Like Catherine, the load accumulates and eventually Rose is overburdened and breaks down. Although she does not know when that might happen. She knows her colleagues will be there to support her; that makes it easier for her to accept that it is how it is. Rose has a relationship with her older colleagues that does not extend to the younger generation. She feels 
comfortable being comforted by them in the knowledge that she does not upset them, that they have the capacity to deal with her distress and her need to debrief and cry. Like Catherine, Rose's experience has a bodily dimension (van Manen, 1997). The mental-emotional load of the work shows its toll. Rose crumbles, without warning, her boundaries and strength reduced to pieces. She "breaks down". After all the giving she has a need to have a cry, receive some comfort, a hug and debrief with a cup of tea surrounded by her trusted friends who understand how hard it is.

Jody speaks about debriefing with colleagues:

Sometimes I talk to my colleagues about things that get to me. But only to the senior ones because they know what it is like. The families that are incredibly dysfunctional and hideous to care for, I think you have to keep talking about those people because nobody else gives a toss as far as management is concerned so you'd better debrief with your colleagues because they're very stressful to look after. They're your friends and they don't judge you for being who you are, they know how hard it is and you trust them. But often there isn't enough time to debrief. Management have got no understanding of what it is we are doing. They're [management] almost like a pack of teenagers, there is just not a lot of communicating with them, they haven't got it going on. (Jody)

Jody finds it tough to care for families going through TOP when there are complex social issues. She feels it is especially important to debrief after caring for families that are 'dysfunctional' and challenging. Possibly Jody has attempted to raise such difficulties and challenges with superiors yet without success. 'They don't give a toss' seems an expression of Jody's frustration, of feeling unsupported. The details of caring for women through TOP seem poorly understood by management and Jody describes a breakdown of communication with management which might be stopping her from approaching the midwife in charge. There is only one option for Jody if she needs to talk - with her friends at work, despite a shortage of time. She has made friends at work amongst experienced colleagues who are also caring for women through TOP. Like Rose, Jody needs to know her friends have the maturity to listen and share her experience so she can talk in a safe space, and, more importantly, she needs to know she will not be judged for what she might say and for being herself. 
Ruby relates her reasoning regarding why she debriefs with colleagues:

I guess my job is not something that you would go out and wave the flag about and say this is what I do. I don't think it is a socially acceptable job because you never know what side of the fence others are sitting on with the terminations and I don't want to get into an ethical debate with somebody because I staunchly am where I am. So it is difficult. But the people who I work closely with are also involved in terminations and therefore there is that acceptance amongst ourselves. It's like being part of a team. There is that sense of community amongst us. (Ruby)

Ruby firmly supports women in regard to TOP. Yet, it appears that Ruby is unable to be proud of her work, of the care she provides to women who face TOP. She is unable to express her satisfaction in a wider social context. The social debate regarding the ethical side of TOP is something Ruby shies away from. She is fearful of being drawn into a judgemental discussion. It is therefore difficult for Ruby to access support and debriefing opportunities outside of work, or even just to talk about the work she does in an informal setting. However, Ruby feels accepted amongst her colleagues who work with her and undertake the role of providing TOP care. She is part of the team. She feels "a sense of community" where there seems to be understanding, sharing of similar ethical values, support and friendship. Ruby, similar to Maria, Rose and Jody, is a member of an unspoken community, a group of midwives who have the shared lived experience of what it means to care for women and families through TOP. This knowledge creates a bond for the midwives, a safety net where they can reach out to each other for support and debriefing.

Kate identified that there is no pastoral care available to offer support for midwives. Currently the only service midwives can access for counselling free of charge is the Employee Assistance Provider Service (EAPS). The EAPS supports private and public organisations to enhance their employees' wellbeing. This programme can be accessed by all DHB staff for counselling to improve mental, emotional, and physical health. Three sessions are provided without cost to the employee. EAPS counsellors cannot be individually chosen by the employee. Other support services are private counsellors, psychotherapists, professional 
supervisors, which, if accessed by midwives, are to be paid for privately. The midwives considered the EAPS in their dialogues.

Ruby speaks about the time constraints of the allocated sessions:

The surgical team for first trimester terminations have a debriefing facility in the hospital. But there is nothing specific in terms of debriefing for us [midwives] here. We do have EAP we can access for three sessions but then what do I nut it down to? That's my issue. (Ruby)

Specific, targeted debriefing, a simple yet powerful tool for reflection, is not available for the midwives who care for women through TOP where Ruby works. However, EAPS does not have the right feel for Ruby. She struggles with the thought of talking about her work in three sessions with a counsellor. How can she possibly "nut it down to" what the effects of her work are and then open up about her feelings, worries, and thoughts to someone who does not understand what it is she does? The essence of her work, of her caring, and the lingering effects have become so complex, so big over time, that Ruby simply cannot identify which parts she feels the most about, which 'nuts' are the biggest ones to gather. For that to happen Ruby needs more time and a foundation of trust with the counsellor that gives her the confidence that she will be understood and supported.

van Manen's (2014) dimension of 'lived other' describes that how we relate to others embeds us in our world, the connections we form with others and the caring we do makes us understand and transcend ourselves. Previously Ruby revealed that the load of the emotional impact of her caring for women through TOP has the size of an iceberg. The time pressure of only three sessions with the counsellor is an issue that might make Ruby hesitant to access this service. It is likely that the provision of a dedicated ongoing counselling service would give Ruby the reassurance that has the time to form a relationship with the counsellor, peel back the layers, and reconnect with herself.

Sarah discusses her feelings on using the EAPS to debrief:

While [EAP] through work is always on offer I have never felt that it would be even appropriate for this kind of thing. How does it sit going off to an [EAP] 
counsellor, a counsellor whom you never met, and you say I had a really bad day because of this woman who'd chosen to ..., you open the door to them not being okay with that and to them having an opinion on that and I'm not willing to do that. So I prefer to stick with people who I know, I know where they stand on it. I have fantastic midwifery friends who have a similar bent I guess around this to me, so we talk about things and issues. I don't talk to friends outside of midwifery, because that's not safe as a midwife. (Sarah)

Sarah does not feel it is "appropriate" or "safe" to meet with a counsellor. She also makes a clear distinction between midwifery friends and friends outside of midwifery as debriefing partners. As a professional person not familiar with midwifery the counsellor is an outsider to Sarah whom, she fears, might "not be okay" with her caring for women through TOP, might struggle with the ethical and social aspects of termination and be traumatised due to the contents of the discussion. van Manen's (1997) concept of lived other/relationality as the way we maintain a connection in the space we share with each other helps to form an understanding of Sarah's reluctance. Sarah has already shaped an impression of the counsellor in her mind as someone who has an opinion and who, she fears, might judge her and not maintain confidentiality. Yet, there is also a sense of 'notat-home' in Sarah's words, in the sense of 'lived space' (van Manen, 1997). The counsellor's office presents a wholly unfamiliar place to Sarah. There are no comforts of home or the familiarity of a favourite café. There are none of the familiar people that make Sarah feel safe. There is not the relaxed atmosphere that Sarah associates with home, or a familiar environment such as her midwifery friend's home that has become her second home. Sarah prefers to 'stick' with her midwifery friends, who know what it is like, where she does not need to go into details, where there is mutual understanding, a sense of bond and trust and where she can safely open up.

\section{Keeping Going}

The subtheme 'keeping going' arose as the midwives described their motivation to continue caring for women through TOP and how they found reward and acknowledgement in this role. Positive feedback from the women they had cared for was appreciated; however, there was a deeper determination inside them that strengthened their resilience. 
Vivian describes how she finds reward in her role:

I find it rewarding, because you do get a lot of thanks in this role. I find I often get more thanks in those situations [TOP care] than I do in my everyday job in delivery suite. But I don't do it for the feedback, I genuinely want to give women good care. It makes me carry on looking after terminations. If I was told I wasn't going to look after them, this other midwife was but knowing that her heart wasn't really in it I would say no, I'll do it, because I do it for the women. It is something that you've got to want to do, to give good care. That is why I do it, because I know I can give good care, and I respect their decisions and the process. (Vivian)

Caring for women through TOP is not an 'everyday job' for Vivian. It is a different role albeit one she finds satisfying. Just a 'thank you' makes it worthwhile for Vivian, although she is not really in it for that. Vivian shows a sense of altruism in her feeling she can give more to the women than potentially another midwife might. Vivian wants to be there, she wants to keep women safe and make their experience as good as possible. She has true desire and commitment to the woman receiving good care as well as the confidence to support women through a TOP. This altruism is Vivian's motivation that keeps her going back to being with women through TOP.

Vivian's experience has the dimension of 'lived body'. She is confident in herself as a midwife who can deliver 'good care'. Scarlett, citing Davidhizar (1991), wrote that

"self-confidence is the feeling that you know how to do something, that you have the power to make things happen, and that your efforts will be successful. It comes from knowing that knowledge, skill, and experience will result in success - self-confidence being a key ingredient for success". (Scarlett, 2011, What is Self-confidence?)

Vivian has gained confidence from caring for women through TOP multiple times. The positive feedback she has received is acknowledgement to Vivian that she is successful in her efforts, which in turn increases her self-confidence and her willingness to put herself forward time and again.

Ruby speaks about her feelings when everything goes to plan: 
There is also joy in my job. We get feedback from families who say thank you so much and that's all it will take. That there is the reward. I know that we can never make it better, we can't make this outcome any better because it is shit no matter how you look at it. But if I can make that process a little easier to bear, then that's the reward. If I walk away knowing that they have been offered every single type of memory making, that they have got all the documentation that they need, that their care was great, their PCA [patient controlled analgesia] was working perfectly, that is joy. That is absolute joy. (Ruby)

All it takes for Ruby is a 'thank you' from the families she looks after. It confirms to her that she has achieved what she set out to do. For Ruby that is offering all options of memory making, good pain relief, correct documentation and prompt, compassionate care. Yet it is more than just single things; it is knowing that she has wrapped a coat of comfort around the woman, that every resource she can draw on has been utilised and that the woman has had an experience that left her feeling supported throughout the complete process. Ruby's ability to experience joy shows a transcendence of herself and a focus on the woman, rather than herself. The relationality (van Manen, 1997) with the woman gives Ruby a greater purpose for a greater good - to make things a little easier for the woman. A simple 'thank you' is what brings Ruby "joy".

Jody speaks of what keeps her going:

The women are going through lots of physical things and lots of emotional trauma so when we mesh all those things together it is important to get them to a place where they're not broken at the end of it. Part of what I talk about even when we're early on in the day is getting to an understanding of where might they want to be in a year's time. If they are going to try again I have to keep that hope thing alive for them. I talk about giving their bodies a break. For the very, very overweight women I talk about diet and my own battle with losing weight. I talk about giving cigarettes away, about being the healthiest person they can be. They just yearn to hold their baby in their arms. I have experienced that feeling of wanting a baby so bad you can taste it. There's nothing they wouldn't do so I think it's not a bad day to bring in some health advice otherwise you're missing that opportunity for them to lay down good healthy habits. Caring for women through a TOP is the hardest part of my job but it's the most rewarding. I don't want chocolate, I don't want a card but I just want to know that I might have gotten through to them. (Jody) 
Jody's experience has the dimension of time as she tries to get the women she cares for to see past the event of the day and towards a future with a healthy, live baby in their arms. van Manen (1997) said "Through hopes and expectations we have a perspective on life to come..." (p. 104). Jody's motivation is to "keep the hope thing alive'. She is determined to create hope in the women that will give them perspective. Her memories of her own longing for a baby, her battles with her own health, flood her mind as she engages with the women. Jody's dimension of 'lived time', memories of her lived experience, intertwine with her dimension of 'lived other' as Jody's 'self' is revealed in her connectedness with the women (van Manen, 2014). Her practice has been influenced by her experience as she takes the opportunity of a teachable moment, to give some health advice. Nevertheless, it is hard for Jody. More than that, to care for women through TOP is "the hardest part" of her job. Yet, she does not want a card or chocolates. All she wants is to know that she might have reached the women, and that she has given them that flicker of hope that will turn into a flame and pull them through the traumatic event. That is her reward.

Rose tells how she felt about her work:

I do get a lot of them. I had two 2 days running. With somebody who has just lost a baby, that relationship you have is super special. I aim to make it as pleasant as possible. So I get really involved and that's very intense. But it is also very rewarding. My hubby doesn't get the full details but if I tell him I've had another one he says 'you alright, you alright then?' Sometimes I'm a bit teary and he gives me a hug and says 'isn't it about time you stopped doing them?' But I say this is my job. He says 'yeah but other girls should be doing them!' But I tell him it's my job and I'll do it until I finish. (Rose)

Rose takes care of women through TOP frequently. She tries to make the experience for the women as bearable and as 'pleasant' as possible. To be able to do that Rose allows herself to be wrapped up, almost absorbed into the relationship with the woman and the care she gives. There is a sense of nurturing, comforting, near mothering in Rose's words, of giving to the woman without thinking of herself. The relationship with the woman, the intensity and depth of the connection, is what enables Rose to give so much of herself. In that relationship, that giving, Rose finds her reward, and she has found her purpose. Rose's words 'I 
still feel every single one' have already shown the immense emotional impact of the work on her. When her husband sees her crying he tries to fix the tears but Rose insists 'this is my job'. She will not stop. Caring for women who face TOP is a part of who she is. She will continue to care until she retires.

\section{Conclusion}

'Melting an iceberg' has described the significant effects on midwives caring for women through TOP. The midwives experience being emotionally and mentally affected in similar ways. The cases the midwives take on can be complex and challenging and the data has shown that the midwives feel an intensity in their work that they cannot simply put aside when their shift is over. 'Ice cubes piling up into an iceberg', 'residual accumulated grief', 'emotional load or burden' are words the midwives used to describe how they are affected by the sadness and grief they witness. The sadness and grief they feel with the women and for the babies. Time and repetitiveness are contributing factors to the midwives' experience of the emotional burden and the possible alleviation of such. However, the data clearly showed that the midwives are affected by each and every case on a long-term basis. There is a possibility that the bulk of the mental-emotional consequences for midwives are not obvious and remain hidden until midwives reach capacity, or breaking point, and become aware of their feelings. This proves that this particular midwifery role is not an everyday job.

The second subtheme 'offloading' showed that the midwives have a clear need for debriefing and processing what they experience. The lack of scheduled, professional debriefing opportunities for midwives is quite likely contributing to the changed emotional baseline also described as the formation of an iceberg. While the offer of three counselling sessions with the EAPS is available, the midwives expressed concerns about this service. The data showed that the lack of midwifery understanding, lack of connection, possible ethical and social opinions, and time constraints are contributing factors that make midwives hesitant to access EAPS. 
The data in the second subtheme also showed that there is a strong sense of bonding and community amongst the midwives who provide TOP care. The midwives make an obvious distinction between friends, midwifery friends who also care for women through TOP, and midwifery colleagues. As the options for debriefing are extremely limited, the midwives turn to each other for support, leading to the possible conclusion that the shared lived experience of providing TOP care is the foundation for their sense of community. As each midwife in this community 'knows what it's like' there is a strong sense of trust and mutual understanding, of not needing to explain what they do in their role; this serves as the basis for safe debriefing.

The data in the third subtheme 'keeping going' has revealed that the midwives find this particular role highly rewarding, even joyful, despite the joy being intertwined with the grief the midwives feel with the women. The midwives know the sorrow of the woman and her partner and family. They are passionate about alleviating this pain and about making the process of TOP as good as possible. Receiving positive feedback and acknowledgement for their care is the enjoyment and reward the midwives get out of their work. It helps to melt the iceberg a little bit each time. 


\section{Chapter Seven: Facilitating the Space of Birth and Death}

The question of this research study is 'What is the lived experience of midwives caring for women facing termination of pregnancy in the late second and third trimester?' Three essential themes emerged from the findings that describe the phenomenon: a different kind of midwife, staying true to oneself, and melting an iceberg.

In this chapter I describe and discuss the major findings arising from my study. The strengths and limitations of the study will be considered, and the implications of the findings for midwifery practice will be detailed, along with the implications for practice and education. Suggestions for further research will be provided. A summary of the research study will conclude the thesis.

\section{Midwives Facilitate the Space of Birth and Death}

My study has shown that the participant midwives have revealed an understanding of their role as facilitators for the amalgamation of the space of birth and death. Their narratives have brought to light the extraordinary-ness of the moment of transition when the baby is born not into life but into death, and their efforts to preserve the sanctity of that moment.

This finding shows that the role of midwives in TOP care is different to the role in normal labour and birth. The midwives recounted signing an agreement form at their employment interview to verify that they had no conscientious objection to caring for women through TOP. This process might be initiated by the DHBs to ensure that the TOP services continue to operate. Motivated to provide care to women who needed midwifery care the midwives realised that their role had been extended; yet they were not sure what this would entail. Examples of the unknown-ness of caring for women through TOP are seen in Jody's words "I never received any formal preparation or orientation for this role". The midwives' narratives of their unpreparedness signalled they were embarking on a journey which led them to redefining their role and finding themselves within it. Their equipment for this journey was their life experience, their midwifery skills, and 
their travel plan of staying true to themselves by keeping human as they journey with the woman.

The midwives have revealed that the space of TOP is a contrasting effect of two moments of being. Midwives support women to become mothers and bring life into the world. They bear witness to women's pain that opens their body to allow the passage of their child, the beginning of new life, the moment of a first breath. The space is filled with mystery, awe, joy, promise. Yet, in the space of TOP new life is ceasing during the intense, almost violent surges of labour or shortly after, intentionally, planned. A baby is born into the space of parents' dreaded reality, heartbreakingly raw grief and guilt, mixed with the relief that it is over. An anticlimax for the woman when the beginning of life becomes the end of life, and a definite juxtaposition for the midwife. Yet, the participant midwives revealed a deep sense of spirituality within the blending of these two contrasting moments, as expressed by Kate “... it is like moving into another realm" or Sarah "The space that has to be held is the space of a birth and the space of a death." Crowther and Hall (2015) explored spirituality in childbirth, leading to the conclusion that childbirth is a spiritual event that is experienced by women, their families and the midwives caring for them; and that midwifery practice that focuses on being-with-women and woman-centredness is spiritual care.

The midwives in my study revealed their deep respect for a human life, which, no matter how short, has lived and been a part of this world. They honoured the imprint the baby made on the mother's memory with its first kick, the first sound of the heartbeat. In the process of TOP the midwives experience the birth of this baby as an extraordinary, most important moment that must not to be violated.

\section{Supporting Women in Their Decision}

In facilitating this extraordinary moment for the midwives, three aspects blend into a circle and revolve around the baby, the woman and the mother-baby dyad. The midwives spoke about their understanding of the life changing experience of TOP and the impact on the woman. In making sense of the woman's decision to terminate her pregnancy, the midwives revealed an understanding that the 
pregnancy was much wanted. Women made the decision to terminate after an unexpected diagnosis 'out of love' to prevent suffering for their child, themselves and their families. This understanding is an important factor that motivated the midwives to facilitate the best possible experience for the woman within the context of TOP. This is demonstrated by the language the midwives use, calling their families bereaved and acknowledging their loss. Midwives recounted offering women memory making, facilitating photo taking either by themselves or professional photographers. They spoke about making birth plans with the women, about getting family members involved in the birthing process or afterwards to create as many memories for the women as possible. They candidly recounted showing parents how to be parents, which included involving fathers with bathing and dressing their baby, naming their baby, holding and preserving the little body as best they could for as much time with their family. The midwives facilitated celebrations and religious rituals to honour the life of the baby and recounted their feelings of joy, even pride, as they were able to partake in this.

\section{Midwives Preserve the Dignity of the Baby}

The participants revealed that their values and beliefs could be profoundly challenged when they were in dissonance with the beliefs and requests of the women. Jody recounted a story whereby the husband did not allow his wife to hold their baby. Jody saw the mother's silent cues and, despite facing a difficult situation, negotiated for the woman to hold her baby.

The strongest emotional responses from midwives in my study appeared to be related to their perception of preserving the dignity of the baby. Christensen, Christiansen and Petersen (2013) discussed the changed status and increased personalisation of the fetus that had led to a change in rituals regarding memory making in late TOP. In my study the participants acknowledged the fetus as a human being, a life that had lived, had died and that was owed dignity, compassion, celebration, and love as much as any other deceased human. The participants disclosed that they felt a sense of protection towards the often fragile body of the baby and handled it with utmost care. In instances when the baby was born alive and the mother did not want to hold, see or acknowledge the baby, the midwives chose to hold the baby. 
The midwives in my study expressed ways of taking care of their own values in regard to the baby's life. This is in contrast to findings of international research where midwives were challenged when they had to handle the baby, and experienced an ethical dilemma when the baby was born alive (Garel et al., 2007; Mauri et al., 2015; Mayers et al., 2005; Mizuno, 2011).

\section{Connecting with Women in Their Emotional Space}

The participants in my study revealed that they felt an intensity and depth in their relationship to the women during TOP that they did not experience during normal labour and birth in their role as hospital midwives. Their narratives brought to light that the connected-ness with the women is meaningful to midwives. It is an investment mirrored with a sense of quiet satisfaction.

This finding is echoed by those of Gilkison, McAra-Couper, Fielder, Hunter and Austin (2017) which showed that hospital midwives have a particular ability to form close connections with women; especially as they are faced with medical and social complexity. New Zealand hospital midwives see this skill of connecting with women and their families as an essential part of their practice (Gilkison et al., 2017).

The participant midwives spoke about an immersion into the women's emotional space by anticipating their needs well before meeting, sometimes anxiously, depending on religious, cultural, or social context. The midwives want to be the 'right' person for the women to create the best experience for them.

They tried to find common ground with women and their families over everyday things like paying for parking, light banter or silence, tastes for music, even preferences for physical touch to connect. This is a process core midwives follow as part of their everyday working life. Yet, establishing common ground in TOP care is much more important as the midwives' experience hinges on creating a connection with the women. 
The midwives described a sense of heightened awareness to the woman's emotions and needs, responding to silent or verbal requests. This suggests that midwives connect with women on a complex physical, emotional, and spiritual level. They created the space the woman needed at that moment in time, meeting her in her grief and guilt. Going above and beyond themselves the midwives are personally invested in the process.

The midwives recounted that some routine midwifery tasks that are usually part of normal labour and birth, like frequent listening to the fetal heart, are not required in the process of TOP. The midwives replace tasks, which may sometimes seem like ticking boxes, with caring. The connection with women becomes an even more important part of the midwives' experience.

The participant midwives also revealed that the connection with women and their families can nurture and sustain them in a sense of reciprocity. The midwives spoke of having a spiritually uplifting experience with a religious family, describing their rituals around caring for the baby as "divine" and their relationship as "beautiful". Another spoke of the "pure joy" when she knows the process has gone smoothly and she was able to offer every resource to make the experience good and memorable for the woman. When midwives feel connected with the women they try to direct their outlook to the future, towards hope, towards a baby in the mother's arms. A simple "thank you", or a card is all it takes for the midwives to know they achieved what they set out to do, provide the best care possible for the women and babies in their care. This is where their job satisfaction stems from.

\section{Managing a Growing Iceberg}

My study has revealed that the participant midwives experienced 'empty arms' with each woman for whom they provided TOP care. Their narratives have brought to light that they feel grief and sadness anew with each woman they care for and feel the personal and professional losses of their past reverberating within them. As the midwives are not given time or space to make meaning of their feelings, an 'emotional iceberg' of unprocessed grief and sadness accumulates. 
Considering the intense relationship between the midwives and the women, and the efforts the midwives described to achieve the best possible childbirth experience for the women during TOP, it is not surprising that the participants in my study described their role as an emotional burden. A number of authors have echoed this finding. Garel et al. (2007), Cignacco (2002), Mauri et al. (2015), Mizuno (2011) all reported midwives' emotional distress and feeling of being burdened by caring for women through TOP.

Yet, the effects are even more profound. The midwives in my study spoke about how the grief and sadness they feel with the women have now become emotional companions they carry with them continuously. Their words illustrated a build-up of grief and sadness that does not dissipate. The result is the residual accumulation of grief or amassing of an emotional iceberg. The midwives' feelings point unreservedly to a change in their emotional baseline that adjusts over time. Grief and sadness linger and grow as the midwives give too much of themselves and put their heart and soul into their work. Time only relieves some of the burden, some of the pressure of being almost torn apart. TOP care has a lifelong effect on midwives.

Kübler-Ross (2005) has described grief as the intense emotional response to the pain of a loss; yet grief is more than just an emotional reaction. The participants in my study have described physical, mental and spiritual effects of their grief. Considering TOP is a planned anticipated death, the notion of 'anticipatory grief', described by Kübler-Ross and Kessler adds another layer of understanding to the midwives' experience. During the TOP process, death of the baby has either already occurred by fetocide, will occur during the intense labour, or shortly after the birth. Awaiting loss and grieving elicits a more silent response, where words are not necessary or welcome, where touch and being-with is more important than any active doing and affects everyone within this space (Kübler-Ross \& Kessler, 2005). The participating midwives have described their anticipatory grief through their narratives. They meet women in their grief by 'being with' rather than doing. Grief surrounds the midwives before, during and after their caring. 


\section{Unprepared-ness for this Role}

The participants in my study revealed that they were wholly unprepared for the role of providing care to women undergoing TOP. The midwives discussed a lack of education, orientation, and continuing professional updates regarding TOP care. This finding concurs with the international literature. Midwives have repeatedly called for undergraduate education, appropriate orientation and ongoing education updates for this role (Andersson et al., 2014; Christensen et al., 2013; Cignacco, 2002; Garel et al., 2007; Hallden, Lundgren, \& Christensson, 2011; Mauri et al., 2015; Mayers et al., 2005; Mizuno, 2011). The midwives in my study recounted how they had to take a leap of faith when they embarked on this new role. Midwives are unaware of what to expect in practical terms, in regard to documentation and legal aspects, as well as what they might experience emotionally, even personally, when caring for women through TOP.

The findings of my study have shown that the unpreparedness of midwives extends to the processing of their emotional experiences. Kain (2013), Ho Chan (2012), Treggalles (2018) and Funk (2017) discussed the lack of prepared-ness of the caring and allied health professions regarding dealing with death and grief. This echoes the findings of my study. Midwives who work with women through TOP are equally unprepared for processing the grief and sadness that is associated with their role.

\section{Being Challenged to Sustain Themselves}

The participant midwives disclosed that seemingly normal tasks at work not related to TOP can trigger memories, break-downs and acute distress at unpredictable times. Stressful situations could feel more stressful than usual. The midwives felt they were not coping well as they still felt emotional from the last time they cared for a woman through TOP. It is not just at work that the effects of regular TOP care present. The participants had also become aware of grief and sadness in their personal life through flashbacks; along with feelings of heightened stress, insomnia, and irritability. These signs are recognised effects of womancentred and empathetic care work (Dixon et al., 2017; Foureur et al., 2013; Ho Chan \& Tin, 2012; Leinweber \& Rowe, 2010; Mollart, Skinner, Newing, \& Foureur, 
2013; Winters, 2018), also described as secondary trauma, compassion fatigue, and burn-out.

Yet, expecting resilience of nurses and midwives without providing them the tools to address their emotions needs to be re-evaluated (Crowther et al., 2016). Ho Chan and Tin (2012) have described that nurses and midwives working with death are especially vulnerable to compassion fatigue and secondary traumatic stress. Ho Chan (2012) reported helping professions involved in bereavement care might have practical knowledge and associated skills around death and dying, yet their personal resources and self-competence in dealing with their often heavy and deep emotions resulting from their work had never been addressed or acquired. To ensure the sustainability of their work Ho Chan proposed workshops to increase knowledge of self for working with grief, death and dying, as well as regular professional supervision and counselling. Treggalles and Lowrie (2018) supported the idea of self-confidence regarding grief. Knowing oneself might enable health professionals working with death and grief to selectively filter which experiences at work and home can be used to enhance either home life or work practices (Treggalles \& Lowrie, 2018).

\section{Feeling Unsupported}

Poor leadership and communication with management was identified by the midwives as a significant contributing factor to their workplace frustration and distress, especially around challenging situations. The midwives spoke about how being able to sit down for a debrief without time pressure would help alleviate some of the acute, burning distress the midwives feel after a traumatic or difficult day at work, just as is offered after traumatic birth events. The midwives revealed they felt that their role was not understood by management and that there was a lack of communication. They felt unsupported with their extra duties as their plight for extra staffing and reduced workloads on days when TOPs were scheduled was left unacknowledged. Subsequently they felt unappreciated or not valued for their work. 
The participant midwives revealed that formal debriefing had never been offered to them and identified a distinct lack of debriefing opportunities, counselling, or support from their employer for their role. In contrast, some recalled that nurses working with surgical terminations in the operating theatre at the hospital were offered regular counselling through their department. This option was not available to them.

While EAPS is on offer for all DHB employees my findings have shown that the midwives are hesitant to engage with this service. My study has revealed that the time constraint of three sessions, the midwives' perception of a lack of understanding of their role, and the social stigma around TOP are barriers that prevent midwives from accessing the support they so desperately need.

The strongest need for debriefing was felt by the midwives when the process was not straight-forward. Midwives struggled when there were medical complications or when they were unable to connect with the woman and her family due to complex social issues. On occasions the midwives encountered additional challenges, like needing to procure forensic evidence for criminal investigations, without support and orientation from their leaders, which added additional stress.

My study supports national and international findings that the psychological wellbeing of midwives in general, but in particular after TOP, stillbirth, adverse events, and traumatic births is still undervalued and poorly managed. This is despite a large body of evidence that has repeatedly demonstrated that midwives are significantly impacted and psychologically challenged by these events (Andersson et al., 2014; Austin et al., 2013; Cohen et al., 2017; Creedy, Sidebotham, Gamble, Pallant, \& Fenwick, 2017; Dixon et al., 2017; Garel et al., 2007; Jones, 2012; Leinweber \& Rowe, 2010; Mauri et al., 2015; Mayers et al., 2005; Wahlberg et al., 2017). Austin (2013) discussed the need for midwives to be able to talk about the event, to be listened to, and shown compassion. Yet, Austin and Jones (2012) revealed that midwives often had to wait a long time for support and suffered alone and in silence. Effective strategies for debriefing have yet to be developed. 
Treggalles and Laurie (2018) argued that organisations need to support their employees by providing tools to manage the grief associated with their role. The authors proposed that embedding reflective practice and implementing regular supervision or counselling will lead to increased staff wellbeing and satisfaction which in turn will benefit patients and families (Treggalles \& Lowrie, 2018).

\section{Finding Community}

It is clear that the lack of appropriate support for midwives is the factor leading to the midwives' emotional iceberg, their residual, accumulated grief. Their increased need to debrief, especially after complex cases, has not been met. In defiance to this lack of support the participant midwives in my study have revealed a strong sense of community amongst them. In the context of TOP and the associated longterm effects this might not be ideal; however, the shared lived experience of TOP care provides a foundation of knowing, trust, and a sense of 'belonging' for the midwives. Informal, unstructured debriefing is a regular occurrence, an important part of midwifery that for most midwives is a chat in the tearoom over lunch, a cup of coffee or during handover. However, this form of debriefing was not readily available for the midwives doing TOP care as they tried to avoid causing offence to their colleagues on shift who have expressed conscientious objection. Therefore, the midwives made a point of messaging each other, calling once a week to debrief, going out for ad hoc coffees, meeting at each other's homes, or supporting each other at work. This is where they felt safe to talk openly, laugh or cry within their small circle of likeminded midwife friends. The midwives recounted candidly how they 'stick together', how they support each other as part of a team where they feel accepted and where they are listened to without judgment or receiving unsolicited advice.

\section{Valuing the Care of Midwives in Second and Third Trimester Terminations}

Several recent studies have described the importance of midwifery care for women who experience TOP (Deas, 2017; Jones et al., 2017; Lotto et al., 2016). The consequences of late gestation TOP on women are complex and lasting (Lafarge et al., 2014). Midwives are seen as ideally placed to provide TOP care through their 
holistic, woman-centred approach to caring through labour and birth and their emotional intelligence. Lotto (2016) described that procedures perceived as routine by staff hold significance for parents and each step in the process can be another hurdle for women and their partners. A key factor in women's experience is having one dedicated midwife to be solely with them through labour and birth (Carlsson, Bergman, Karlsson, Wadensten, \& Mattsson, 2016; Lotto et al., 2016). Jones (2017) recommended that women require flexible and adaptive care from a familiar midwife who is attuned to the woman's emotional reality.

TOP in the late second and third trimester, while still an 'abortion', is a unique and complex form of pregnancy loss (Lafarge et al., 2014). My study has revealed that midwives facilitate TOP similar to normal birth to provide the best experience to women. Midwifery philosophy is centred in health and wellbeing, with a belief in childbirth as a natural process, even in the face of complexity. This is a contrasting stance to the more clinically, procedural focused approach of nurses. Gallagher (2010) discussed how nurses struggle with the concept of late gestation TOP as they cannot solely focus on the mother, there is a fetus they need to take care of, which they find emotionally distressing. Early gestation TOP does not produce a fetus, therefore nurses view TOP as a therapy and care is delivered in a more medical sense (Gallagher et al., 2010). My study has shown that midwifery care in second and third trimester terminations is of high value as the experience of this life-changing event has lasting psychological consequences for women.

\section{Strengths and Limitations}

Findings acquired through a hermeneutic phenomenological study cannot be generalised. Lived experience is studied through the rich and meaningful data obtained and the size of the ideal sample is difficult to determine (van Manen, 2014). Hence, my sample of eight midwives can be regarded as a strength and limitation; the strength includes rich data obtained through in-depth interviewing. A limitation is that the findings might not be replicated by other midwives in New Zealand. Another limitation of this study might be the snowball sampling that occurred during recruitment; this could possibly lead to selected midwife participants. However, a strength of my study is that the midwives were recruited 
from two different DHBs in the North Island of New Zealand to allow for a broader sample. Considering the small number of midwives who provide TOP care this could be seen as a representative sample.

Preliminary findings have been presented at a conference in Australia whereby the midwives were compelled to share their narratives with me. Their stories and experiences reflected those of my participants, thus resonated with the findings in my study, and adds to the rigour of my analysis.

\section{Recommendations for Education}

Findings from this study have shown that midwives were unprepared for the role of caring for women through TOP. Education would support the recognition of this important role, prepare midwives to provide care to women with confidence, and lay a foundation of strategies to deal with the effects of the role. Midwives as a caring profession need to learn how to process and manage grief and traumatic events at work.

My recommendations for education are:

- The development and incorporation of an integrated module that explores practical, legal, and psychological aspects of TOP care in undergraduate midwives' education. While these aspects are addressed in current undergraduate programmes, the synthesis of these aspects would likely strengthen education.

- Ongoing education in the form of regular, multi-disciplinary workshops or forums for midwives, as well as other health professionals, who fill a role in caring for women during late gestation TOP. Topics should include the legal framework, ethical aspects, documentation and relevant forms, dealing with grief, mentoring and peer support, working with bereaved women, as well as cultural needs and practices e.g. Tūranga Kaupapa. 


\section{Recommendations for Practice}

TOP care that is undertaken on a regular basis needs to be addressed to make it a sustainable role for midwives. Midwives are committed to continuity of care and to the women's experience. Their efforts must be supported by their employers.

My recommendations for practice are:

- Regular opportunities to debrief with management within the employment setting as part of the midwives' position description to acknowledge midwives' emotional responses. Further debriefing of individual cases which midwives experience as complex or traumatic should be implemented.

- The provision of ongoing grief counselling with a counsellor that has been introduced to the role and specialised in grief and trauma. This offer must be part of the midwives' position description and employment contract.

- The implementation of professional supervision for midwives preferably by supervisors who have prior knowledge or experience with the role.

- Midwives need to be able to give one-on-one care when caring for women having a termination. This means management must be proactive in scheduling extra staff for days when women are booked for TOP.

- Flexible work hours to enable midwives to stay on to care for a woman providing continuity of care as this is known to be beneficial for women/families and midwives.

- Recognition of the role by management through the immediate offer of debriefing. Ideally the midwife manager would connect with the midwife regularly during and following the completion of TOP care.

- Midwives require mentoring and peer support in their role.

\section{Recommendations for Further Research}

- Establish how many midwives provide TOP care in New Zealand and how TOP care is undertaken.

- Explore why midwives express objection to providing TOP care.

- Uncover the barriers for LMC midwives in providing TOP care to their client/s. 
- Develop and implement a postgraduate educational programme regarding advanced gestation TOP. Assess changes in knowledge and practice following an educational programme.

- Implement a training programme to foster self-competence in dealing with grief and then measure outcomes.

- Implement grief counselling for midwives who provide TOP care and evaluate effectiveness.

- Develop and implement an undergraduate module regarding TOP.

\section{Summary}

My study has revealed that caring for women through TOP is an intense, complex experience with long-lasting psychological effects for midwives. The three themes that emerged throughout the analysis of the data add to the already established body of evidence as well as provide a deeper level of understanding of the midwives' experience. The themes have revealed that this part of midwives' role is far from the normality of midwifery care. The narratives brought to light that midwives' experience with TOP is complex with different aspects emerging over time. The midwives were clearly unprepared for this role. While bereavement care has been incorporated into undergraduate training, education specifically to prepare midwives for TOP care has so far not been designed. Midwives embark on this journey with their midwifery knowledge, skills and life experience, mixed with a leap of faith. More importantly midwives are unprepared for the emotional effects of caring for women through TOP. Grief and sadness accumulate over time as the midwives do not receive counselling or professional supervision. The emotional burden of TOP care has been described in the literature. What my study adds is that midwives suffer the psychological effects for a long time. This presents a significant challenge for midwives to sustain themselves in their role. Social and medical complexity during TOP can add another, acute layer to the midwives' experience. Yet, debriefing with management is generally not available, leaving the midwives to feel unsupported and undervalued.

While the unpreparedness and the psychological burden of caring for women through TOP have been highlighted, the midwives have described their role as 
intensely rewarding and a source of great job satisfaction. Their community is tight-knit and the camaraderie amongst them sustains them. Revealing the empathy and the passion they bring to this role, the midwives have demonstrated their support of women's choice and take care to preserve the babies' dignity. This creates an intense feeling of connectedness to women, their babies and the process that is unique to this role.

The midwives have come to see their role as facilitators of the amalgamation of the spaces of birth and death. This is a new finding that adds to the existing body of evidence. Being aware of the traumatic nature of TOP the midwives create a space around women that honours their childbirth experience as well as the loss of a much wanted child. Therein lies the value of midwifery care for women who face TOP in the late second and third trimester.

In Chapter one I revealed my pre-understandings in line with the methodology which underpins my research study and which has been described in Chapter three. My findings arose from my participants' data which I rigorously analysed, and I acknowledge that my interpretation might be open to further interpretation. However, the intensity and long-lasting effects of TOP care upon the midwives who participated in my study was greater than I anticipated. The analogy of the iceberg, which I analysed in-depth, shows the enormity of this role.

In answering my research question, this study reveals the midwives' experience is joy and satisfaction, connecting with women and camaraderie. At the same time, it is a process of managing a growing emotional iceberg from relentless caring and giving that is intertwined with grief and sadness as the midwives traverse the landscape of facilitating the space of birth and death. 


\section{References}

Andersson, I.-M., Gemzell-Danielsson, K., \& Christensson, K. (2014). Caring for women undergoing second-trimester medical termination of pregnancy. Contraception, 89(5), 460-5.

http://doi.org/10.1016/j.contraception.2014.01.012

Austin, D., Smythe, E., \& Jull, A. (2013). Midwives ' wellbeing following adverse events - what does the research indicate? New Zealand College Of Midwives, $2013,19-23$.

Carlsson, T., Bergman, G., Karlsson, A.-M., Wadensten, B., \& Mattsson, E. (2016). Experiences of termination of pregnancy for a fetal anomaly: A qualitative study of virtual community messages. Midwifery, 41, 54-60.

http://doi.org/10.1016/j.midw.2016.08.001

Christensen, A. V., Christiansen, A. H., \& Petersson, B. (2013). Faced with a dilemma: Danish midwives' experiences with and attitudes towards late termination of pregnancy. Scandinavian Journal of Caring Sciences, 27(3), 913920. http://doi.org/10.1111/scs.12004

Cicirelli, V. G. (2011). Religious and nonreligious spirituality in relation to death acceptance or rejection. Death Studies, 35(2), 124-146.

http://doi.org/10.1080/07481187.2011.535383

Cignacco, E. (2002). Between professional duty and ethical confusion: Midwives and selective termination of pregnancy. Nursing Ethics, 9(2).

Clair, S. (2008). A Maori perspective on death and dying. Kai Tiaki Nursing New Zealand, (May). Retrieved from http://www.nzonscreen.com/title/oncewere-warriors-1994/background\#critique_2

Coggins, J. (2012). Viewpoint: Caring for the dying - lessons learnt in New Zealand. Kai Tiaki Nursing New Zealand, 18(4), 30-32. http://doi.org/10.1111/j.14401800.2004.00195.7

Cohen, R., Leykin, D., Golan-Hadari, D., \& Lahad, M. (2017). Exposure to traumatic events at work, posttraumatic symptoms and professional quality of life among midwives. Midwifery, 50(September 2016), 1-8.

http://doi.org/10.1016/j.midw.2017.03.009

Conectus. (2016). Mokopuna Ora - healthy pregnancy and baby. Auckland:

University of Auckland. Retrieved from https://mokopunaora.nz/sites/dev- 
mkpo/files/2016-03/MokopunaOra-introduction.pdf

Creedy, D. K., Sidebotham, M., Gamble, J., Pallant, J., \& Fenwick, J. (2017).

Prevalence of burnout, depression, anxiety and stress in Australian midwives:

A cross-sectional survey. BMC Pregnancy and Childbirth, 17(1), 1-8.

http://doi.org/10.1186/s12884-016-1212-5

Crotty, M. (1998). The foundations of social research - meaning and perspective in the research process. St Leonards: SAGE Publications Ltd.

Crowther, S., \& Hall, J. (2015). Spirituality and spiritual care in and around childbirth. Women and Birth, 28(2), 173-178.

http://doi.org/10.1016/j.wombi.2015.01.001

Crowther, S., Hunter, B., McAra-Couper, J., Warren, L., Gilkison, A., Hunter, M., ... Kirkham, M. (2016). Sustainability and resilience in midwifery: A discussion paper. Midwifery, 40, 40-48. http://doi.org/10.1016/j.midw.2016.06.005

Dahlstrom, D. (2012). Martin Heidegger. In S. Luft \& S. Overgaard (Eds.), The Routledge Companion to Phenomenology (p. 716). Routledge.

de Chesnay, M. (2014). Nursing research using phenomenology: qualitative designs and methods in nursing. (M. De Chesnay, Ed.). New York: Springer Publishing Company.

Deas, C. (2017). Reducing the psychological impact of terminations for fetal abnormality: A literature review. Evidence Based Midwifery, 15(1), 29-34.

Dixon, L., Guilliland, K., Pallant, J., Sidebotham, M., Fenwick, J., McAra-Couper, J., \& Gilkison, A. (2017). The emotional wellbeing of New Zealand midwives: Comparing responses for midwives in caseloading and shift work settings. New Zealand College of Midwives Journal, (53), 5-14. http://doi.org/http://dx.doi.org/10.12784/nzcomjnl53.2017.1.5-14

Dowling, M. (2007). From Husserl to van Manen. A review of different phenomenological approaches. International Journal of Nursing Studies, 44(1), 131-142. http://doi.org/10.1016/j.ijnurstu.2005.11.026

Dowling, M., \& Cooney, A. (2012). Research approaches related to phenomenology: Negotiating a complex landscape. Nurse Researcher, 20, 21-27. http://doi.org/10.7748/nr2012.11.20.2.21.c9440

Drach-Zahavy, A., Buchnic, R., \& Granot, M. (2016). Antecedents and consequences of emotional work in midwifery: A prospective field study. International Journal of Nursing Studies, 60, 168-178. 
http://doi.org/10.1016/j.ijnurstu.2016.04.014

Edwards, L., \& Hui, L. (2018). First and second trimester screening for fetal structural anomalies. Seminars in Fetal and Neonatal Medicine, 23(2), 102111. http://doi.org/10.1016/j.siny.2017.11.005

Elliott, C. (2017). Emotional labour: Learning from the past, understanding the present. British Journal of Nursing, 26(19), 1070-1077. http://doi.org/10.12968/bjon.2017.26.19.1070

Ellis, K., Fisher, J., Leigh, B., Schott, J., \& Mahmood, T. (2010). Termination of pregnancy for fetal abnormality in England,Scotland and Wales: Report of a working group. RCOG Guidelines. Retrieved from https://www.rcog.org.uk/globalassets/documents/guidelines/terminationpr egnancyreport18may2010.pdf

Foureur, M., Besley, K., Burton, G., Yu, N., \& Crisp, J. (2013). The consequences for resilience. The Contemporary Nurse, 45(1), 114-125.

Funk, L. M., Peters, S., \& Roger, K. S. (2017). The emotional labor of personal grief in palliative care: Balancing caring and professional identities. Qualitative Health Research, 27(14), 2211-2221. http://doi.org/10.1177/1049732317729139

Gallagher, K., Porock, D., \& Edgley, A. (2010). The concept of "nursing" in the abortion services. Journal of Advanced Nursing, 66(4), 849-857. http://doi.org/10.1111/j.1365-2648.2009.05213.x

Gardenier, D., McMullen, P., \& Philipsen, N. (2018). Do conscience clauses violate patients' rights? Journal for Nurse Practitioners, 14(6), 448-449. http://doi.org/10.1016/j.nurpra.2018.03.012

Gardner, R. (2013). Introduction to debriefing. Seminars in Perinatology, 37(3), 166-174. http://doi.org/10.1053/j.semperi.2013.02.008

Garel, M., Etienne, E., Blondel, B., \& Dommergues, M. (2007). French midwives' practice of termination of pregnancy for fetal abnormality. At what psychological and ethical cost? Prenatal Diagnosis, 27, 622-628. http://doi.org/10.1002/pd

Gemzell-Danielsson, K., \& Lalitkumar, S. (2008). Second trimester medical abortion with mifepristone-misoprostol and misoprostol alone: A review of methods and management. Reproductive Health Matters, 16(31 SUPPL.), 162-172. http://doi.org/10.1016/S0968-8080(08)31371-8 
Gilkison, A., McAra-Couper, J., Fielder, A., Hunter, M., \& Austin, D. (2017). The core of the core: What is at the heart of hospital core midwifery practice in New Zealand? New Zealand College of Midwives Journal, (53), 30-37.

Graham, R. H., Mason, K., Ranking, J., \& Robson, S. C. (2009). The role of feticide in the context of late termination of pregnancy: A qualitative study of health professionals' and parents' views. Prenatal Diagnosis, 29, 875-881. http://doi.org/10.1002/pd

Grbich, C. (2013). Qualitative Data Analysis: An introduction (2nd editio). London: SAGE Publications Ltd.

Guililand, K., \& Pairman, S. (2010). The midwifery partnership: A model for practice (2nd ed.). Christchurch: New Zealand College of Midwives.

Habiba, M., Da Frè, M., Taylor, D. J., Arnaud, C., Bleker, O., Lingman, G., ... Viafora, C. (2009). Late termination of pregnancy: A comparison of obstetricians' experience in eight European countries. BJOG: An International Journal of Obstetrics and Gynaecology, 116(10), 1340-1349. http://doi.org/10.1111/j.1471-0528.2009.02228.x

Hallden, B.-M., Lundgren, I., \& Christensson, K. (2011). Ten Swedish midwives' lived experiences of the care of teenagers' early induced abortions. Health Care for Women International, 32(5), 420-440. http://doi.org/10.1080/07399332.2010.535937

Hanna, D. R. (2005). The lived experience of moral distress: Nurses who assisted with elective abortions. Research and Theory for Nursing Practice, 19(1), 95124. http://doi.org/10.1891/rtnp.19.1.95.66335

Heidegger, M. (2006). Sein und Zeit (19th ed.). Tuebingen: Max Niemeyer Verlag. Ho Chan, W. C., \& Tin, A. F. (2012). Beyond knowledge and skills: Self-competence in working with death, dying, and bereavement. Death Studies, 36(10), 899913. http://doi.org/10.1080/07481187.2011.604465

Holloway L., Habib T., Allan P., M. C. (2017). Report of the Abortion Supervisory Committee. Wellington, New Zealand. Retrieved from https://www.ranzcog.edu.au/RANZCOG_SITE/media/RANZCOGMEDIA/Women\%27s Health/Statement and guidelines/Clinical Gynaecology/Termination-of-pregnancy-(C-Gyn-17)-Review-July2016.pdf?ext=.pdf

Hunter, B., \& Warren, L. (2014). "Midwives' experiences of workplace resilience" 
Practising Midwife, 17(10), 29-32.

http://doi.org/10.1016/j.midw.2014.03.010

Huntington, A. D. (2002). Working with women experiencing mid-trimester termination of pregnancy: The integration of nursing and feminist knowledge in the gynaecological setting. Journal of Clinical Nursing, 11(2), 273-279. http://doi.org/10.1046/j.1365-2702.2002.00586.x

Jones, K. (2012). A heavy heart and a pocket full of grief: An interpretive inquiry of midwives' first experience of stillbirth as a community based midwife. Auckland University of Technology.

Jones, K., Baird, K., \& Fenwick, J. (2017). Women's experiences of labour and birth when having a termination of pregnancy for fetal abnormality in the second trimester of pregnancy: A qualitative meta-synthesis. Midwifery, 50(March), 42-54. http://doi.org/10.1016/j.midw.2017.03.014

Kafle, N. P. (2013). Hermeneutic phenomenological research method simplified. Bodhi: An Interdisciplinary Journal, 5(1), 181-200. http://doi.org/10.3126/bodhi.v5i1.8053

Kain, V. J. (2013). An exploration of the grief experiences of neonatal nurses: A focus group study. Journal of Neonatal Nursing, 19(2), 80-88. http://doi.org/10.1016/j.jnn.2012.04.001

Kisorio, L. C., \& Langley, G. C. (2016). Intensive care nurses' experiences of end-oflife care. Intensive and Critical Care Nursing, 33, 30-38. http://doi.org/10.1016/j.iccn.2015.11.002

Koch, T. (1994). Establishing rigour in qualitative research: The decision trail. Journal of Advanced Nursing, 19(5), 976-986. http://doi.org/10.1111/j.13652648.1994.tb01177.x

Korenromp, M. J., Christiaens, G. C. M. L., Van Den Bout, J., Mulder, E. J. H., Hunfeld, J. A. M., Bilardo, C. M., ... Visser, G. H. A. (2005). Long-term psychological consequences of pregnancy termination for fetal abnormality: A crosssectional study. Prenatal Diagnosis, 25(3), 253-260. http://doi.org/10.1002/pd.1127

Kübler-Ross, E., \& Kessler, D. (2005). On grief and grieving: Finding the meaning of grief. New York: Scribner.

Lafarge, C., Mitchell, K., \& Fox, P. (2013). Women's experiences of coping with pregnancy termination for fetal abnormality. Qualitative Health Research, 
23(7), 924-36. http://doi.org/10.1177/1049732313484198

Lafarge, C., Mitchell, K., \& Fox, P. (2014). Termination of pregnancy for fetal abnormality: A meta-ethnography of women's experiences. Reproductive Health Matters, 22(44), 191-201. http://doi.org/10.1016/S0968$8080(14) 44799-2$

Le Grice, J. S., \& Braun, V. (2017). Indigenous (Māori) perspectives on abortion in New Zealand. Feminism and Psychology, 27(2), 144-162. http://doi.org/10.1177/0959353517701491

Leask, M. (2015). An exceptional choice?: How young New Zealand women talk about abortion. Australian Feminist Studies, 30(84), 179-198. http://doi.org/10.1080/08164649.2015.1046305

Leinweber, J., \& Rowe, H. J. (2010). The costs of "being with the woman": Secondary traumatic stress in midwifery. Midwifery, 26(1), 76-87. http://doi.org/10.1016/j.midw.2008.04.003

Lindström, M., Jacobsson, L., Wulff, M., \& Lalos, A. (2007). Midwives' experiences of encountering women seeking an abortion. Journal of Psychosomatic Obstetrics and Gynecology, 28(4), 231-237. http://doi.org/10.1080/01674820701343505

Lindström, M., Wulff, M., Dahlgren, L., \& Lalos, A. (2011). Experiences of working with induced abortion: Focus group discussions with gynaecologists and midwives/nurses. Scandinavian Journal of Caring Sciences, 25(3), 542-548. http://doi.org/10.1111/j.1471-6712.2010.00862.x

Ling, J., Hunter, S. V., \& Maple, M. (2014). Navigating the challenges of trauma counselling: How counsellors thrive and sustain their engagement. Australian Social Work, 67(2), 297-310. http://doi.org/10.1080/0312407X.2013.837188

Lotto, R., Armstrong, N., \& Smith, L. K. (2016). Care provision during termination of pregnancy following diagnosis of a severe congenital anomaly - a qualitative study of what is important to parents. Midwifery, 43(October), 14-20. http://doi.org/10.1016/j.midw.2016.10.003

Lyus, R., Creed, K., Fisher, J., \& McKeon, L. (2014). Termination of pregnancy for fetal abnormality. British Journal of Midwifery, 22(May), 332-337. Retrieved from http://www.rcog.org.uk/files/rcogcorp/TerminationPregnancyReport18May2010.pdf 
MacDonald, C. M. (2003). Evaluation of stress debriefing interventions with military populations. Military Medicine, 168(12), 961-968.

Maguire, M., Light, A., Kuppermann, M., Dalton, V. K., Steinauer, J. E., \& Kerns, J. L. (2015). Grief after second-trimester termination for fetal anomaly: A qualitative study. Contraception, 91(3), 234-239. http://doi.org/10.1016/j.contraception.2014.11.015

Mauelshagen, A., Sadler, L. C., Roberts, H., Harilall, M., \& Farquhar, C. M. (2009). Audit of short term outcomes of surgical and medical second trimester termination of pregnancy. Reproductive Health, 6(1), 1-6. http://doi.org/10.1186/1742-4755-6-16

Mauri, P. A., Ceriotti, E., Soldi, M., \& Guerrini Contini, N. N. (2015). Italian midwives' experiences of late termination of pregnancy. A phenomenologicalhermeneutic study. Nursing \& Health Sciences, 17(August 2014), 243-249. http://doi.org/10.1111/nhs.12180

Mauri, P. A., \& Squillace, F. (2017). The experience of Italian nurses and midwives in the termination of pregnancy: a qualitative study. The European Journal of Contraception \& Reproductive Health Care, 22(3), 227-232. http://doi.org/10.1080/13625187.2017.1318846

Mayers, P., Parkes, B., Green, B., \& Turner, J. (2005). Experiences of registered midwives assisting with termination of pregnancies at a tertiary level hospital. Health $S A, 10(1), 15-25$.

McCulloch, A., \& Weatherall, A. (2017). The fragility of de facto abortion on demand in New Zealand Aotearoa. Feminism and Psychology, 27(1), 92-100. http://doi.org/10.1177/0959353516679432

McLennan, A., \& Walker, S. (2015). Prenatal assessment of fetal structural abnormalities. Retrieved from https://www.ranzcog.edu.au/RANZCOG_SITE/media/RANZCOGMEDIA/Women\%27s Health/Statement and guidelines/ClinicalObstetrics/Prenatal-assessment-of-fetal-structural-conditions-(C-Obs-60)Amended-May-2016_1.pdf?ext=.pdf

Megaw, L., \& Dickinson, J. (2018). Feticide and late termination of pregnancy. O\&G Magazine, 20(2).

Midwifery Council of New Zealand. (2015). Midwifery workforce survey. Wellington. Miles, M., Chapman, Y., Francis, K., \& Taylor, B. (2013). Exploring Heideggerian 
hermeneutic phenomenology: a perfect fit for midwifery research. Women and Birth : Journal of the Australian College of Midwives, 26(4), 273-6. http://doi.org/10.1016/j.wombi.2013.06.003

Mizuno, M. (2011). Confusion and ethical issues surrounding the role of Japanese midwives in childbirth and abortion: A qualitative study. Nursing and Health Sciences, 13, 502-506. http://doi.org/10.1111/j.1442-2018.2011.00647.x Mizuno, M., Kinefuchi, E., Kimura, R., \& Tsuda, A. (2013). Professional quality of life of Japanese nurses/midwives providing abortion/childbirth care. Nursing Ethics, 20(5), 539-50. http://doi.org/10.1177/0969733012463723

Mollart, L., Skinner, V. M., Newing, C., \& Foureur, M. (2013). Factors that may influence midwives work-related stress and burnout. Women and Birth, 26(1), 26-32. http://doi.org/10.1016/j.wombi.2011.08.002

New Zealand Government. (2018). Births, Deaths and Marriages.

Nicholson, J., Slade, P., \& Fletcher, J. (2010). Termination of pregnancy services: Experiences of gynaecological nurses. Journal of Advanced Nursing, 66(10), 2245-2256. http://doi.org/10.1111/j.1365-2648.2010.05363.x

Pairman, S., Pincombe, J., Tracy, S., \& Thorogood, C. (2015). Midwifery: Preparation for practice (3rd ed.). Sydney, Australia: Churchill Livingstone. Retrieved from https://books.google.co.nz/books?id=BkjeoQEACAAJ\&source=gbs_ViewAPI\&r edir_esc=y

Parker, A., Swanson, H., \& Frunchak, V. (2014). Needs of labor and delivery nurses caring for women undergoing pregnancy termination. JOGNN - Journal of Obstetric, Gynecologic, and Neonatal Nursing, 43(4), 478-487. http://doi.org/10.1111/1552-6909.12475

PMMRC. (2017). Eleventh annual report of the perinatal and maternal mortality review committee. Wellington, New Zealand. Retrieved from http://www.hqsc.govt.nz/our-programmes/mrc/pmmrc

Racher, F. E., \& Robinson, S. (2003). Are phenomenology and postpositivism strange bedfellows? Western Journal of Nursing Research, 25(5), 464-481; discussion 482-491. http://doi.org/10.1177/0193945903253909

RANZCOG. (2016). Late termination of pregnancy (C-Gyn 17a). College Statements and Guidelines. Retrieved from www.ranzcog.edu.au/statements-guidelines RANZCOG. (2018). Subspecialists. Retrieved June 17, 2018, from https://www.ranzcog.edu.au/members/Member- 
categories/Fellow/Subspecialist

RCOG. (2011). The care of women requesting induced abortion: Evidence based clinical guideline number 7. United Kingdom.

Reed, R. (2011). Sharing stories: Reclaiming birth knowledge. Midwifery Today, Autumn

Reinholz, D., Casati, S., Beretta, O., \& Merlani, G. (2018). Termination of pregnancy in a border region between Switzerland and Italy (2008-2015). Swiss Medical Weekly, 148(July), 1-7. http://doi.org/10.4414/smw.2018.14636

Rich, S., Graham, M., Taket, A., \& Shelley, J. (2013). Navigating the terrain of lived experience: The value of lifeworld existentials for reflective analysis. International Journal of Qualitative Methods, (12), 498-510.

Sandelowski, M. (1993). Rigor or rigor mortis: The problem of rigor in qualitative research revisited. Advances in Nursing Science, 16(2), 1.

Sattler, D. N., Boyd, B., \& Kirsch, J. (2014). Trauma-exposed firefighters:

Relationships among posttraumatic growth, posttraumatic stress, resource availability, coping and critical incident stress debriefing experience. Stress and Health, 30(5), 356-365. http://doi.org/10.1002/smi.2608

Scarlett, Y. (2011). The experience of becoming clinically self-confident.

Sciscione, A., Berghella, V., Blackwell, S., Boggess, K., Helfgott, A., Iriye, B., ... Stone, J. (2014). Society for maternal-fetal medicine (SMFM) special report: The maternal-fetal medicine subspecialists' role within a health care system. American Journal of Obstetrics and Gynecology, 211(6), 607-616. http://doi.org/10.1016/j.ajog.2014.09.013

Smythe, E. (2011). From beginning to end: How to do hermeneutic interpretive phenomenology. In G. Thompson, F. Dykes, \& S. Downe (Eds.), Qualitative Research in Midwifery and Childbirth Phenomenological Approaches (p. 264). Routledge (2011).

Smythe, E., Ironside, P., Sims, S., Swenson, M., \& Spence, D. (2008). Doing Heideggerian hermeneutic research: A discussion paper. International Journal of Nursing Studies, 45(9), 1389-97.

http://doi.org/10.1016/j.ijnurstu.2007.09.005

Stodart, K. (2018). Caring respectfully for the dying. Kai Tiaki Nursing New Zealand, 24(4).

The Ministry of Health. (2012a). Antenatal screening for Down Syndrome and other 
conditions. Guidelines for health practitioners. Wellington, New Zealand. Retrieved from https://www.nsu.govt.nz/health-professionals/2784.aspx The Ministry of Health. (2012b). Guidelines for consultation with obstetric and related medical services (referral guidelines). Wellington: The New Zealand Ministry of Health.

The Ministry of Justice. Crimes Act 1961, 43386 (1961). New Zealand. Retrieved from http://www.legislation.govt.nz/act/public/1961/0043/63.0/DLM327382.ht $\mathrm{ml}$

The Ministry of Justice. Contraception, Sterilisation, and Abortion Act 1977 (1977). Wellington, New Zealand: New Zealand Government. Retrieved from http://www.legislation.govt.nz/act/public/1977/0112/latest/DLM18538.ht $\mathrm{ml}$

The Ministry of Justice. (2018). Abortion Supervisory Committee. Retrieved November 15, 2018, from https://www.justice.govt.nz/tribunals/abortionsupervisory-committee/

Thomas, E., \& Magilvy, J. K. (2011). Qualitative rigor or research validity in qualitative research. Journal for Specialists in Pediatric Nursing, 16, 151-155. http://doi.org/10.1111/j.1744-6155.2011.00283.x

Treggalles, K., \& Lowrie, D. (2018). An exploration of the lived experience of professional grief among occupational therapists working in palliative care settings. Australian Occupational Therapy Journal, (February). http://doi.org/10.1111/1440-1630.12477 United Nations. (2012). Convention on the elimination of all forms of discrimination against women: Concluding observations of the committee on the elimination of discrimination against women (Vol. 52nd sessi).

van Manen, M. (1996). Phenomenological pedagogy and the question of meaning. Phenomenology and Educational Discourse, (1996), 39-64.

van Manen, M. (1997). Researching lived experience: Human science for an action sensitive pedagogy (2nd ed.). New York: The Althouse Press.

van Manen, M. (1998). Modalities of body experience in illness and health. Qualitative Health Research, 8(1), 7-24. http://doi.org/10.1177/104973239800800102 van Manen, M. (2014). Phenomenology of practice: Meaning-giving methods in 
phenomenological research and writing. New York: Routledge.

van Manen, M. (2017). Phenomenology in its original sense. Qualitative Health Research, 27(6), 810-825. http://doi.org/10.1177/1049732317699381

van Manen, M., Higgins, I., \& van der Riet, P. (2016). A conversation with Max van Manen on phenomenology in its original sense. Nursing and Health Sciences, 18(1), 4-7. http://doi.org/10.1111/nhs.12274

Wahlberg, Andreen Sachs, M., Johannesson, K., Hallberg, G., Jonsson, M., Skoog Svanberg, A., \& Högberg, U. (2017). Post-traumatic stress symptoms in Swedish obstetricians and midwives after severe obstetric events: a crosssectional retrospective survey. BJOG: An International Journal of Obstetrics and Gynaecology, 124(8), 1264-1271. http://doi.org/10.1111/1471-0528.14259 Winters, A. (2018). A guide for childbirth professionals when the infant dies. International Journal of Childbirth Education, 33(3), 2013-2018.

Yang, C.-F., Che, H.-L., Hsieh, H.-W., \& Wu, S.-M. (2016). Concealing emotions: Nurses' experiences with induced abortion care. Journal of Clinical Nursing, 25(9-10), 1444-1454. http://doi.org/10.1111/jocn.13157 


\section{Appendices}

\section{Appendix A: Ethics Approval}

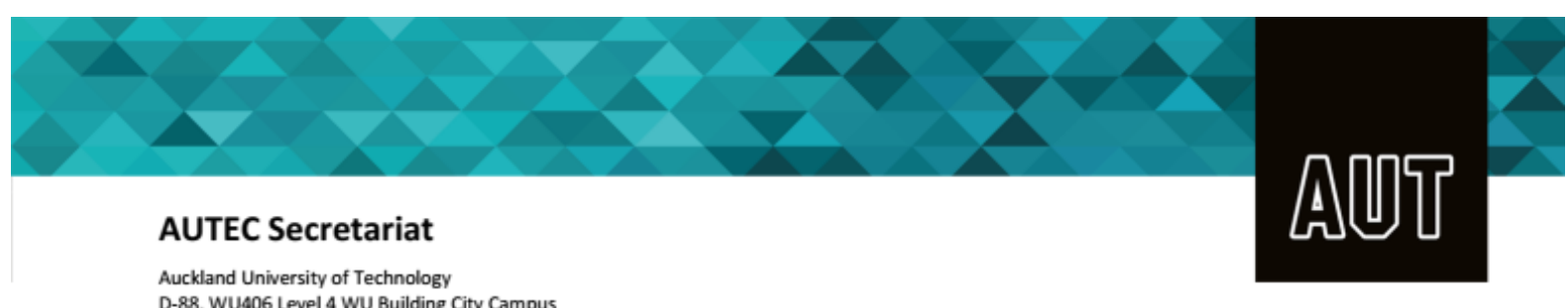

D-88, WU406 Level 4 WU Building City Campus

T: +6499219999 ext. 8316

E: ethics@aut.ac.nz

www.aut.ac.nz/researchethics

20 January 2017

Andrea Gilkison

Faculty of Health and Environmental Sciences

Dear Andrea

Re Ethics Application: 16/350 The lived experience of midwives caring for women facing termination of pregnancy in the late second and third trimester

Thank you for providing evidence as requested, which satisfies the points raised by the Auckland University of Technology Ethics Committee (AUTEC).

Your ethics application has been approved for three years until 20 January 2020.

As part of the ethics approval process, you are required to submit the following to AUTEC:

- A brief annual progress report using form EA2, which is available online through http://www.aut.ac.nz/researchethics. When necessary this form may also be used to request an extension of the approval at least one month prior to its expiry on 20 January 2020;

- A brief report on the status of the project using form EA3, which is available online through http://www.aut.ac.nz/researchethics. This report is to be submitted either when the approval expires on 20 January 2020 or on completion of the project.

It is a condition of approval that AUTEC is notified of any adverse events or if the research does not commence. AUTEC approval needs to be sought for any alteration to the research, including any alteration of or addition to any documents that are provided to participants. You are responsible for ensuring that research undertaken under this approval occurs within the parameters outlined in the approved application.

AUTEC grants ethical approval only. If you require management approval from an institution or organisation for your research, then you will need to obtain this. If your research is undertaken within a jurisdiction outside New Zealand, you will need to make the arrangements necessary to meet the legal and ethical requirements that apply there.

To enable us to provide you with efficient service, please use the application number and study title in all correspondence with us. If you have any enquiries about this application, or anything else, please do contact us at ethics@aut.ac.nz.

All the very best with your research,

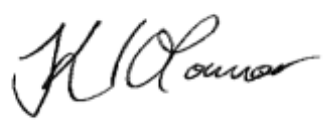

Kate O'Connor

Executive Secretary

Auckland University of Technology Ethics Committee

Cc:

susanne.armour@aut.ac.nz 


\section{Appendix B: Participant Information Sheet}

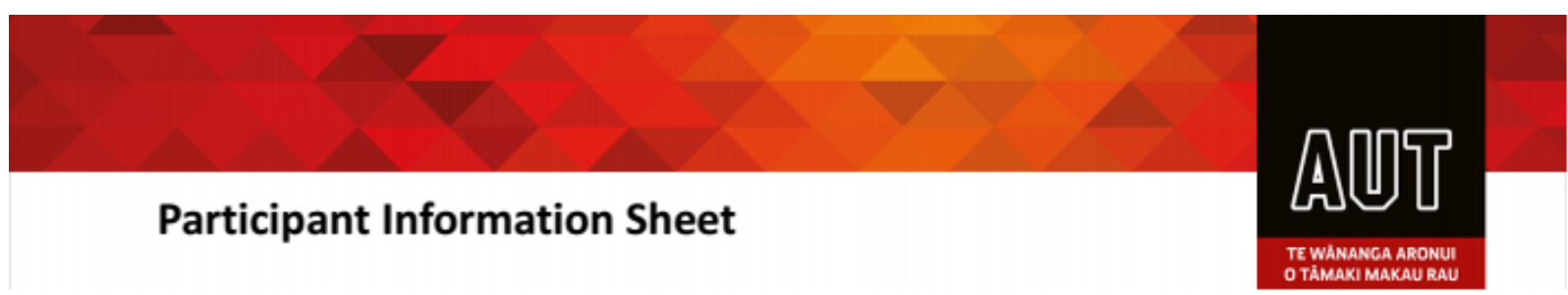

Date Information Sheet Produced:

05/09/2016

Project Title

The lived experience of midwives caring for women facing termination of pregnancy in the late second and third trimester.

\section{An Invitation}

Dear midwife, you are invited to participate in a research study gathering the experiences of midwives caring for women going through late second and third trimester terminations of pregnancy (TOP). My name is Susanne Armour. I have been a midwife for 18 years with several years experience working with women facing TOP as well as working in fetal medicine. This research is part of a master degree with AUT.

Your participation in this research is entirely voluntary. Should you agree to participate you may withdraw at any time before we analyse the interviews, without giving a reason.

What is the purpose of this research?

The care you provide to women going through TOP after 20 weeks gestation is a challenging part of midwifery practice. It has yet to be properly recognized. The aim of this study is to describe your experiences as well as identifying support structures that can support you in providing termination care to women and their partners.

This research will form my Master thesis. The findings will be published in midwifery journals and presented at midwifery forums and conferences.

How was I identified and why am I being invited to participate in this research?

You have been invited to participate because you expressed interest to Andrea or myself after seeing our poster advertising this research study. You are eligible to take part in this study if you have practised as a midwife for at least 2 years and are currently working with women going through TOP or within the last 12 month.

How do I agree to participate in this research?

You will be asked to fill in a consent form once you are satisfied that you have received enough information to make an informed choice. The form will be provided by myself prior to your participation.

Your participation in this research is voluntary (it is your choice) and whether or not you choose to participate will neither advantage nor disadvantage you. You are able to withdraw from the study at any time. If you choose to withdraw from the study, then you will be offered the choice between having any data that is identifiable as belonging to you removed or allowing it to continue to be used. However, once the findings have been produced removal of your data may not be possible.

What will happen in this research?

If you decide to take part in this study it will involve an individual interview of $60-90$ minutes outside of your workplace. This can be at your home or at a quiet, private place that is convenient for you.

The interview will be recorded on an audiotape with your permission. Your stories recorded on this tape will be confidentially transcribed into text. The transcriptionist is employed at AUT and will have signed a confidentiality form. You will receive a copy of this transcript to check and correct. You will have 2 weeks to let us know if you would like information edited or deleted.

I will then work with the text as part of the study.

What are the discomforts and risks?

I am aware that the recounting of your experiences might bring up a certain amount of grief and trauma and cause you some distress. Your interview will be conducted with empathy and understanding, as I myself have collected similar experiences over the years. Your confidentiality and privacy are important to me. The section below will detail how you will be protected. 


\section{How will these discomforts and risks be alleviated?}

You will be offered the support of an experienced, registered counsellor to address feelings of grief, loss or trauma should you express the need. AUT Health Counselling and Wellbeing is able to offer three free sessions of confidential counselling support for adult participants in an AUT research project. These sessions are only available for issues that have arisen directly as a result of participation in the research, and are not for other general counselling needs. To access these services, you will need to:

- drop into our centres at WB219 or AS104 or phone (09) 9219992 City Campus or (09) 9219998 North Shore campus to make an appointment. Appointments for South Campus can be made by calling 921 9992

- let the receptionist know that you are a research participant, and provide the title of my research and my name and contact details as given in this Information Sheet

For acute distress and immediate assistance you can also access Lifeline Aotearoa on Freephone 0800543354 or www.lifeline.org.nz.

Alternatively you can contact EAP https://www.eapservices.co.nz/contact for three free sessions of confidential counselling with a registered counsellor in your local area.

What are the benefits?

The main benefit is your valuable contribution towards understanding midwives' needs when caring for women who terminate their pregnancy. It will help identify structures that can support you, that might make this aspect of midwifery care less challenging and inform midwifery practice.

You will also be contributing hugely to achieving a master degree. There are no immediate benefits in your participation in this study.

\section{How will my privacy be protected?}

The professional transcriptionist transcribing the audiotaped interview will have signed a confidentiality agreement for your protection.

The audio recording of the interview and the transcription are only available to me as the researcher and Andrea, my supervisor.

You will be asked to choose a fictional name for the written text. You will be known by your fictional name during the interview, in the transcript, in the thesis and in publications and conference presentations. No information identifying you as a participant will be used. All potentially identifying information will be kept private. We will do our best to ensure confidentiality.

What are the costs of participating in this research?

The participation in this research study will cost you 60 to 90 minutes of your time outside work. I appreciate your time is precious. The interview will take place at your home or at a place that is quiet and convenient for you.

What opportunity do I have to consider this invitation?

If you would like to participate or you have any questions regarding this study please email me within 10 working days of this invitation: susanne.armour@aut.ac.nz

Will I receive feedback on the results of this research?

Yes, if you wish, we will send you the research findings once it the research has been completed. This can be emailed or sent to your home address.

What do I do if I have concerns about this research?

Any concerns regarding the nature of this project should be notified in the first instance to the Project Supervisor, Dr Andrea Gilkison, email: andrea.gilkison@aut.ac.nz

Concerns regarding the conduct of the research should be notified to the Executive Secretary of AUTEC, Kate O’Connor, ethics@aut.ac.nz,921 9999 ext 6038.

Whom do I contact for further information about this research?

Please keep this Information Sheet and a copy of the Consent Form for your future reference. You are also able to contact the research team as follows:

\section{Researcher Contact Details:}

Susanne Armour, email: susanne.armour@aut.ac.nz 
Project Supervisor Contact Details:

Dr Andrea Gilkison, andrea.gilkison@aut.ac.nz, ph. 09-9219999 ext. 7720.

Approved by the Auckland University of Technology Ethics Committee on 20.01.2017, AUTEC Reference number 16/350. 


\section{Appendix C: Consent Form}

\section{Consent Form}

Project title: The lived experience of midwives caring for women facing termination of pregnancy in the late second and third trimester.

\section{Project Supervisor: Dr Andrea Gilkison}

Researcher:

\section{Susanne Armour}

I I have read and understood the information provided about this research project in the Information Sheet dated 05.09.2016.

I I have had an opportunity to ask questions and to have them answered.

O I understand that notes will be taken during the interviews and that they will also be audio-taped and transcribed.

O I understand that taking part in this study is voluntary (my choice) and that I may withdraw from the study at any time without being disadvantaged in any way.

O I understand that if I withdraw from the study then I will be offered the choice between having any data that is identifiable as belonging to me removed or allowing it to continue to be used. However, once the findings have been produced, removal of my data may not be possible.

I lagree to take part in this research.

I I wish to receive a summary of the research findings (please tick one): YesO NoO

Participant's signature:

Participant's name:

Participant's Contact Details (if appropriate):

Date:

Approved by the Auckland University of Technology Ethics Committee 20.January 2017 AUTEC Reference number $16 / 350$

Note: The Participant should retain a copy of this form. 


\section{Appendix D: Confidentiality Agreement}

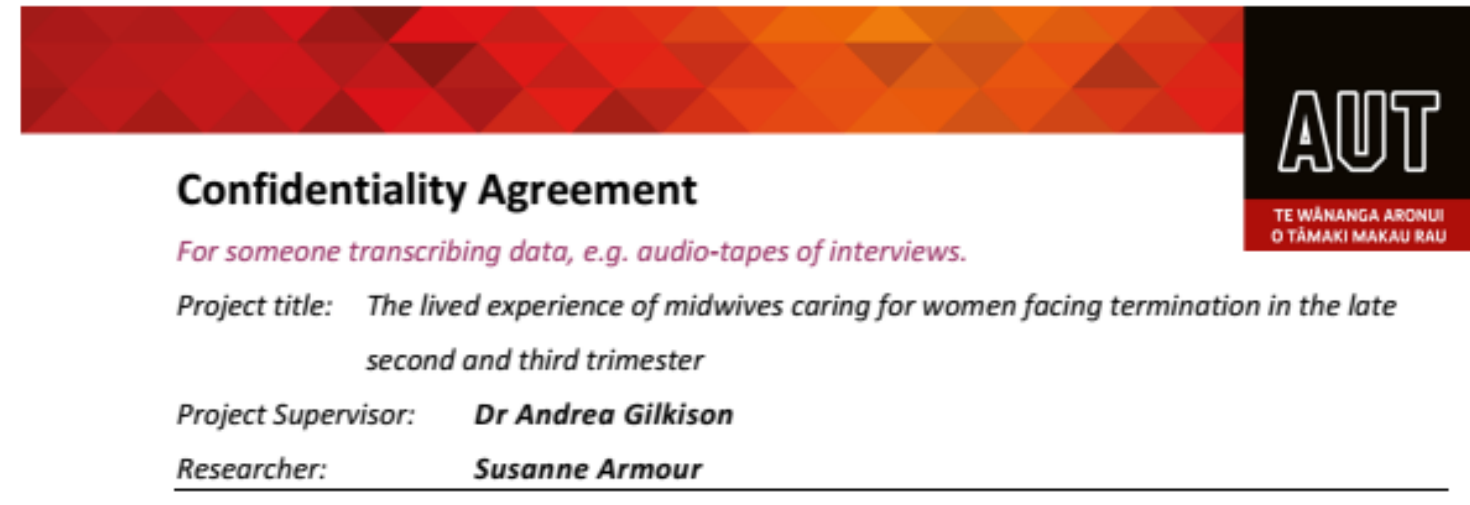

d I understand that all the material I will be asked to transcribe is confidential.

I understand that the contents of the tapes or recordings can only be discussed with the researchers.

I will not keep any copies of the transcripts nor allow third parties access to them.

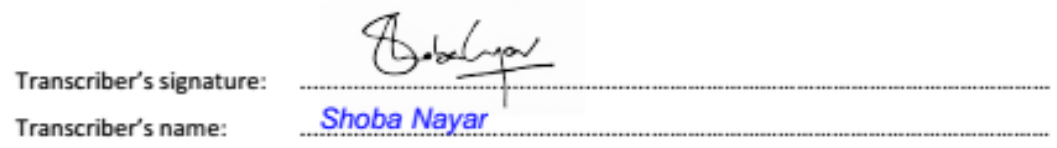

Transcriber's Contact Details (if appropriate):

Email: snayar19@gmail.com

Date: 3rd April 2017

Project Supervisor's Contact Details (if appropriate):

Dr Andrea Gilkison

Faculty of Environmental \& Health Science

School of Clinical Sciences

09-921 9999 ext. 7720

andrea.gilkison@aut.ac.nz

Approved by the Auckland University of Technology Ethics Committee on type the date on which the final approval was granted AUTEC Reference number type the AUTEC reference number Note: The Transcriber should retain a copy of this form. 


\section{Appendix E: Researcher Safety Protocol}

Appendix II: Researcher safety protocol

EA1 Application for ethics approval by AUTEC

Applicant: Dr. Andrea Gilkison

Primary researcher: Susanne Armour

1. Susanne Armour as the primary researcher will provide the schedule of interviews to her supervisor, Dr. Andrea Gilkison.

2. Susanne will notify Andrea of any changes to the schedule immediately.

3. Susanne will send a text message to Andrea before entering a participant's property and also when the interview has been concluded and Susanne has left the property.

4. Susanne will ask if other occupants of the house will be present/at home during the interviews.

5. If Susanne feels unsafe at any stage she will leave the premises and notify Andrea or police.

6. Susanne will assess when scheduling the interview if dogs are on the participant's property and if they will be locked away for the duration of the interview. If the participant cannot guarantee the safety of the researcher the interview will take place at a different, safe, private location agreed on by Susanne and the participant. 


\section{Appendix F: Poster Advertisement}

\section{Are you a midwife caring for women who face late termination of pregnancy as part of your regular midwifery practice?}

We would be very interested to talk to you about your experience with caring for women facing termination of pregnancy in the late second and third trimester.

\section{What this study is about}

Termination of Pregnancy (TOP) care is an aspect of midwifery practice that can be rewarding but also challenging and confusing. Knowledge around the experience of midwives with TOP care is still limited worldwide. European midwives have commented on a lack of support structures and their ethical and emotional struggles. There is no comparable research in New Zealand.
This study is an opportunity for midwives to talk about their experiences with this poorly acknowledged part of their role. With your contribution my aim is to explore what looking after women who go through TOP means to you and what could possibly support you in your role.

Your participation would contribute to my Master of Health Science qualification.
About me

As a midwife of 18 years I have cared for many women going through TOP and during the last two years I have worked in maternal-fetal medicine. I currently live in Sydney where I work in the labour and birthing suite.

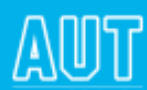

Approved by AUTEC AUT Ethics Committee - 16/350.
What your participation will involve Allowing me to meet you at your home or a quiet, private place of your choosing for a face-to-face interview that will take about 60-90 minutes of your time.

If you would like to participate, or if you would like more information, please email me susanne.armour@aut.ac.nz 